\title{
Sleep problems in individuals with genetic disorders associated with intellectual disability
}

Citation for published version (APA):

Maas, A. P. H. M. (2014). Sleep problems in individuals with genetic disorders associated with intellectual disability. [Doctoral Thesis, Maastricht University]. Maastricht University.

https://doi.org/10.26481/dis.20140227am

Document status and date:

Published: 01/01/2014

DOI:

10.26481/dis.20140227am

Document Version:

Publisher's PDF, also known as Version of record

\section{Please check the document version of this publication:}

- A submitted manuscript is the version of the article upon submission and before peer-review. There can be important differences between the submitted version and the official published version of record.

People interested in the research are advised to contact the author for the final version of the publication, or visit the DOI to the publisher's website.

- The final author version and the galley proof are versions of the publication after peer review.

- The final published version features the final layout of the paper including the volume, issue and page numbers.

Link to publication

\footnotetext{
General rights rights.

- You may freely distribute the URL identifying the publication in the public portal. please follow below link for the End User Agreement:

www.umlib.nl/taverne-license

Take down policy

If you believe that this document breaches copyright please contact us at:

repository@maastrichtuniversity.nl

providing details and we will investigate your claim.
}

Copyright and moral rights for the publications made accessible in the public portal are retained by the authors and/or other copyright owners and it is a condition of accessing publications that users recognise and abide by the legal requirements associated with these

- Users may download and print one copy of any publication from the public portal for the purpose of private study or research.

- You may not further distribute the material or use it for any profit-making activity or commercial gain

If the publication is distributed under the terms of Article $25 \mathrm{fa}$ of the Dutch Copyright Act, indicated by the "Taverne" license above, 
Sleep problems in individuals with genetic disorders associated with intellectual disability 

The research presented in this thesis was conducted at the Governor Kremers Centre (GKC) at the Maastricht University Medical Centre (MUMC+). The project was carried out in collaboration with 's Heeren Loo Zorggroep.

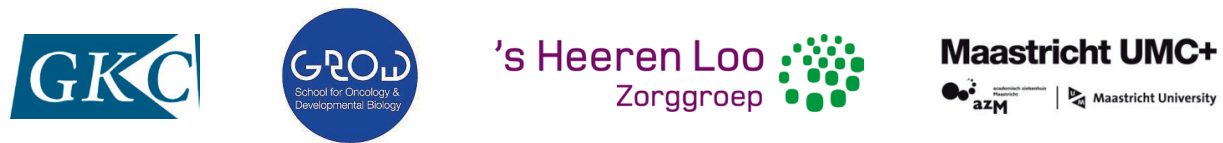

(C) 2014 Anneke Maas

Layout: Gert Jan Bosgra

Production: Ipskamp

ISBN: 978-94-6259-056-4

Financial support for the printing of this thesis was kindly provided by:

's Heeren Loo Zorggroep. 


\title{
Sleep problems in individuals with genetic disorders associated with intellectual disability
}

\author{
PROEFSCHRIFT
}

ter verkrijging van de graad van doctor aan de Universiteit Maastricht, op gezag van de Rector Magnificus, Prof. dr. L.L.G. Soete, volgens het besluit van het College van Decanen, in het openbaar te verdedigen op donderdag 27 februari 2014 om I6.00 uur

door

Anneke Petronella Helena Maria Maas 


\section{Promotores}

Prof. dr. L.M.G. Curfs

Prof. dr. R. Didden (Radboud Universiteit Nijmegen)

\section{Beoordelingscommissie}

Prof. dr. G.J. Kok (voorzitter)

Prof. dr. T.A.M.J. van Amelsvoort

Dr. K. Spruyt

Dr. L. Wiggs (Oxford Brookes University, United Kingdom)

Prof. dr. M. Zeegers 
In herinnering aan mijn oma's 



\section{CONTENTS}

Chapter I General introduction

Chapter 2 Psychometric properties of a sleep questionnaire for use in 27 individuals with intellectual disability

Chapter 3 Prevalence and associations of sleep problems in three genetic syndromes

3.I Sleep problems in individuals with Jacobsen syndrome $\quad$ 5I $^{\text {I }}$

3.2 Sleep problems in individuals with $\mathrm{Cri}$ du Chat syndrome: $\quad 65$ A comparative study

3.3 Exploration of differences in types of sleep disturbance and severity of sleep problems between individuals with Cri du Chat syndrome, Down syndrome and Jacobsen syndrome: A case control study

3.4 Sleep disturbances and behavioural problems in adults with Prader-Willi syndrome

3.5 Scatter plot analysis of excessive daytime sleepiness and severe disruptive behaviour in adults with Prader-Willi syndrome: A pilot study

Chapter 4 General discussion

Summary I5I

Samenvatting 157

Dankwoord I62

Curriculum vitae I64

Publications I66 
CHAPTER 1

GENERAL INTRODUCTION 
Chapter I 


\section{GENETIC DISORDERS ASSOCIATED WITH INTELLECTUAL DISABILITY}

Intellectual disability (ID) is characterised by significant limitations in intellectual functioning and in adaptive behaviour, originating before the age of I8 (Shalock et al., 20IO). ID indicates a heterogeneous group of individuals. Until recently, the classification of individuals with ID was based on the IQ level (i.e., mild, moderate, severe, and profound ID). However, this classification was abandoned by the American Association on Intellectual and Developmental Disabilities (AAIDD; Shalock et al., 20IO). Another common distinction made within the group of individuals with ID is that between syndromic ID and nonsyndromic ID (NS). In syndromic ID, individuals have additional anomalies, such as dysmorphic and medical features, and in NS limitations in intellectual functioning and adaptive behaviour are the sole clinical phenotypic features (Van Bokhoven, 20II). The multifactorial approach to the aetiology of ID in the AAIDD (Shalock et al., 20I0) focuses on types of risk factors (biomedical, social, behavioural, and educational) and timing of exposure to these risk factors (prenatal, perinatal, and postnatal). One aetiology for ID classified under prenatal exposure to biomedical factors is genetic disorders. To date, most of the mutations in genes that have ID as a phenotypic feature cause syndromic ID (see Van Bokhoven, 20II; Vissers et al., 20IO). Examples of genetic disorders causing syndromic ID are for instance: a trisomy of chromosome 2I in Down syndrome, a deletion from the II. 2 band in the short arm of chromosome I7 in Smith-Magenis syndrome, and the absent expression of maternally expressed genes on chromosome I5qII-qI3 in Angelman syndrome (see e.g., Cassidy \& Allanson, 20Iо; Willemsen \& Kleefstra, 20I3). From the midnineties of the twentieth century phenotypes of genetic disorders were expanded to include behaviours. Thus the phenotype of a genetic disorder includes both dysmorphic and medical features and various behavioural features, ranging from cognition and language to adaptive and maladaptive behaviours (Hodapp \& Dykens, 2012; Nyhan, I972; O'Brien, 2002). In order to enable parents, professional caregivers, physicians, special educators, and other professionals to provide the best possible care, they must be informed about the health problems and behavioural problems that might occur during the development of an individual with a specific genetic disorder. Among these health problems and behavioural problems, specific sleep problems might be a phenotypic feature in genetic disorders associated with ID.

\section{SLEEP RESEARCH IN INDIVIDUALS WITH INTELLECTUAL DISABILITY}

Ever since empirical clinical sleep research in individuals with ID started in the mideighties of the twentieth century, researchers have described two types of sleep 
problems in their studies: settling problems and night waking (see e.g., Bartlett, Rooney, \& Spedding, I985; Clements, Wing, \& Dunn, I986; Quine, I991). About a decade after empirical clinical sleep research in individuals with ID commenced, researchers started to describe problems with daytime sleepiness and problems with abnormal behaviours during sleep as sleep problems, besides settling problems and night waking (see e.g., Brylewski \& Wiggs, I998; Wiggs \& Stores, I996). This fits in with the three main presenting complaints about sleep - insomnia, excessive sleepiness, and parasomnias - distinguished in the International Classification of Sleep Disorders 2nd edition (ICSD-2) of the American Academy of Sleep Medicine (AASM; 2005). Settling problems and night waking belong to insomnia, problems with daytime sleepiness belong to excessive sleepiness, and problems with abnormal behaviours during sleep belong to parasomnias (AASM, 2005). Quine (200I) did not only describe symptoms of insomnia and parasomnias, but also symptoms of obstructive sleep apnoea. She did this in an attempt to focus on the underlying cause of a presenting sleep problem, also called the 'sleep disorder'. Identification of the sleep disorder is important for successful treatment (see e.g., Stores \& Stores, 2013; Wiggs \& Stores, 2004). In the ICSD-2, different types of sleep disturbance are subdivided in six broad categories of sleep disorders: (a) Insomnia, (b) Sleep Related Breathing Disorders, (c) Hypersomnias of Central Origin, (d) Circadian Rhythm Sleep Disorders, (e) Parasomnias, and (f) Sleep Related Movement Disorders (AASM, 2005).

Different aspects of sleep problems (such as assessment, definition, prevalence, associated factors, and treatment) in individuals with ID and other neurodevelopmental disabilities have been addressed in several reviews (see e.g., Didden \& Sigafoos, 200I; Dorris, Scott, Zuberi, Gibson, \& Espie, 2008; Tietze et al., 20I2; Van de Wouw, Evenhuis, \& Echteld, 20I2). Instruments for the assessment of sleep problems in individuals with ID can be divided into indirect and direct observation. In indirect observations (i.e., questionnaires, interviews, sleep diaries), information is provided by parents or professional caregivers and they are therefore called subjective measures. Direct observations (i.e., polysomnography, actigraphy, time sampling methods) are more objective measures of sleep (Didden \& Sigafoos, 200I). In studies using direct observations, sleep onset latency is used to describe settling problems, wake time after sleep onset to describe night waking, and sleep efficiency (SE) to summarise the data collected on sleep (see e.g., Espie \& Tweedie, I99I). Consensus exists on the cut-off for SE, but no consensus exists on duration and frequency criteria of settling problems and night waking (see e.g., Van de Wouw et al., 20I2).

Reported prevalence rates of sleep problems range between $\mathrm{I} 3$ and $86 \%$ in children

I Sleep efficiency is the ratio between total time spent asleep and total time spent in bed expressed as a percentage. This can be calculated from actigraphy, polysomnography, time sampling methods, and a sleep diary. The cut-off point for satisfactory sleep is $85 \%$ (see e.g., Espie \& Tweedie, I99I). 
with ID (Didden \& Sigafoos, 200I), between 54 and 99\% in children with multiple disabilities (Tietze et al., 20I2), and between 9 and 34\% in adults with ID (Van de Wouw et al., 20I2). The wide ranges can be explained by the different definitions of a sleep problem and different instruments that were used to assess the prevalence of sleep problems. This makes comparison between studies difficult, if not impossible. In addition, it is important to note that in general these prevalence rates concern the presenting sleep problems and not the sleep disorders.

Several variables have been mentioned as factors that might be related to sleep problems, e.g., age, living environment, level of cognitive functioning, medical conditions (such as physical disability), psychiatric conditions (such as autism spectrum disorder), behavioural problems, level of adaptive skills, physiological factors (such as medication use), and reinforcing consequences provided by parents or professional caregivers (Didden \& Sigafoos, 200I; Van de Wouw et al., 20I2). For example, a positive correlation between sleep problems and behavioural problems has been found in children and adults with ID (see e.g., Brylewski \& Wiggs, I999; Didden, Korzilius, Van Aperlo, Van Overloop, \& De Vries, 2002; Wiggs \& Stores, I996). To our knowledge, there is only one study that has systematically reviewed associations of sleep problems in individuals with ID, more specifically in adults (Van de Wouw et al., 20I2), and they could not draw firm conclusions, because the methodological quality of the studies they included in their review was generally low.

Treatment of sleep problems should be aimed at the underlying causes of sleep problems, whether intrinsic, including medical factors, or contextual, including parental behaviours and environmental factors (see e.g., Dorris et al., 2008; Van de Wouw et al., 2012). Medical factors include pain, epilepsy, sleep apnoea, and disturbances in melatonin secretion. Appropriate sleep hygiene practice and behavioural strategies address contextual factors that maintain sleep problems (see e.g., Jan et al., 2008; Richdale \& Wiggs, 2005).

In the first review on sleep studies in individuals with ID G. Stores (I992) stated that " [...] investigators have often described heterogeneous groups of patients, failing to make important distinctions regarding severity of mental handicap or its cause. It is essential in the much-needed further research in this area to consider subgroups and types individually" (p. I303). The level of ID was taken into account in two studies investigating children with ID (Didden et al., 2002; Robinson \& Richdale, 2004) and in both studies children with more severe levels of ID show significantly more sleep problems than children with milder levels of ID. During the nineties of the twentieth century several researchers started studying the prevalence of sleep problems in samples of individuals with a specific genetic disorder associated with ID, namely Rett syndrome (Piazza, Fisher, Kiesewetter, Bowman, \& Moser, I990), tuberous sclerosis 
(Hunt \& Stores, 1994), Down syndrome (Stores, Stores, \& Buckley, I996), Sanfilippo syndrome (Colville, Watters, Yule, \& Bax, 1996), Williams syndrome (Sarimski, I996; Einfeld, Tonge, \& Florio, 1997), Prader-Willi syndrome (Richdale, Cotton, \& Hibbit, I999; Sarimski, 1996), and Smith-Magenis syndrome (Smith, Dykens, \& Greenberg, I998), resulting in descriptions of sleep in more homogeneous groups of individuals with ID.

\section{SLEEP PROBLEMS IN INDIVIDUALS WITH GENETIC DISORDERS ASSOCIATED WITH INTELLECTUAL DISABILITY}

Sleep problems are a common complaint in a number of genetic syndromes ${ }^{2}$, namely Smith-Magenis syndrome (SMS), Angelman syndrome (AS), Prader-Willi syndrome (PWS), Down syndrome (DS), Rett syndrome (RS), Williams syndrome (WS), Fragile X syndrome (FXS), Sanfilippo syndrome (SS), and tuberous sclerosis (TS) (Cassidy \& Allanson, 20IO; Curfs, Moog, \& Didden, 200I; Dykens, Hodapp, \& Finucane, 2000; Stores \& Wiggs, 200I; Wiggs, 2007). Sleep problems have adverse consequences for individuals with a genetic syndrome. Behavioural features of the genetic syndrome, such as problems with cognitive and adaptive functioning and behavioural problems, might be exacerbated by sleep problems (Stores \& Stores, 20I3). In addition, sleep problems have adverse consequences for parents of individuals with ID (see e.g., Chu \& Richdale, 2009; Gallagher, Phillips, \& Carroll, 20I0). Parents of children with a genetic syndrome need adequate and appropriate support to deal with the specific sleep problems of their child within their family (Hodapp \& Dykens, 20I2; World Health Organization, 20I0). However, parents or professional caregivers ${ }^{3}$ of individuals with a genetic syndrome do not always receive advice on or help with treatment and when treatment is provided, this is often not effective (see e.g., Didden, Korzilius, Smits, \& Curfs, 2004). Appropriate support for parents dealing with sleep problems of individuals with a specific genetic syndrome starts with the careful description of the sleep problems and factors that might be associated with them.

To provide an overview of the prevalence of sleep problems in genetic syndromes, we have reviewed I4 studies targeting prevalence of sleep problems in the abovementioned genetic syndromes between 1990 and 2007. We were also interested to find out whether types of sleep disturbance and factors associated with sleep problems were explored, and what measurement methods were used. Reported prevalence rates of sleep problems are shown in Table I. In 5 out of I4 studies no additional data were

\footnotetext{
2 In this thesis the term genetic syndrome refers to intellectual disabilities with a known genetic disorder (as oppose to ID with a known acquired disorder and ID with a unknown aetiology).

3 From here 'parents' refers to both parents and professional caregivers.
} 


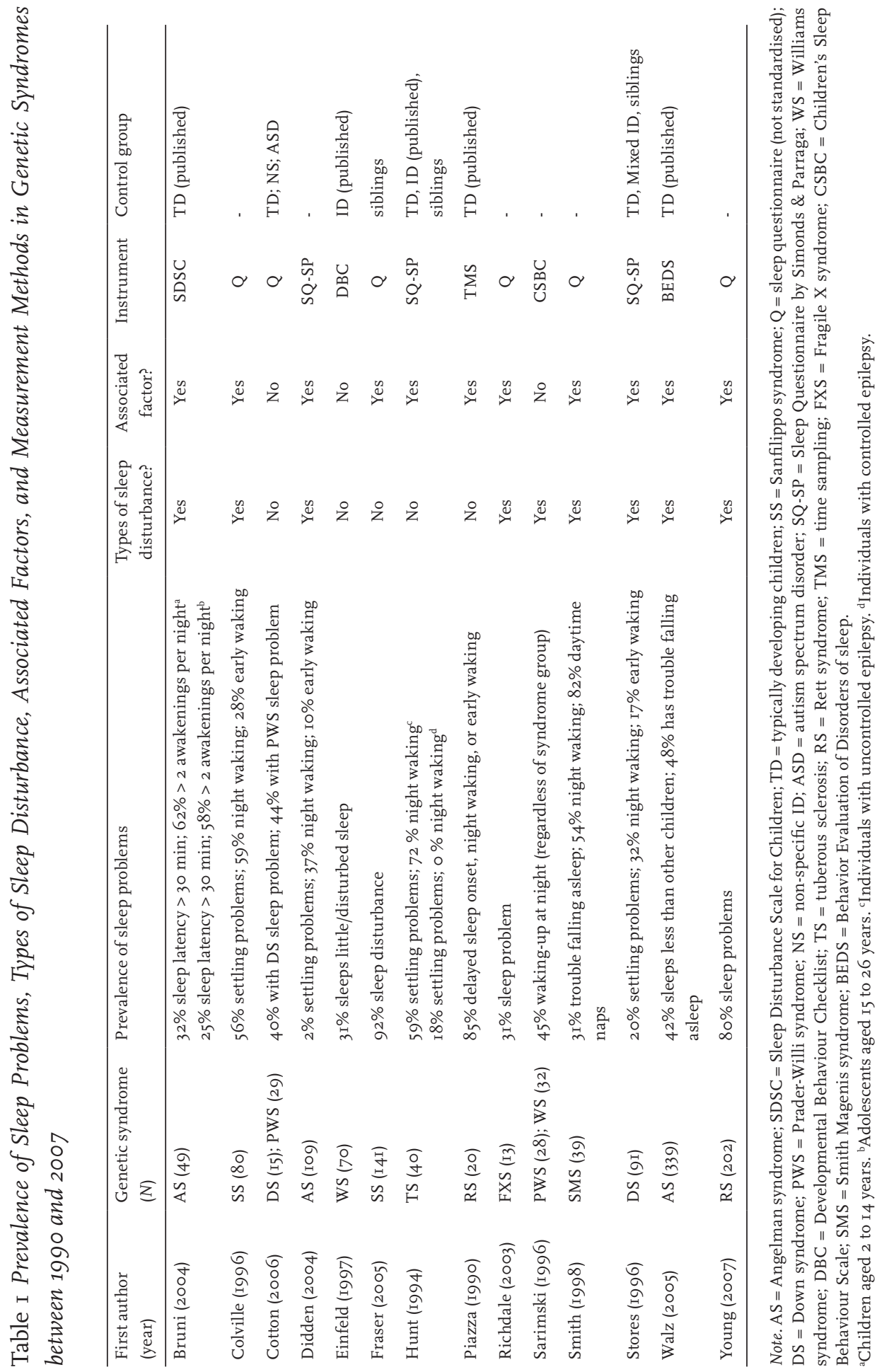


presented on types of sleep disturbance. In II out of I4 studies associations between sleep problems and one or more variables were explored, and age (8 out of in studies), genetic subtype (4 out of II studies), and epilepsy (4 out of II studies) were investigated most frequently. In 6 studies a standardised sleep questionnaire was used to measure sleep, in another 6 studies a newly developed sleep questionnaire was used, in I study a general behaviour scale for individuals with ID was used, and in I study a time sampling method was used (see Table I). In 6 studies a comparison of prevalence rates was made between individuals with the genetic syndrome and individuals without the genetic syndrome. In 4 out of 6 studies the comparison group was comprised of siblings, typically developing children, and/or individuals with mixed ID, and in 3 out of 6 studies data were compared with previously reported prevalence rates of typically developing children or individuals with ID. This review shows that: (a) prevalence rates are high and vary between as well as within these genetic syndromes, (b) types of sleep disturbance and other variables that might be associated with sleep problems have not been investigated systematically in these genetic syndromes, (c) with the exception of one study (Piazza et al., I990), prevalence of sleep problems was assessed using a questionnaire. The results on the prevalence rates of sleep problems have to be interpreted carefully because there are at least two important limitations regarding the methodological quality of the studies. Firstly, nearly $50 \%$ of the studies did not use a standardised sleep questionnaire to measure the prevalence of sleep problems in individuals with ID. Secondly, about $40 \%$ of the studies did not include a comparison group to examine whether sleep problems in individuals with a genetic syndrome were syndrome-specific.

\section{ASSESSMENT OF PREVALENCE OF SLEEP PROBLEMS IN INDIVIDUALS WITH GENETIC SYNDROMES}

In two reviews (Lewandowski, Toliver-Sokol, \& Palermo, 20II; Tietze et al., 20I2) regarding the assessment of sleep in children it is mentioned that polysomnography is the gold standard to assess sleep, but authors agree on several limitations of polysomnography. These limitations are: (a) polysomnography is laboratory-based and might not reflect sleep in the natural environment, (b) polysomnography addresses a short period of time, usually one or two nights, (c) polysomnography fails to identify behaviours of children and parents related to sleep problems. So, polysomnography does not seem suitable to assess the prevalence of sleep problems. Although actigraphy measures sleep in the natural environment for an extended period of time (but most often not longer than 7 to I4 days) (Meltzer, Montgomery-Downs, Insana, 
\& Walsh, 20I2), it also fails to identify behaviours of children and parents related to sleep problems. In addition, Meltzer, Montgomery-Downs, et al. (20I2) mention that actigraphy has poor specificity to detect waking after sleep onset. A standardised sleep questionnaire questions the natural environment and a long period of time (e.g., past three months). In standardised sleep questionnaires, items on behaviours of children and parents related to sleep are included. However, this is done in retrospect. In addition, questionnaires are limited to assessing those aspects of sleep and sleep problems that are observed by parents and this might be difficult for some aspects (e.g., exact time of sleep onset). So, to assess the prevalence of sleep problems a standardised sleep questionnaire, actigraphy, or a combination of both instruments can be used. More participants can be investigated at the same time with standardised sleep questionnaires than with actigraphy. Furthermore, for a significant number of individuals with ID it is not possible to wear an actigraph, which causes a sample bias (see e.g., Van Dijk, Hilgenkamp, Evenhuis, \& Echteld, 20I2). Finally, Meltzer, Walsh, Traylor and Westin (2012) mention that interdevice reliability between actigraphs in their study was poor and that problems may arise when comparing results of studies using different brands of actigraphs. Therefore, collecting data on prevalence of sleep problems in individuals with a genetic syndrome by a standardised sleep questionnaire may be preferable to actigraphy.

The Sleep Questionnaire developed by Simonds and Parraga (1982) was developed to examine sleep in school-aged children and adolescents. This standardised questionnaire was adapted for use in individuals with ID by Wiggs and Stores (1996) and has been frequently used in sleep studies in individuals with ID (see e.g., Brylewski \& Wiggs, I998; Didden et al., 2002; Wiggs \& Stores, 1996) and in individuals with genetic syndromes (i.e., Didden et al., 2004; Stores et al., 1996). Next to demographic information and data on prevalence of sleep problems, data on different types of sleep disturbance can be collected using the SQ-SP (Stores, Wiggs, \& Campling, I998).

In studies in individuals with genetic syndromes the use of a comparison or 'control' group is the norm (e.g., Oliver \& Woodcock, 2008). When little is known about sleep in a genetic syndrome, a study design without a control group is useful to explore for sleep problems and types of sleep disturbance (e.g., Hodapp \& Dykens, 200I). In a follow-up study, comparisons with groups with mixed or heterogeneous ID should be used to test whether a specific feature of sleep characterises a group with a specific genetic syndrome or, conversely, individuals with ID. Such a follow-up study would provide more information than a cross-sectional study of a genetic syndrome without a control group (e.g., Hodapp \& Dykens, 200I). Comparisons within a genetic syndrome test whether a difference on sleep characteristics between genetic subtypes of a syndrome exists. 


\section{RESEARCH QUESTIONS AND OUTLINE OF THE THESIS}

The aim of this thesis is to contribute to sleep phenotyping of genetic syndromes. This thesis is divided into two parts: Part I. Sleep questionnaire and Part 2. Prevalence and associations of sleep problems in three genetic syndromes. The Sleep Questionnaire developed by Simonds and Parraga (I982) was selected to collect data on prevalence of sleep problems and types of sleep disturbance in individuals with a genetic syndrome. Furthermore, three variations (no control group, control group, and control for genetic subtype) of the cross-sectional study design were selected to investigate the prevalence of sleep problems in individuals with a genetic syndrome.

The study described in Part I. Sleep questionnaire aims to provide an answer to the following research questions:

I. Is part four of the Sleep Questionnaire developed by Simonds and Parraga (SQ-SP; I982) a reliable and valid tool in assessing sleep and different types of sleep disturbance in individuals with ID? What is the factor structure of the SQSP in individuals with ID and do these factors fit into different types of sleep disturbance that are subdivided in the six broad categories of sleep disorders of the International Classification of Sleep Disorders 2nd edition (AASM, 2005)?

The studies described in Part 2. Prevalence and associations of sleep problems in three genetic syndromes aim to provide an answer to the following main research questions:

2. What is the prevalence of sleep problems and which variables are associated with sleep problems in Jacobsen syndrome? Are these specific for individuals with this syndrome?

3. What is the prevalence of sleep problems and which variables are associated with sleep problems in Cri du Chat syndrome? Are these specific for individuals with this syndrome?

4. What is the prevalence of sleep disturbances in adults with Prader-Willi syndrome (PWS) and are these associated with behavioural problems? Besides behavioural problems, what other variables are associated with sleep disturbances in adults with PWS? Are these related to the genetic subtype of PWS?

5. What is the temporal distribution of excessive daytime sleepiness and severe disruptive behaviour in adults with PWS? Is the temporal distribution of those behaviours specific for adults with this syndrome? 


\section{PSYCHOMETRIC PROPERTIES OF A SLEEP QUESTIONNAIRE FOR USE IN INDIVIDUALS WITH INTELLECTUAL DISABILITY}

The SQ-SP (Simonds \& Parraga, I982) is a standardised sleep questionnaire that was adapted for use in individuals with ID by Wiggs and Stores (1996). At the time this study was conducted, psychometric properties including the factor structure of the SQ-SP had not been examined well in individuals with ID. Therefore, we investigated the reliability, the validity, and the structure of part four of the SQ-SP. Reliability of the SQ-SP was examined by exploring internal consistency and test-retest reliability. Convergent validity and concurrent validity were explored by correlating total scores on the SQ-SP with scores obtained using another sleep questionnaire (i.e., Sleep Disturbance Scale for Children; Bruni et al., 1996) and the Composite Sleep Index (CSI) another construct of sleep problems (Wiggs \& Stores, I998), respectively. An exploratory factor analysis and a confirmatory factor analysis were performed to define the factor structure of the SQ-SP. Results of this study are presented in Chapter 2 of this thesis.

\section{SLEEP PROBLEMS IN INDIVIDUALS WITH JACOBSEN SYNDROME}

Jacobsen syndrome (JS) is a rare genetic disorder caused by a terminal deletion in the long arm of chromosome II (Grossfeld et al., 2004). Little is known about sleep in JS. There are several anecdotal reports (from parents and clinical experience) suggesting that sleep problems might be prevalent in individuals with JS. At the time this study was conducted, no scientific research had been carried out on sleep in individuals with JS. Therefore, we investigated the prevalence of sleep problems as well as described types of sleep disturbance and other behaviours related to sleep in addition to exploring other variables that might be related to sleep in a relatively large sample of individuals with JS $(N=43)$ using the adapted version of the SQ-SP (Wiggs \& Stores, 1996). Results of this study are presented in Chapter 3.I of this thesis.

To determine whether the severity of sleep problems and the types of sleep disturbance were specific for individuals with JS, we compared the data collected with the SQ-SP of individuals with JS $(n=25)$ to those of individuals with NS $(n=25)$, DS $(n=25)$, and CDC $(n=25)$. Individuals with NS were matched to those with JS, DS, and CDC on age, level of cognitive functioning, presence of epilepsy, and use of medication related to sleep problems. Results of this study are presented in Chapter 3.3. 


\section{SLEEP PROBLEMS IN INDIVIDUALS WITH CRI DU CHAT SYNDROME}

Cri du Chat syndrome (CDC) is a rare genetic disorder caused by a partial deletion in the short arm of chromosome 5 (Cornish \& Bramble, 2002). Results of two studies suggest that sleep problems may be relatively common in children with CDC (Cornish \& Pigram, 1996; Cornish, Oliver, Standen, Bramble, \& Collins, 2003) reporting prevalence rates of sleep problems up to nearly $50 \%$. However, in these studies, sleep problems were not assessed with a standardised sleep questionnaire and no information on different types of sleep disturbance was presented. Moreover, no control group of individuals with NS was used in these studies and it remains unclear whether the reported sleep problems are specific for children with CDC. Therefore, we investigated sleep in 30 individuals with CDC using the SQ-SP. Sleep problems, behaviours related to sleep, and types of sleep disturbance in individuals with CDC were compared with those of individuals with NS $(n=30)$ and DS $(n=30)$. Individuals with NS were matched to those with CDC on age and cognitive functioning. Results of this study are presented in Chapter 3.2 of this thesis.

Additional information on the five types of sleep problems and severity of sleep problems (expressed in the CSI) in 25 individuals with CDC and three comparison groups (i.e., NS, DS, and JS) is presented in Chapter 3.3.

\section{SLEEP DISTURBANCES AND BEHAVIOURAL PROBLEMS IN ADULTS WITH PRADER-WILLI SYNDROME}

PWS is a genetic disorder caused by the absent expression of paternally expressed genes on chromosome I5qII-qI3. The absent expression is caused by a paternal deletion, a maternal uniparental disomy (mUPD) or an imprinting defect; the so-called genetic subtypes of PWS (Holm et al., I993). Besides more or less characteristic behavioural problems, sleep disturbance (i.e., excessive daytime sleepiness) or sleep apnoea is listed as one of the 'minor criteria' in the clinical diagnostic criteria for PWS (Holm et al., I993). In I999, Richdale, Cotton and Hibbit performed a study on sleep disturbances in individuals with PWS with a subsample of 7 adults and a control group consisting of 8 adults without ID, using standardised sleep questionnaires, i.e., Epworth Sleepiness Scale (Johns, I99I) and the Sleep Disorders Questionnaire (Douglass et al., 1994). Excessive daytime sleepiness (EDS), snoring, and night waking seemed to be present in adults. In the subsample of children an association was found between EDS and behavioural problems in all domains of a standardised behaviour questionnaire (i.e., Developmental Behaviour Checklist; Einfeld \& Tonge, 1994), however no data were collected for the 
adult subsample. Aside from the small sample size of the adult sample and the lack of information on the relationship between sleep disturbances and behavioural problems for the adult subsample, the diagnosis of PWS was not confirmed by genetic testing. Despite these shortcomings, Richdale et al.'s study has not been replicated, resulting in an incomplete picture on sleep disturbances and the association with behavioural problems in adults with PWS. Therefore, we investigated sleep disturbances, behavioural problems, and other variables that might be associated with sleep problems in a large sample of adults $(N=79)$ with genetically confirmed PWS using the same standardised sleep and behaviour questionnaires as Richdale et al. did. To determine whether there is a difference between the two most prevalent genetic subtypes of PWS results of adults with paternal deletion $(n=45)$ were compared with those of adults with mUPD $(n=33)$. Results of this study are presented in Chapter 3.4 of this thesis.

Just like parent reports, standardised questionnaires are a means of indirect observations of sleep and behaviour and this may limit validity of the results. Direct observations of EDS and severe disruptive behaviour such as skin-picking and aggression in a sample of adults with PWS using a control group of adults with NS may provide more valid information on the occurrence of these behavioural problems. Furthermore, the standardised questionnaires used in Chapter 3.4 do not provide information on the temporal distribution of EDS and severe disruptive behaviour while it is generally known that behavioural problems in individuals with ID may be highly correlated with time of day or day of week (Touchette, MacDonald, \& Langer, I985). Therefore, we explored temporal characteristics of EDS and severe disruptive behaviour in 7 adults with individuals with PWS and 5 individuals with NS using direct observations (intervals of $2 \mathrm{hr}$ ). Individuals with NS were matched to those with PWS on gender, age, level of ID, body mass index, number and type of daytime activities, and living situation. Results of this study are presented in Chapter 3.5.

In Chapter 4, the general discussion, the results of the studies described in this thesis will be addressed, the methodological considerations and clinical implications will be discussed, and considerations for future sleep research in genetic syndromes will be described. A summary completes this thesis. 


\section{REFERENCES}

American Academy of Sleep Medicine (2005). International classification of sleep disorders, 2nd edition: Diagnostic and coding manual. Westchester, IL: Author.

Bartlett, L. B., Rooney, V., \& Spedding, S. (1985). Nocturnal difficulties in a population of mentally handicapped children. British Journal of Mental Subnormality, 31, 54-59.

Bokhoven, H. van (20II). Genetic and epigenetic networks in intellectual disabilities. Annual Review of Genetics, 45, 8I-IO4.

Bruni, O., Ferri, R., D’Agostino, G., Miano, S., Roccella, M., \& Elia, M. (2004). Sleep disturbances in Angelman syndrome: A questionnaire study. Brain \& Development, 26, 233-240.

Bruni, O., Ottaviano, S., Guidetti, V., Romoli, M., Innocenzi, M., Cortesi F., \& Giannotti, F. (I996). The Sleep Disturbance Scale for Children (SDSC): Construction and validation of an instrument to evaluate sleep disturbances in childhood and adolescence. Journal of Sleep Research, 5, 25I-26I.

Brylewski, J., \& Wiggs, L. (I999). Sleep problems and daytime challenging behaviour in a community-based sample of adults with intellectual disability. Journal of Intellectual Disability Research, 43, 504-512.

Brylewski, J. E., \& Wiggs, L. (I998). A questionnaire survey of sleep and night-time behaviour in a community-based sample of adults with intellectual disability. Journal of Intellectual Disability Research, 42, I54-162.

Cassidy, S. B., \& Allanson, J. E. (2010). Management of genetic syndromes (3rd ed.). Hoboken, NJ: John Wiley \& Sons.

Chu, J., \& Richdale, A. L. (2009). Sleep quality and psychological wellbeing in mothers of children with developmental disabilities. Research in Developmental Disabilities, 30 , I5I2-I522.

Clements, J., Wing, L., \& Dunn, G. (I986). Sleep problems in handicapped children: A preliminary study. Journal of Child Psychology and Psychiatry, 27, 399-407.

Colville, G. A., Watters, J. P., Yule, W., \& Bax, M. (I996). Sleep problems in children with Sanfilippo syndrome. Developmental Medicine a Child Neurology, 38, 538-544.

Cornish, K., \& Bramble, D. (2002). Cri du Chat syndrome: Genotype-phenotype correlations and recommendations for clinical management. Developmental Medicine Q Child Neurology, 44, 494-497.

Cornish, K., Oliver, C., Standen, P., Bramble, D., \& Collins, M. (2003). Cri du Chat syndrome: Handbook for parents and professionals (2nd ed.). Earl Shilton, England: Cri du Chat Syndrome Support Group.

Cornish, K. M., \& Pigram, J. (I996). Developmental and behavioural characteristics of Cri du Chat syndrome. Archives of Disease in Childhood, 75, 448-450. 
Cotton, S., \& Richdale, A. (2006). Brief report: Parental descriptions of sleep problems in children with autism, Down syndrome, and Prader-Willi syndrome. Research in Developmental Disabilities, 27, I5I-I6I.

Curfs, L. M. G., Moog, U., \& Didden, R. (200I). Slaapstoornissen bij een genetisch bepaalde verstandelijke handicap [Sleep disturbances in intellectual disability caused by a genetic disorder]. In R. Didden \& L. M. G. Curfs (Eds.), Slaap en slaapproblemen bij verstandelijk gehandicapten [Sleep and sleep problems in individuals with intellectual disability] (pp. 85-I04). Houten, the Netherlands: Bohn Stafleu Van Loghum.

Didden, R., Korzilius, H., Aperlo, B. van, Overloop, C. van, \& Vries, M. de (2002). Sleep problems and daytime problem behaviours in children with intellectual disability. Journal of Intellectual Disability Research, 46, 537-547.

Didden, R., Korzilius, H., Smits, M. G., \& Curfs, L. M. G. (2004). Sleep problems in individuals with Angelman syndrome. American Journal on Mental Retardation, 109, $275-284$.

Didden, R., \& Sigafoos, J. (200I). A review of the nature and treatment of sleep disorders in individuals with developmental disabilities. Research in Developmental Disabilities, 22, $255-272$.

Dijk, E. van, Hilgenkamp, T. I. M., Evenhuis, H. M., \& Echteld, M. A. (20I2). Exploring the use of actigraphy to investigate sleep problems in older adults with intellectual disability. Journal of Intellectual Disability Research, 56, 204-2II.

Dorris, L., Scott, N., Zuberi, S., Gibson, N., \& Espie, C. (2008). Sleep problems in children with neurological disorders. Developmental Neurorehabilitation, 11, 95-II4.

Douglass, A. B., Bornstein, R., Nino-Murcia, G., Keenan, S., Miles, L., Zarcone, V. P., Jr., ... Dement, W. C. (I994). The Sleep Disorders Questionnaire I: Creation and multivariate structure of the SDQ. Sleep, 17, I60-167,

Dykens, E. M., Hodapp, R. M., \& Finucane, B. M. (2000). Genetics and mental retardation syndromes: A new look at behavior and interventions. Baltimore, MD: Paul H. Brookes.

Einfeld, S. L., \& Tonge, B. J. (I994). Manual for the Developmental Behaviour Checklist (Primary Carer Version). Melbourne, Australia: Monash University, Centre of Developmental Psychiatry.

Einfeld, S. L., Tonge, B. J., \& Florio, T. (I997). Behavioral and emotional disturbance in individuals with Williams syndrome. American Journal on Mental Retardation, 102, 45-53.

Espie, C. A., \& Tweedie, F. M. (I99I). Sleep patterns and sleep problems amongst people with mental handicap. Journal of Mental Deficiency Research, 35, 25-36.

Fraser, J., Gason, A. A., Wraith, J. E., \& Delatycki, M. B. (2005). Sleep disturbance in Sanfilippo syndrome: A parental questionnaire study. Archives of Disease in Childhood, 90, I239-I242. 
Gallagher, S., Philips, A. C., \& Carroll, D. (20I0). Parental stress is associated with poor sleep quality in parents caring for children with developmental disabilities. Journal of Pediatric Psychology, 35, 728-737.

Grossfeld, P. D., Mattina, T., Lai, Z., Favier, R., Lyons Jones, K., Cotter, F., Jones, C., \& the IIq consortium (2004). The iाq terminal deletion disorder: A prospective study of IIo cases. American Journal of Medical Genetics, 129A, 5I-6I.

Hodapp, R. M., \& Dykens, E. M. (200I). Strengthening behavioural research on genetic mental retardation syndromes. American Journal on Mental Retardation, 106, 4-I5.

Hodapp, R. M., \& Dykens, E. M. (2012). Genetic disorders of intellectual disability: Expanding our concepts of phenotypes and of family outcomes. Journal of Genetic Counseling, 21, 76I-769.

Holm, V. A., Cassidy, S. B., Butler, M. G., Hanchett, J. M., Greenswag, L. R., Whitman, B. Y., \& Greenberg, F. (I993). Prader-Willi syndrome: Consensus diagnostic criteria. Pediatrics, 91, 398-402.

Hunt, A., \& Stores G. (I994). Sleep disorder and epilepsy in children with tuberous sclerosis: A questionnaire-based study. Developmental Medicine \& Child Neurology, 36, I08-II5.

Jan, J. E., Owens, J. A., Weiss, M. D., Johnson, K. P., Wasdell, M. B., Freeman, R. D., \& Ipsiroglu, O. S. (2008). Sleep hygiene for children with neurodevelopmental disabilities. Pediatrics, 122, I343-I350.

Johns, M. W. (I99I). A new method for measuring daytime sleepiness: The Epworth Sleepiness Scale. Sleep, 14, 540-545.

Lewandowski, A. S., Toliver-Sokol, M., \& Palermo, T. M. (20II). Evidence-based review of subjective pediatric sleep measures. Journal of Pediatric Psychology, 36, 780-793.

Meltzer, L. J., Montgomery-Downs, H. E., Insana, S. P., \& Walsh, C. M. (2012). Use of actigraphy for assessment in pediatric sleep research. Sleep Medicine Reviews, 16 , 463-475.

Meltzer, L. J., Walsh, C. M., Traylor, J., \& Westin, A. M. L. (20I2). Direct comparison of two new actigraphs and polysomnography in children and adolescents. Sleep, 35, I59-I66.

Nyhan, W. L. (I972). Behavioral phenotypes in organic genetic diseases: Presidential address to the Society for Pediatric Research (May I, I97I). Pediatric Research, 6, I-9.

O'Brien, G. (Ed.) (2002). Behavioural phenotypes in clinical practice. London, England: Mac Keith Press.

Oliver, C., \& Woodcock, K. (2008). Integrating levels of explanation in behavioural phenotype research [Editorial]. Journal of Intellectual Disability Research, 52, 807-809.

Piazza, C. C., Fisher, W., Kiesewetter, K., Bowman, L., \& Moser, H. (I990). Aberrant sleep patterns in children with the Rett syndrome. Brain \& Development, 12, 488-493. 
Quine, L. (I99I). Sleep problems in children with mental handicap. Journal of Mental Deficiency Research, 35, 269-290.

Quine, L. (200I). Sleep problems in primary school children: Comparison between mainstream and special school children. Child: Care, Health and Development, 27, 20I-22I.

Richdale, A., \& Wiggs, L. (2005). Behavioral approaches to the treatment of sleep problems in children with developmental disorders: What is the state of the art? International Journal of Behavioral and Consultation Therapy, 1, 165-190.

Richdale, A. L. (2003). A descriptive analysis of sleep behaviour in children with Fragile X. Journal of Intellectual a Developmental Disability, 28, I35-I44.

Richdale, A. L., Cotton, S., \& Hibbit, K. (I999). Sleep and behaviour disturbance in Prader-Willi syndrome: A questionnaire study. Journal of Intellectual Disability Research, 43, 380-392.

Robinson, A. M., \& Richdale, A. L. (2004). Sleep problems in children with an intellectual disability: Parental perceptions of sleep problems, and views of treatment effectiveness. Child: Care, Health and Development, 30, I39-150.

Sarimski, K. (I996). Specific eating and sleeping problems in Prader-Willi and WilliamsBeuren syndrome. Child: Care, Health and Development, 22, I43-I5O.

Shalock, R. L., Borthwick-Duffy, S. A., Bradley, V. J., Buntinx, W. H. E., Coulter, D. L., Craig, E. M., ... Yeager, M. H. (2010). Intellectual Disability: Definition, classification, and systems of Supports (irth ed.). Washington, DC: American Association on Intellectual and Developmental Disabilities.

Simonds, J. F., \& Parraga, H. (1982). Prevalence of sleep disorders and sleep behaviors in children and adolescents. Journal of the American Academy of Child Psychiatry, 21, 383-388.

Smith, A. C. M., Dykens, E., \& Greenberg, F. (I998). Sleep disturbance in Smith-Magenis syndrome (del I7pir.2). American Journal of Medical Genetics, 81, I86-I9I.

Stores, G. (I992). Sleep studies in children with a mental handicap. Journal of Child Psychology and Psychiatry, 33, I303-1317.

Stores, G., \& Stores, R. (2013). Sleep disorders and their clinical significance in children with Down syndrome. Developmental Medicine a Child Neurology, 55, I26-130.

Stores, G., \& Wiggs, L. (Eds.) (200I). Sleep disturbances in children and adolescents with disorders of development: Its significance and management. London, England: Mac Keith Press.

Stores, G., Wiggs, L., \& Campling, G. (I998). Sleep disorders and their relationship to psychological disturbance in children with epilepsy. Child: Care, Health and Development, 24, 5-I9.

Stores, R., Stores, G., \& Buckley, S. (I996). The pattern of sleep problems in children with Down's syndrome and other intellectual disabilities. Journal of Applied Research in Intellectual Disabilities, 9, I45-I59. 
Tietze, A.-L., Blankenburg, M., Hechler, T., Michel, E., Koh, M., Schlüter, B., \& Zernikow, B. (20I2). Sleep disturbances in children with multiple disabilities. Sleep Medicine Reviews, 16, II7-I27.

Touchette, P. E., MacDonald, R. F., \& Langer, S. N. (I985). A scatter plot for identifying stimulus control of problem behaviour. Journal of Applied Behavior Analysis, 18, 343$35 \mathrm{I}$.

Vissers, L. E. L. M., Ligt, J. de, Gilissen, C., Janssen, I., Steehouwer, M., Vries, P. de, ... Veltman, J. A. (2010). A de novo paradigm for mental retardation. Nature Genetics, 42, IIO9-III2.

Walz, N. C., Beebe, D., \& Byars, K. (2005). Sleep in individuals with Angelman syndrome: Parent perceptions of patterns and problems. American Journal on Mental Retardation, 110, 243-252.

Wiggs, L. (2007). Sleep disorders. In A. Carr, G. O’Reilly, P. Noonan Walsh \& J. McEvoy (Eds.), The handbook of intellectual disability and clinical psychology practice (pp. 37I42I). Hove, England: Routledge.

Wiggs, L., \& Stores, G. (I996). Severe sleep disturbance and daytime challenging behaviour in children with severe learning disabilities. Journal of Intellectual Disability Research, 40, 518-528.

Wiggs, L., \& Stores, G. (I998). Behavioural treatment for sleep problems in children with severe learning disabilities and challenging daytime behaviour: Effect on sleep patterns of mother and child. Journal of Sleep Research, 7, II9-I26.

Wiggs, L., \& Stores, G. (2004). Sleep patterns and sleep disorders in children with autistic spectrum disorders: Insights using parent report and actigraphy. Developmental Medicine \& Child Neurology, 46, 372-380.

Willemsen, M. H., \& Kleefstra, T. (20I3). Making headway with genetic diagnostics of intellectual disabilities. Clinial Genetics. Advance online publication. doi: Io.IIII/ cge.I2244

World Health Organization (2010). Better health, better lives: Children and young people with intellectual disabilities and their families. Copenhagen, Denmark: Author. Retrieved from http:// www.euro.who.int/__data/assets/pdf_file/oo03/ı26408/e9442I.pdf

Wouw, E. van de, Evenhuis, H. M., \& Echteld, M. A. (20I2). Prevalence, associated factors and treatment of sleep problems in adults with intellectual disability: A systematic review. Research in Developmental Disabilities, 33, I310-I332.

Young, D., Nagarajan, L., Klerk, N. de, Jacoby, P., Ellaway, C., \& Leonard, H. (2007). Sleep problems in Rett syndrome. Brain a Development, 29, 609-6I6, 
CHAPTER 2

Psychometric Properties of a Sleep QUESTIONNAIRE FOR USE IN INDIVIDUALS with Intellectual Disability

Maas, A. P. H. M., Didden, R., Korzilius, H., Braam, W., Collin, P., Smits, M. G., \& Curfs, L. M. G. (20II). Research in Developmental Disabilities, 32, $2467-2479$. 


\section{ABSTRACT}

We examined the psychometric properties of one part of the Sleep Questionnaire developed by Simonds and Parraga (SQ-SP; 1982), a questionnaire that is frequently used to explore sleep problems and behaviors related to sleep in individuals with intellectual disability (ID). The SQ-SP was completed for 345 individuals with ID (sleep clinic $n=$ I46; control group $n=$ I03; published studies $n=68$; psychiatric clinic $n=28$ ). Internal consistency was good (Cronbach's $\alpha=.80$ ) and test-retest reliability for the total SQ-SP score was also good (Spearman's rank correlation $=.83$, $p<. \mathrm{OI})$. Convergent validity was adequate $(r=.79, p<.00 \mathrm{I})$ and concurrent validity was satisfactory $(r=.52, p<.00 \mathrm{I})$. Exploratory factor analysis suggested a 5 -factor structure (Snoring, Daytime sleepiness, Complaints related to sleep, Sleep apnoea and Anxiety related to sleep). Internal consistency of the five factors ranged from modest (Cronbach's $\alpha=.57$ ) to good (Cronbach's $\alpha=.82$ ). Confirmatory factor analysis corroborated the 5 -factor structure. The Composite Sleep Index, the total SQ-SP score and the factor scores on Daytime sleepiness and Complaints related to sleep were able to differentiate the control group from the sleep clinic group. The SQ-SP appears to be a reliable and valid tool in assessing sleep and different types of sleep disturbance in individuals with ID. 


\section{INTRODUCTION}

Individuals with intellectual disability (ID) are at increased risk for developing sleep problems with reported prevalence rates from $15 \%$ to $85 \%$ of the samples (Didden \& Sigafoos, 200I). Prevalence of sleep problems is usually assessed by questionnaires. Two important limitations of assessing prevalence rates by questionnaires have to be considered. Firstly, various questionnaires with unknown psychometric properties in individuals with ID are used across studies and more than half of the studies do not use standardised questionnaires to collect data. Secondly, about half of the studies use questionnaires that lack information on different types of sleep disturbance and solely address complaints about sleep (e.g., settling problems, night waking problems, daytime sleepiness) and as a result almost no prevalence rates are presented of types of sleep disturbance which are mentioned in the International Classification of Sleep Disorders 2nd edition (ICSD-2; American Academy of Sleep Medicine [AASM], 2005). In the ICSD-2, different types of sleep disturbance are subdivided in broad categories of sleep disorders such as Sleep Related Breathing Disorders, Circadian Rhythm Sleep Disorders, Parasomnias, and Sleep Related Movement Disorders. Different types of sleep disturbance may reflect sleep disorders that could be the underlying cause of a presenting sleep problem (or complaint). Information on sleep disorders is necessary for treatment of a sleep problem (Wiggs \& Stores, 2004).

Over the past decades several standardised questionnaires of which items are based on the precursors of the ICSD-2 (AASM, 2005) have been developed in the field of pediatric sleep research. Examples of these multidimensional questionnaires addressing sleep in school-aged children and adolescents are the Sleep Questionnaire by Simonds and Parraga (SQ-SP; I982), the Children's Sleep Behavior Scale (CSBS; Fisher, Pauley, \& McGuire, I989), the Sleep Disturbance Scale for Children (SDSC; Bruni et al., I996), the Children's Sleep Habits Questionnaire (CSHQ; Owens, Spirito, \& McGuinn, 2000) and the Behavioral Evaluation of Disorders of Sleep (BEDS; Schreck, Mulick, \& Rojahn, 2003). However, the SQ-SP was adapted for use in individuals with ID by Wiggs and Stores (I996) and at present the SQ-SP is the most often used standardised sleep questionnaire in sleep studies in individuals with ID (Brylewski \& Wiggs, I998; Didden, Korzilius, Van Aperlo, Van Overloop, \& De Vries, 2002; Didden, Korzilius, Smits, \& Curfs, 2004; Hunt \& Stores, I994; Johnson, Wiggs, Stores, \& Huson, 2005; Maas et al., 2009; Maas et al., 2008; Quine, 200I; Stores, Stores, \& Buckley, I996). Other questionnaires were used less often in individuals with ID, such as the CSHQ (Annaz, Hill, Ashworth, Holley, \& Karmiloff-Smith, 20II; Breau \& Camfield, 20II; Carter, McCaughey, Annaz, \& Hill, 2008; Ghanizadeh \& Faghih, 20II; Kronk, Dahl, \& Noll, 2009; MacCrosain \& Byrne, 2009), the SDSC (Bruni et al., 2004; Hartshorne et al., 2009), the BEDS (Conant, Thibert, \& Thiele, 2009; Walz, Beebe, \& Byars, 2005), and the CSBS (Sarimski, I996). 
Psychometric properties including the structure of the SDSC and BEDS were well examined in samples of children and adolescents without ID (Spruyt \& Gozal, 20II), but it is unknown if these results may be generalised to samples of individuals with ID. Psychometric properties of the SQ-SP were examined to a lesser extent and were reported across one sample of individuals without ID (Simonds \& Parraga, I982) and two samples of individuals with ID (Hunt \& Stores, I994; Stores, Stores, Fellows, \& Buckley, I998). Test-retest reliability (after two weeks) for each of the items of the SQ-SP was high $(r=.83$-I $)$ and the questionnaire was assumed to have face validity for children and adolescents without ID (Simonds \& Parraga, I982). Information obtained with the SQ-SP was found to correspond very closely to information obtained with sleep diaries kept by parents of children with ID who had tuberous sclerosis (Hunt \& Stores, I994). As for the structure, R. Stores, Stores, Fellows and Buckley (I998) performed exploratory factor analysis on the results of the SQ-SP in children with ID who had Down syndrome and obtained three significant sleep factors: (a) Sleep onset problems, (b) Sleep maintenance problems, and (c) Disordered breathing during sleep. This 3-factor structure has not been confirmed in other samples of individuals with ID. In other studies (Johnson et al., 2005; Maas et al., 2009; Maas et al., 2008; Stores, Wiggs, \& Campling, 1998) targeting individuals with and without ID several items of the SQ-SP were grouped together to reflect five types of sleep disturbance encountered in clinical practice: (a) Poor quality sleep, (b) Anxieties about sleep, (c) Parasomnias, (d) Disordered breathing during sleep, and (e) Early waking. Until now, this structure has not been explored nor confirmed by factor analysis.

The aim of the present study is to demonstrate the reliability and the validity of the SQ-SP. Firstly, reliability of the SQ-SP was examined by exploring internal consistency and test-retest reliability after three to four weeks. Secondly, convergent validity was explored by correlating total scores on the SQ-SP with total scores on the SDSC, and concurrent validity was explored by correlating total scores on the SQ-SP with Composite Sleep Index (CSI) scores. Thirdly, an exploratory factor analysis (EFA) and a confirmatory factor analysis (CFA) were performed to define the factor structure of the SQ-SP and to evaluate if these factors fit in with the types of sleep disturbance encountered in clinical practice and/or the sleep disorders mentioned in the ICSD-2 (AASM, 2005). Finally, we assessed the degree to which the SQ-SP detected differences between individuals with ID from a control group and individuals referred to a sleep clinic.

\section{METHOD}

\section{PARTICIPANTS}

The SQ-SP was completed for 345 individuals with ID and was completed by parents or professional caregivers of: (a) individuals who consulted the sleep clinic for individuals with ID $(n=$ I46, 76 male, Mage = II years I month, $S D=$ Io years 6 months, age range: 
I year 3 months 66 years o months), (b) individuals from a control group who attended a special day care centre, special school, or adult activity centre for individuals with ID $(n=$ I03, 64 male, Mage = I2 years Io months, $S D=9$ years 9 months, age range: $\mathrm{I}$ year o months-55 years 8 months), (c) participants of two published studies ( $n=68,26$ male, Mage $=$ II years 6 months, $S D=8$ years I month, age range: I year 7 months-47 years 9 months; Maas et al., 2009; Maas et al., 2008), and (d) individuals who consulted a psychiatric clinic for children and adolescents with ID $(n=28$, 2I male, Mage = II years 5 months, $S D=3$ years 7 months, age range: 5 years 5 months-22 years 5 months) (see section Procedure for information about recruitment).

Of the 345 participants, I 87 participants (54\%) were male and their mean age was II years and 8 months ( $S D=9$ years 5 months, range: I year $\circ$ months- 66 years o months). Most participants $(9 \mathrm{I} \%, n=309)$ lived with their parents and 23 participants $(7 \%)$ lived in a community group home or residential facility. Aetiology of ID was known for I79 (52\%) participants, including: (a) Down syndrome $(n=44)$, (b) Jacobsen syndrome $(n=35)$, (c) Cri du Chat syndrome $(n=29)$, (d) Angelman syndrome $(n=12)$, (e) PraderWilli syndrome $(n=7)$, (f) Rett syndrome $(n=4)$, (g) Smith Magenis syndrome $(n=3)$, (h) Williams syndrome $(n=3)$, (i) Fragile X syndrome $(n=2)$, and (j) other $(n=40)$.

\section{Materials}

The SQ-SP was originally developed by Simonds and Parraga (I982) and was modified by Wiggs and Stores (1996, 2004) and consisted of five parts. Part one addresses demographic information (e.g., name and dosage of current medication and presence of seizure disorders). The second part covers current (i.e., last three months) behaviours related to settling to sleep, night waking and early waking. In part three, parents are asked to fill in at what times their child usually goes to bed, wakes up in the morning, among other topics related to the sleep pattern. The fourth part assesses the frequency of occurrence of 45 behaviours related to sleep (e.g., 'Bangs head in sleep or going off to sleep', 'Snores loudly during sleep', 'Doesn't want to go to bed because afraid') on a 7-point Likert-type scale, from 'Never' (I) to 'Daily' (7) (see Appendix). The last part contains items about parents' impression of their childrens current or past sleep problems, as well as treatment of their childrens sleep problem. A total score on the SQ-SP could be retrieved on the basis of the sum of scores of 45 items in part four. Three items were deleted because of insufficient reliability and as a result total score was calculated on the remaining 42 items (see section Internal consistency), with a possible range from 42 to 294 .

To assess concurrent validity the total score on the SQ-SP was compared with the CSI. The CSI is a construct that reflects the severity of sleep problems (Wiggs \& Stores, I998). The frequency of problems with settling, night waking, early waking, and cosleeping 
and the duration of settling and night waking were derived from the SQ-SP, resulting in the CSI ranging from $\circ$ to I2. A score of $\geq 4$ is indicative of a severe sleep problem. A difference of I point on the CSI would suggest that an individual took more than I hr to settle to sleep instead of 30 to $60 \mathrm{~min}$.

To assess convergent validity the total score on the SQ-SP was compared with the total score on the Sleep Disturbance Scale for Children (SDSC). The SDSC (Bruni et al., I996) consists of 26 items that are rated on a 5-point Likert-type scale, from 'Never' (I) to 'Always (daily)' (5). The scores of the items were summed to derive a total SDSC score with a possible range from 26 to I30. A total SDSC score of 39 has been reported to be a sensitive cut-off to identify children with disturbed sleep (Bruni et al., I996). Psychometric properties of the SDCS have been examined in two groups of children aged between 5 to I5 years without ID: (a) children referred to a sleep clinic, and (b) healthy control children from public schools (Bruni et al., I996). Internal consistency of the total scale (Cronbach's $\alpha=.7$ I for the sleep disordered group and Cronbach's $\alpha=.79$ for the control group) was adequate and test-retest reliability $\left(r_{s}=.7 \mathrm{I}\right)$ of the total scale was also adequate when administered to children with sleep disorders and healthy controls. Factor analysis explained $44 \%$ of the variance and yielded six factors: (a) Disorders of initiating and maintaining sleep, (b) Sleep breathing disorders, (c) Disorders of arousal, (d) Sleep-wake transition disorders, (e) Disorders of excessive somnolence, and (f) Sleep hyperhydrosis (Bruni et al., I996).

\section{Procedure}

Sample recruitment procedures differed for the four groups (see section Participants). The parents of the individuals from the sleep clinic completed the questionnaire as part of the assessment procedure. The parents of the individuals from control group were recruited via their childrens day care centre, special school, or adult activity centre. The parents of individuals participating in two published studies were recruited via the American IIq Research Group and the Dutch Cri du Chat Parent Association. The parents of the individuals from a psychiatric clinic were randomly selected by the director of the clinic.

All parents received a questionnaire package by mail. Each package consisted of a covering letter, a questionnaire, a consent form and a stamped self-addressed envelope. Individuals for whom more than nine responses were missing or for whom more than four subsequent responses were missing on part four of the SQ-SP were excluded from this study.

Sleep clinic for individuals with intellectual disability. The SQ-SP was provided to parents of $\mathrm{I}_{3}$ individuals referred to the sleep clinic by a pediatrician or physician specialising in individuals with ID during the period September 2005-July 2009. The 
SQ-SP was completed prior to an interview and no specific instructions were given on completion of the questionnaire. Seventeen individuals were excluded because of missing responses.

Control group. The SQ-SP was provided with a letter explaining the aim of the study (i.e., assessing the nature of sleep and the prevalence of sleep problems in individuals with ID). Response rate of the control group was II9 out of 350 (34\%). Parents of six individuals refused to participate, one individual was a patient from the sleep clinic was therefore excluded and nine individuals were excluded because of missing responses.

Two published studies. The SQ-SP was provided with a letter explaining the aim of the study (i.e., assessing the nature of sleep and the prevalence of sleep problems in individuals with a specific syndrome associated with ID; see Maas et al., 2009; Maas et al., 2008). Response rate was 50 out of I05 (48\%) from individuals with chromosome IIq disorders (i.e., Jacobsen syndrome or other chromosome IIq disorder) and 30 out of 54 (55.5\%) from individuals with Cri du Chat syndrome. In this study, data were reanalysed and eleven individuals with chromosome iıq disorders and one individual with Cri du Chat syndrome were excluded because of missing responses.

Psychiatric clinic for children and adolescents with intellectual disability. The SQ-SP and the SDSC were provided with a letter explaining the aim of the study (i.e., assessing psychometric properties of the SQ-SP). One of the parents was asked to complete both the SQ-SP and the SDSC. To assess test-retest reliability, three to four weeks after the completion of the first assessment, the same parent was asked to complete a second SQ-SP. Response rate of the first assessment was 30 out of 74 (4I\%). Parents of one individual refused to participate and one individual was excluded because of missing responses. Both the SQ-SP and the SDSC were completed for 23 out of 28 participants $(82 \%)$. Response rate of the second assessment was I5 out of $28(54 \%)$.

\section{Statistical Analyses}

Cronbach's $\alpha$ coefficient and item-total correlation coefficients were calculated to assess internal consistency of part four of the SQ-SP. Cronbach's $\alpha$ coefficient was also calculated to assess internal consistency of five types of sleep disturbance encountered in clinical practice (see section Introduction). Test-retest reliability for all items of part four of the SQ-SP was assessed by using percentage of exact and adjacent agreement and Spearman's rank correlation (because sample size was small, $n=15$ ). Percentage of exact and adjacent agreement between the first and second assessment of the SQ-SP was calculated for each rater (i.e., parent). Convergent validity of the SQ-SP was assessed by 
calculating Pearson correlation between total scores on the SQ-SP and total scores on the SDSC. Concurrent validity of the SQ-SP was assessed by calculating Pearson correlation between the total scores on the SQ-SP and the CSI. We expected that this correlation was neither I nor o (Cicchetti, I994). Both the total score and the CSI measure aspects of sleep (therefore correlation not o) but each measures different aspects of sleep (therefore correlation not I). EFA was performed using SPSS (version I5.0) and CFA was conducted with AMOS (version I7.0). CFA was conducted to test competing theoretical structures and to assess which structure has the best empirical underpinning. To avoid excluding participants from the CFA because of one or a few missing items, missing values were substituted with median scores of all participants for that item. Differences on the SQSP between individuals from the control group and individuals referred to the sleep clinic were tested. Independent samples $t$ tests were performed to test differences on the CSI score and the total SQ-SP score between the groups. To test differences on factor scores between both groups Mann-Whitney tests were performed (because factor scores were not found to be normally distributed).

\section{RESULTS}

\section{RELIABILITY}

Internal consistency. See Table I for descriptive statistics on the items of part four of the SQ-SP. Reliability analysis was performed on item scores using 345 of the SQSP's completed by parents. Missing data were excluded listwise and item 22 was deleted because of zero variance. Item 15 and 29 were deleted because of negative item-total correlations (-.06 and -.04). Cronbach's $\alpha$ for the SQ-SP was .80 ( $n=103,42$ items), which indicates good reliability. Mean item-total correlation for the total scale was .28 ( $S D=. \mathrm{I} 4$ ) with a range from .oI to .57 (see Table 2 ). Cronbach's $\alpha$ did not significantly increase after deletion of single items.

Five types of sleep disturbance encountered in clinical practice were distinguished in other studies (see section Introduction). Cronbach's $\alpha$ for Poor quality sleep (item 6 , 24) was .08 ( $n=329)$, Anxieties about sleep (item I4, I5, I6, I7, I8, I9) was .45 ( $n=294)$, Parasomnias (item I, 2, 3, 4, I2, I3) was .27 ( $n=282)$, and Disordered breathing during sleep (item 8, 9, I0) was .40 ( $n=3$ I 8$)$. Cronbach's $\alpha$ could not be calculated for Early waking (item 32). Reliability of each of the types of sleep disturbance was poor.

Test-retest reliability. The mean interval between the first and second assessment was 32.7 days ( $S D=3.0$, range: $27-38, n=15$ ). See Table 3 for percentages of exact and adjacent agreements and Spearman's rank correlation coefficients for each of the items of the SQ- 
Psychometric Properties of a Sleep Questionnaire

Table I Mean Score (SD) for Each Item of Part Four of the Sleep Questionnaire

\begin{tabular}{|c|c|c|}
\hline Item & $n$ & $M(S D)$ \\
\hline I & 334 & I. 88 (I. 55$)$ \\
\hline 2 & 339 & I.IO (0.62) \\
\hline 3 & 322 & $2.19 \quad(2.01)$ \\
\hline 4 & 342 & I.6I (I.60) \\
\hline 5 & 339 & I.89 (т.93) \\
\hline 6 & 333 & 3.I7 (2.53) \\
\hline 7 & 339 & I.05 (0.43) \\
\hline 8 & 334 & $2.75 \quad(2.2 \mathrm{I})$ \\
\hline 9 & $34 \mathrm{I}$ & I.38 (I.I6) \\
\hline IO & $33 \mathrm{I}$ & I.4O (I.3O) \\
\hline II & 334 & $4.40(2.87)$ \\
\hline I2 & 313 & I.29 (0.86) \\
\hline I3 & 337 & I.26 (0.98) \\
\hline I4 & 329 & I.36 (I.I8) \\
\hline I5 & 328 & I.04 (0.38) \\
\hline I6 & 332 & I.94 (2.02) \\
\hline I7 & 323 & I.94 (2.13) \\
\hline I8 & 340 & $4.08(2.92)$ \\
\hline I9 & 335 & $4.66(2.84)$ \\
\hline 20 & 333 & $2.50 \quad(2.57)$ \\
\hline $2 \mathrm{I}$ & 336 & I.2I (0.93) \\
\hline 22 & 323 & I.09 (0.66) \\
\hline 23 & 339 & I.98 (I.94) \\
\hline 24 & $34 \mathrm{I}$ & $2.87(2.2 \mathrm{I})$ \\
\hline 25 & 334 & $3.00(2.69)$ \\
\hline 26 & 333 & I. 8 I (I.94) \\
\hline 27 & 329 & I. 83 (т. 83 ) \\
\hline 28 & 290 & $3.9 \mathrm{I} \quad(2.68)$ \\
\hline 29 & 315 & I.26 (0.90) \\
\hline 30 & 340 & $2.40(2.22)$ \\
\hline $3 \mathrm{I}$ & 335 & $2.44(2.2 \mathrm{I})$ \\
\hline 32 & 330 & $2.5 \mathrm{I} \quad\left(\mathrm{I} .9^{8}\right)$ \\
\hline 33 & 334 & I.49 (I.48) \\
\hline 34 & 327 & І. 88 (г.8г) \\
\hline 35 & 268 & I.I3 (0.70) \\
\hline 36 & 339 & $2.90(2.39)$ \\
\hline 37 & 334 & I.3I (I.I4) \\
\hline 38 & 337 & $2.23(2.08)$ \\
\hline 39 & 327 & I.96 (I.96) \\
\hline 40 & 337 & I.27 (I.04) \\
\hline $4 \mathrm{I}$ & 302 & I.69 (I.72) \\
\hline 42 & 340 & I.4० (I.09) \\
\hline 43 & 308 & $2.50 \quad(2.32)$ \\
\hline 44 & $33 \mathrm{I}$ & $2.65(2.24)$ \\
\hline 45 & $286^{\mathrm{a}}$ & 2.I4 (I.85) \\
\hline
\end{tabular}

${ }^{\mathrm{a}} \mathrm{A}$ part of the participants $(n=55)$ completed a version of the Sleep Questionnaire (Simonds \& Parraga, 1982) without item 45 .
Table 2 Item-Total Correlations for Each Item of Part Four of the Sleep Questionnaire

\begin{tabular}{|c|c|c|}
\hline Item & $r$ & $\begin{array}{l}\text { Cronbach's } \alpha \\
\text { if Item Deleted }\end{array}$ \\
\hline I & .27 & .79 \\
\hline 2 & .28 & .80 \\
\hline 3 & .30 & .79 \\
\hline 4 & .24 & .80 \\
\hline 5 & .39 & .79 \\
\hline 6 & $.4 \mathrm{I}$ & .79 \\
\hline 7 & .13 & .80 \\
\hline 8 & .53 & .78 \\
\hline 9 & $.3 \mathrm{I}$ & .80 \\
\hline IO & .13 & .80 \\
\hline II & .24 & .80 \\
\hline I2 & .29 & .80 \\
\hline I3 & .26 & .80 \\
\hline I4 & .22 & .80 \\
\hline I6 & .22 & .80 \\
\hline I7 & .09 & .80 \\
\hline I8 & .07 & $.8 \mathrm{I}$ \\
\hline I9 & .23 & .80 \\
\hline 20 & .34 & .79 \\
\hline $2 \mathrm{I}$ &.$I 4$ & .80 \\
\hline 23 & .08 & .80 \\
\hline 24 & .34 & .79 \\
\hline 25 &. $\mathrm{I} 4$ & .80 \\
\hline 26 &. OI & .80 \\
\hline 27 & .28 & .79 \\
\hline 28 & .34 & .79 \\
\hline 30 & .38 & .79 \\
\hline $3 \mathrm{I}$ &.$I 7$ & .80 \\
\hline 32 & .34 & .79 \\
\hline 33 &. $\mathrm{I7}$ & .80 \\
\hline 34 & .37 & .79 \\
\hline 35 & .05 & .80 \\
\hline 36 & .57 & .78 \\
\hline 37 & .20 & .80 \\
\hline 38 & .57 & .78 \\
\hline 39 & .43 & .79 \\
\hline 40 & .25 & .80 \\
\hline $4 \mathrm{I}$ & .43 & .79 \\
\hline $4^{2}$ & .43 & .79 \\
\hline 43 & .23 & .80 \\
\hline 44 & .36 & .79 \\
\hline 45 & .36 & .79 \\
\hline
\end{tabular}


Table 3 Percentage of Exact Agreement, Percentage of Adjacent Agreement, and Spearman's Rank Correlation for Each Item of Part Four of the Sleep Questionnaire

\begin{tabular}{|c|c|c|c|c|c|}
\hline Item & $n$ & EA (\%) & AA (\%) & $r_{s}$ & $p$ (two-tailed) \\
\hline I & I5 & 47 & 87 & .82 & $<.001$ \\
\hline 2 & I5 & 87 & 93 & I & $<.001$ \\
\hline 3 & I5 & 87 & 93 & -.07 & .80 \\
\hline 4 & I5 & 100 & 100 & - & - \\
\hline 5 & I5 & 93 & 93 & I & $<.001$ \\
\hline 6 & I4 & $7 \mathrm{I}$ & 79 & .69 & $<.0 \mathrm{I}$ \\
\hline 7 & I5 & 100 & 100 & - & - \\
\hline 8 & I5 & 60 & 80 &. $\mathrm{I} 8$ & $.5 \mathrm{I}$ \\
\hline 9 & I5 & IOO & IOO & - & - \\
\hline IO & I5 & 100 & IO० & - & - \\
\hline II & I5 & 87 & I0० & .90 & $<.001$ \\
\hline I2 & I5 & 60 & 93 & .39 & .15 \\
\hline I3 & I5 & 100 & 100 & I & $<.001$ \\
\hline I4 & I5 & 73 & 87 & .75 & $<$. OI \\
\hline I6 & I5 & 73 & 73 & .68 & $<$.OI \\
\hline I7 & I4 & 86 & 100 & .93 & $<.001$ \\
\hline I8 & I5 & 73 & 87 & $.8 \mathrm{I}$ & $<.001$ \\
\hline I9 & I4 & 7I & $7 \mathrm{I}$ & .64 & $.0 \mathrm{I}$ \\
\hline 20 & $\mathrm{I} 3$ & 85 & 85 & .76 & $<$. OI \\
\hline $2 \mathrm{I}$ & I5 & IOO & IO० & - & - \\
\hline 23 & I5 & 87 & 93 & .53 & .04 \\
\hline 24 & I5 & 73 & 93 & .78 & $<. \mathrm{OI}$ \\
\hline 25 & I5 & 80 & 87 & .82 & $<.001$ \\
\hline 26 & I5 & 80 & 80 & .58 & .02 \\
\hline 27 & I5 & 87 & 93 & .73 & $<$.OI \\
\hline 28 & I5 & 67 & 73 & .67 & $<$. OI \\
\hline 30 & I5 & 73 & 80 & .62 & .OI \\
\hline $3 \mathrm{I}$ & I3 & 77 & IOO & .92 & $<.001$ \\
\hline 32 & I4 & 79 & 93 & .39 &. $\mathrm{I7}$ \\
\hline 33 & I4 & 86 & 86 & 99 & $<.001$ \\
\hline 34 & I5 & 80 & 87 & .65 & $<$. OI \\
\hline 35 & I5 & 80 & 80 & .59 & .02 \\
\hline 36 & I5 & 87 & 93 & .49 & .07 \\
\hline 37 & I5 & 93 & 93 & - & - \\
\hline 38 & I5 & 67 & 80 & -.19 & .49 \\
\hline 39 & I5 & 87 & 93 & - & - \\
\hline 40 & I4 & IOO & IOO & - & - \\
\hline $4 \mathrm{I}$ & I5 & 80 & 93 & .26 & .35 \\
\hline $4^{2}$ & I5 & 93 & 100 & .73 & $<$. OI \\
\hline 43 & I5 & 67 & 80 & .82 & $<.001$ \\
\hline 44 & I5 & 73 & 87 & .73 & $<$.OI \\
\hline 45 & I5 & 80 & 87 & .36 & .I9 \\
\hline
\end{tabular}

Note. $\mathrm{EA}=$ exact agreement; $\mathrm{AA}=$ adjacent agreement; $\mathrm{A}$ dash indicates that data could not be obtained because scores on this item were a constant at the first or the second assessment. 
SP. Mean percentage of exact agreement was 82 ( $S D=12.6$, range: $47-\mathrm{Io}$ ) and mean percentage of adjacent agreement was 90 ( $S D=8.5$, range: $7 \mathrm{I}-\mathrm{IO} O)$, which indicates good test-retest reliability. Mean Spearman's rank correlation between the first and second assessment for the items was .65 ( $S D=.29$, range: -.I9-I), which indicates moderate testretest reliability. Spearman's rank correlation between the first and second assessment for SQ-SP total score was .83 ( $p<$.oI, $n=\mathrm{I} 5)$, which indicates good test-retest reliability.

Convergent and concurrent validity. Pearson correlation between the total scores on the SQ-SP and the total scores on the SDSC was $.79(p<.001, n=23)$, which indicates adequate convergent validity. Pearson correlation between the total scores on the SQ-SP and the CSI was .52 ( $p<$. .OOI, $N=345)$, which shows a moderate correlation.

\section{FACTOR AnAlyses}

Exploratory factor analysis. An EFA to identify empirically driven subscales was conducted using 345 of the SQ-SP's completed by parents. Missing data were deleted pairwise. Initial EFA, using a principal axis factoring analysis with oblimin rotation was conducted on 42 items, extracting five factors with Eigenvalues > I.o (explaining 30\% of the variance). Fourteen items were subsequently eliminated, 7 due to low communalities (<.ro), 4 due to low communalities and with a loading $<.30$ and 3 due to cross loadings (factor loadings $\geq 1.30 \mid$ and the difference between the highest and second highest factor loading $<|.20|$ ). Subsequently a principal axis factoring analysis with oblimin rotation was conducted on the remaining 28 items and revealed five factors, which we labeled as:

(I) Snoring, (2) Daytime sleepiness, (3) Complaints related to sleep, (4) Sleep apnoea, and (5) Anxiety related to sleep.

Together, these five factors explained $39 \%$ of the variance. Eigenvalues and percentages of variances explained for each factor and factor loadings for each item are described in Table 4. Cronbach's $\alpha$ for the first factor was .8I ( $n=239,7$ items). Cronbach's $\alpha$ for Factor 2 was .7I ( $n=30$ I, 5 items), Factor 3 was .7I ( $n=26$ I, 9 items), Factor 4 was .82 ( $n=316,3$ items), and Factor 5 was $.57(n=280,4$ items). The internal consistency for Factors I and 4 was good, for Factors 2 and 3 adequate, and for Factor 5 modest. The internal consistency for the final 28 items was Cronbach's $\alpha=.77$ ( $n=153$ ), which indicates adequate reliability.

Confirmatory factor analysis. A CFA was conducted to test the hypothesised structure based on empirical research (i.e., EFA) and clinical experience using 345 of the SQ-SP's completed by parents. CFA was conducted with items which loaded most strongly (i.e., $\geq \cdot 40$ ) on the five factors derived from the final EFA (see Figure I). Correlations between the latent factors and a few error terms were allowed. Goodness-of-fit was determined by 
Table 4 Exploratory Factor Analysis for Items of Part Four of the Sleep Questionnaire

\begin{tabular}{|c|c|c|c|c|c|}
\hline \multicolumn{2}{|c|}{ Factor } & & $\begin{array}{l}\text { Factor } \\
\text { loading }\end{array}$ & Eigenvalue & $\%$ Variance \\
\hline \multicolumn{3}{|c|}{ Factor I } & & 4.52 & I6 \\
\hline \multirow[t]{7}{*}{ Item } & 38 & Snores more than half the time & .93 & & \\
\hline & 39 & Always snores & .84 & & \\
\hline & 8 & Snores loudly & .77 & & \\
\hline & 36 & Heavy or loud breathing & $.6 \mathrm{I}$ & & \\
\hline & 28 & Mouth breathing & .47 & & \\
\hline & 27 & Sleeps with neck extended & .36 & & \\
\hline & 43 & Dry mouth on waking up in the morning & .30 & & \\
\hline \multicolumn{3}{|c|}{ Factor 2} & & 2.12 & 8 \\
\hline \multirow[t]{5}{*}{ Item } & 44 & Daytime sleepiness $^{\mathrm{a}}$ & $.9 \mathrm{I}$ & & \\
\hline & 24 & Seems drowsy, but can stop themselves from sleeping ${ }^{a}$ & .68 & & \\
\hline & 23 & Has urges to go to sleep and can't stop themselves ${ }^{\mathrm{a}}$ & .50 & & \\
\hline & 32 & Wakes in the morning before 5:00 a.m. and stays awake & .47 & & \\
\hline & 20 & Needs sleep medication & .35 & & \\
\hline \multicolumn{2}{|c|}{ Factor 3} & & & I. 89 & 7 \\
\hline \multirow[t]{9}{*}{ Item } & 5 & Quick movements of arms or legs & .60 & & \\
\hline & 6 & Restless sleep & .57 & & \\
\hline & 34 & Startles or jerks part of the body while falling asleep & .52 & & \\
\hline & 4I & Legs feel restless & $.5 \mathrm{I}$ & & \\
\hline & 33 & Sweats excessively while falling asleep & .47 & & \\
\hline & 42 & Episodes of confused behaviour & .40 & & \\
\hline & 9 & Gags or chokes & .39 & & \\
\hline & 30 & Sweats excessively & .35 & & \\
\hline & I3 & Sleep terrors ${ }^{\mathrm{b}}$ & .30 & & \\
\hline \multicolumn{2}{|c|}{ Factor 4} & & & I. 35 & 5 \\
\hline \multirow[t]{3}{*}{ Item } & IO & Repeatedly stops breathing for $15-30$ seconds & -.94 & & \\
\hline & 40 & Stops breathing & -.80 & & \\
\hline & 37 & Has trouble breathing or struggles to breath & -.53 & & \\
\hline \multicolumn{2}{|c|}{ Factor 5} & & & I.०० & 4 \\
\hline \multirow[t]{4}{*}{ Item } & I4 & Doesn't want to go to bed because afraid & .79 & & \\
\hline & I7 & Afraid of the dark & .62 & & \\
\hline & $3 \mathrm{I}$ & Reluctant to go to bed & .42 & & \\
\hline & $\mathrm{I} 2$ & Wakes in the night complaining of nightmares ${ }^{c}$ & .32 & & \\
\hline
\end{tabular}

${ }^{a}$ During the day. ${ }^{b}$ First half of the night. 'Last half of the night.

evaluating the ratio of C-MIN to degrees of freedom (C-MIN/df), goodness of fit index (GFI), adjusted goodness of fit index (AGFI), and root mean square error of approximation (RMSEA). For C-MIN/df, values of < I.०० constitute good fit and values between I.०० and 2.00 acceptable fit. For both GFI and AGFI, values $>.95$ constitute good fit and values $>.90$ acceptable fit. For the RMSEA values $<.06$ constitute good fit (Byrne, 20IO). 


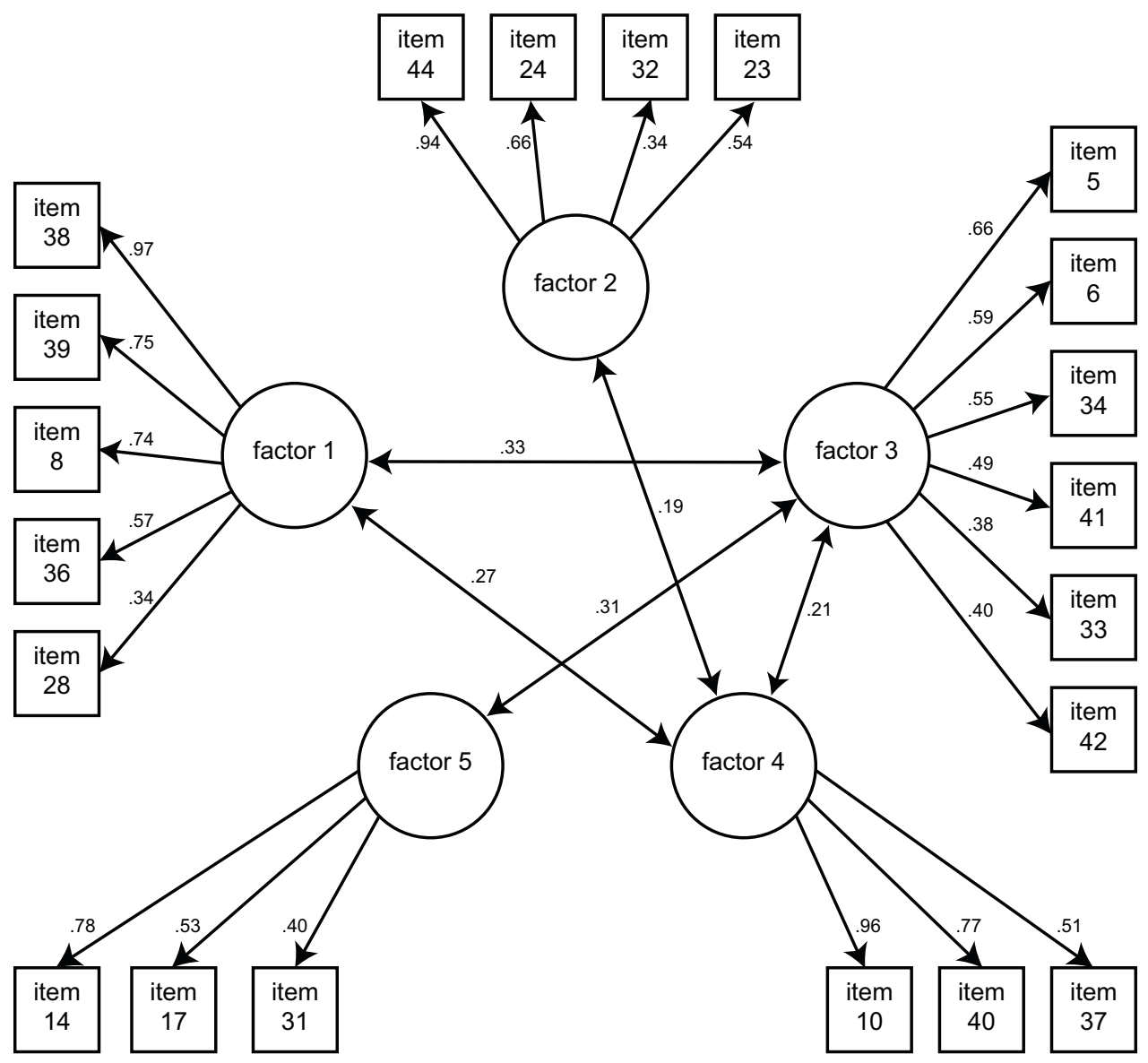

Figure 1. Relationships among observed and latent variables.

The final confirmatory model with the five factors demonstrated an acceptable fit to the data: $\mathrm{C}-\mathrm{MIN} / \mathrm{df}=\mathrm{I} .48, \mathrm{GFI}=.93, \mathrm{AGFI}=.9 \mathrm{I}, \mathrm{RMSEA}=.04$. A model with four factors (in which items of Factor I and Factor 4 were lumped together) led to a worse fit to the data, indicating discriminating validity of Factors I and 4.

\section{Comparison of Scores between Control Group and Sleep Clinic Group}

The SQ-SP scores for individuals from the control group were compared to the SQ-SP scores for individuals referred to the sleep clinic. Individuals who received medication related to sleep problems were excluded in both groups to rule out the effect of treatment of sleep problems. Leaving 9I individuals from the control group (57 male, Mage = I3 years 2 months, $S D=9$ years II months, age range: I year $\circ$ months- 55 years 8 months) 
Table 5 Mean Scores (SDs) and Median Scores for Sleep Factors by Group

\begin{tabular}{|c|c|c|c|c|c|}
\hline Factor & $n$ & $M(S D)$ & $M d n$ & $z^{a}$ & $p$ \\
\hline \multicolumn{6}{|l|}{ Factor I: Snoring } \\
\hline Sleep clinic & $5^{\mathrm{I}}$ & I3.80 (9.39) & $\mathrm{I} 2$ & 0.44 & .66 \\
\hline Control group & 46 & I2.93 (9.03) & II & & \\
\hline \multicolumn{6}{|l|}{ Factor 2: Daytime sleepiness } \\
\hline Sleep clinic & 56 & $13.39(6.40)$ & I3 & 6.01 & $<.00 \mathrm{I}$ \\
\hline Control group & 57 & $6.74 \quad(3.9 \mathrm{I})$ & 5 & & \\
\hline \multicolumn{6}{|c|}{ Factor 3: Complaints related to sleep } \\
\hline Sleep clinic & 45 & II.93 (6.82) & Io & 2.93 & .003 \\
\hline Control group & 54 & $8.72 \quad(4.77)$ & 6 & & \\
\hline \multicolumn{6}{|l|}{ Factor 4: Sleep apnoea } \\
\hline Sleep clinic & 58 & $3.9^{8} \quad(3.45)$ & 3 & 0.58 & .57 \\
\hline Control group & 58 & 3.48 (т.66) & 3 & & \\
\hline \multicolumn{6}{|c|}{ Factor 5: Anxiety related to sleep } \\
\hline Sleep clinic & 53 & $5.9 \mathrm{I} \quad(4.07)$ & 3 & I. 58 &. II \\
\hline Control group & 57 & $4.96(3.58)$ & 3 & & \\
\hline
\end{tabular}

${ }^{a}$ Mann-Whitney tests.

and 77 individuals from the sleep clinic (39 male, Mage $=$ I2 years I month, $S D=$ II years Io months, age range: 2 years 0 months -66 years o months). More individuals from the control group had been diagnosed with Down syndrome $(32 \%, n=29)$ than in the sleep clinic group (I3\%, $n=\mathrm{IO})$ and this difference was statistically significant $\left(\alpha^{2}(\mathrm{I})=8.34\right.$, $p=.006)$. Therefore, in both groups individuals with Down syndrome were excluded from further analysis, leaving 62 individuals in the comparison group $(36$ male, Mage $=$ II years I month, $S D=7$ years I month, age range: 3 years 3 months-3I years 6 months) and 67 individuals in the sleep clinic group (30 male, Mage = I2 years 4 months, $S D=$ II years Io months, age range: 2 years 8 months- 66 years o months). Results of a Mann-Whitney test showed that there was no statistically significant difference between the groups on age in months $(z=0.0 \mathrm{I}, p=.99)$ and $\operatorname{sex}\left(\alpha^{2}(\mathrm{I})=2.28, p=. \mathrm{I} 60\right)$. The groups were comparable by level of cognitive functioning ( $p=.82$, two-tailed Fisher's exact test).

The mean CSI for the control group was I.45 and Io individuals (I6\%) had a score $\geq 4(S D=\mathrm{I} .82$, range: $0-7)$. The mean CSI for the sleep clinic was 4.30 and $4 \mathrm{I}$ individuals $(6 \mathrm{I} \%)$ had a score $\geq 4(S D=2.74$, range: $0-\mathrm{IO})$. This difference was statistically significant $(t(\mathrm{I} 27)=6.89, p<.00 \mathrm{I})$, indicating that individuals from the sleep clinic showed more severe sleep problems than individuals from the control group.

The total scores on the SQ-SP for control group ranged from $4 \mathrm{I}$ to I43 $(M=76.8 \mathrm{I}$, $S D=25.04)$. For the sleep clinic group, the total scores ranged from 52 to I55 $(M=9 \mathrm{I} .24, S D=2 \mathrm{I} .84)$. This difference was statistically significant $(t(\mathrm{I} 27)=3.50$, 
$p=.00 \mathrm{I})$, indicating that individuals from the sleep clinic group showed more behaviours related to sleep disorders than individuals from the control group. Eighteen individuals $(27 \%)$ of the sleep clinic group had total scores on the SQ-SP one standard deviation above the mean of the control group.

The mean factor scores and the standard deviations are shown in Table 5. Differences between groups on mean factor scores were explored using Mann-Whitney tests. Mean scores on all factors were higher for the sleep clinic group than for the control group. Differences between groups on Factors 2 and 3 were statistically significant, suggesting that on average, individuals from the sleep clinic group showed more daytime sleepiness and complaints related to sleep than individuals from the control group. Differences between groups on Factors I, 4, and 5 were not statistically significant, suggesting that in the main, there was no difference between both groups in frequency of snoring, sleep apnoea and anxieties related to sleep.

\section{DISCUSSION}

This is the first study to investigate internal consistency, test-retest reliability, convergent and concurrent validity, and factor structure of part four of the Sleep Questionnaire by Simonds and Parraga (SQ-SP; I982) which assesses behaviours related to sleep in individuals with ID. Part four of the SQ-SP has good internal consistency and test-retest reliability. Convergent validity was adequate.

A moderate statistically significant correlation was obtained between the total score on the SQ-SP and the CSI, which indicates that the total score reflects frequency of behaviours related to sleep, but not severity of sleep problems. Vice versa a more severe sleep problem does not automatically lead to a higher frequency of behaviours related the sleep. A high total score on the SQ-SP may indicate the presence of one or more sleep problems with multiple underlying sleep disorders.

EFA revealed five factors (i.e., Snoring, Daytime sleepiness, Complaints related to sleep, Sleep apnoea, and Anxiety related to sleep), with internal consistency ranging from modest to good. In CFA the 5-factor structure could be confirmed. The 5 -factor structure does not fit the five types of sleep disturbance encountered in clinical practice reported in other studies (Johnson et al., 2005; Maas et al., 2009; Maas et al., 2008; Stores, Wiggs, et al., 1998). EFA did not reveal a factor that could be labeled as the clinical type parasomnias. Items of part four of the SQ-SP referring to parasomnias were eliminated from EFA because of low communalities and/or low factor loadings. The latter is not surprising, because these items refer to different types of parasomnias (i.e., sleepwalking, sleep enuresis) and are not interrelated (see low internal consistency 
for Parasomnias, Cronbach's $\alpha=.27)$. Items of the clinical type Disordered breathing were assigned on the basis of results of EFA to three different factors (i.e., Snoring, Sleep apnoea, and Complaints related to sleep), which indicates that the factors Snoring and Sleep apnoea are symptoms reflecting specific sleep disorders. This is remarkable because in other questionnaires such as the SDSC snoring and sleep apnoea make one factor (Bruni et al., I996). Items of the clinical types Poor quality sleep and Early waking were lumped together in the factor labeled as Daytime sleepiness. Daytime sleepiness seems to reflect a consequence of both poor quality sleep and early waking. Although one of the factors is labeled as Anxiety related to sleep, this factor has only two items (i.e., Afraid of going to bed; Afraid of the dark) in common with the clinical type Anxieties about sleep. Three of the remaining items of the clinical type Anxieties about sleep (i.e., Insists on sleeping with somebody else; Needs security object; Insists on bedtime ritual) seem to refer to circumstances concerning falling asleep or sleep-onset associations. In the present study, these three items were eliminated because of low communalities or multiple factor loadings and therefore do not compromise a specific sleep factor. This is striking because these three items together fit in with the sleep disorder Behavioral Insomnia of Childhood (Sleep-Onset Type) of the ICSD-2 (AASM, 2005). In addition, the five factors of the SQ-SP do not exactly match the six broad ICSD-2 categories of sleep disorders (i.e., Insomnia, Sleep Related Breathing Disorders, Hypersomnias of Central Origin, Circadian Rhythm Sleep Disorders, Parasomnias, and Sleep Related Movement Disorders) that are distinguished in the ICSD-2. Each factor of the SQ-SP consists of behaviours that reflect complaints or symptoms that belong to different sleep disorders.

The validity of the SQ-SP was also demonstrated by the ability of the CSI and the total score on the SQ-SP to differentiate between individuals with ID from the control group and individuals with ID referred to the sleep clinic. Individuals referred to the sleep clinic showed more severe sleep problems than individuals from the control group. Factors that were more prevalent in the sleep clinic group were Daytime sleepiness and Complaints related to sleep (e.g., sleep related movement disorders). Within the control group some individuals ( $\mathrm{I} 6 \%$ ) had severe sleep problems and were under consideration for referral to the sleep clinic.

Our data suggest that the SQ-SP has good potential for assessing prevalence of different types of sleep disturbance in individuals with ID, both in research and in clinical practice. However, there are some limitations in the use of the SQ-SP to assess prevalence of different types of sleep disturbance. Firstly, parent reports such as the SQSP are subjective and omissions might occur if parents are not present or awake during the whole period when the individual is asleep (Wiggs \& Stores, 2004). Secondly, the SQ-SP provides a general screening for sleep disturbances and it is not possible to make a diagnosis of sleep disorders (ICSD-2; AASM, 2005) based on the SQ-SP solely. To make 
a clinical diagnosis of a specific sleep disorder additional information about sleep is necessary such as information about sleep scheduling, the sleep environment, presleep activities and daytime activities (i.e., sleep hygiene). This information can be obtained by sleep history, sleep diary and sleep hygiene questionnaire. Furthermore, information about developmental, medical and psychiatric history is necessary. Diagnosis of some sleep disorders requires more objective measurements, such as audiovisual recordings (video) and/or polysomnography for assessing sleep disorders included in the categories Parasomnias or Sleep Related Breathing Disorders (Wiggs, 2007).

The results of the present study should be interpreted in the context of the study's methodological shortcomings. The first shortcoming relates to the heterogeneity of the sample which may limit the validity of the results. All individuals with ID were included, leading to a sample with a wide age range, different levels of ID and comorbidity. In this study, no exclusions were made based on medical condition (e.g., epilepsy), psychiatric condition (e.g., autism spectrum disorder), or medication use (e.g., anticonvulsants, methylphenidate, melatonin), which may influence sleep. In this study, no exclusions were made because heterogeneity is an essential feature of the population of individuals with ID and the aim of the present study was to examine the psychometric properties of the SQ-SP in this population. Furthermore, the relatively small sample size did not allow subdividing the sample to explore the factor structure in specific groups of individuals with ID (such as autism spectrum disorder). The second shortcoming relates to the fact that we did not compare the data to a clinical diagnosis of sleep disorders or objective measurements such as polysomnography. Therefore it remains unclear how the different factors of the SQ-SP exactly relate to different sleep disorders as described in the ICSD-2 (AASM, 2005). The third shortcoming relates to the method of CFA. Often CFA is conducted on another sample than the initial EFA. However, the number of participants in this study was too low to divide the sample in two samples.

Despite these shortcomings, the present study shows that the SQ-SP is a reliable and valid tool in assessing the prevalence of different types of sleep disturbance in individuals with ID. Further research is required to evaluate the preliminary results of this study (specifically results of the CFA in a new sample and comparison of results with clinical assessment and objective measurements) and to evaluate other psychometric properties of the SQ-SP (such as intrarater reliability). 


\section{REFERENCES}

American Academy of Sleep Medicine (2005). International classification of sleep disorders, 2nd edition: Diagnostic and coding manual. Westchester, IL: Author.

Annaz, D., Hill, C. M., Ashworth, A., Holley, S., \& Karmiloff-Smith, A. (2OII). Characterisation of sleep problems in children with Williams syndrome. Research in Developmental Disabilities, 32, I64-169.

Breau, L. M., \& Camfield, C. S. (20II). Pain disrupts sleep in children and youth with intellectual and developmental disabilities. Research in Developmental Disabilities, 32, 2829-2840.

Bruni, O., Ferri, R., D’Agostino, G., Miano, S., Roccella, M., \& Elia, M. (2004). Sleep disturbances in Angelman syndrome: A questionnaire study. Brain \& Development, 26, 233-240.

Bruni, O., Ottaviano, S., Guidetti, V., Romoli, M., Innocenzi, M., Cortesi, F., \& Giannotti, F. (I996). The Sleep Disturbance Scale for Children (SDSC): Construction and validation of an instrument to evaluate sleep disturbances in childhood and adolescence. Journal of Sleep Research, 5, 25I-26I.

Brylewski, J. E., \& Wiggs, L. (I998). A questionnaire survey of sleep and night-time behaviour in a community-based sample of adults with intellectual disability. Journal of Intellectual Disability Research, 42, I54-162.

Byrne, B. M. (2010). Structural equation modeling with AMOS: Basic concepts, applications, and programming (2nd ed.). New York, NY: Routledge.

Carter, M., McCaughey, E., Annaz, D., \& Hill, C. M. (2008). Sleep problems in a Down syndrome population. Archives of Disease in Childhood, 94, 308-310.

Cicchetti, D. V. (I994). Guidelines, criteria, and rules of thumb for evaluating normed and standardized assessment instruments in psychology. Psychological Assessment, 6, 284-290.

Conant, K. D., Thibert, R. L., \& Thiele, E.A. (2009). Epilepsy and the sleep-wake patterns found in Angelman syndrome. Epilepsia, 50, 2497-2500.

Didden, R., Korzilius, H., Aperlo, B. van, Overloop, C. van, \& Vries, M. de (2002). Sleep problems and daytime problem behaviours in children with intellectual disability. Journal of Intellectual Disability Research, 46, 537-547.

Didden, R., Korzilius, H., Smits, M. G., \& Curfs, L. M. G. (2004). Sleep problems in individuals with Angelman syndrome. American Journal on Mental Retardation, 109, 275-284.

Didden, R., \& Sigafoos, J. (200I). A review of the nature and treatment of sleep disorders in individuals with developmental disabilities. Research in Developmental Disabilities, 22, 255-272. 
Fisher, B. E., Pauley, C., \& McGuire, K. (1989). Children's Sleep Behavior Scale: Normative data on 870 children in grades I to 6. Perceptual and Motor Skills, 68, 227-236.

Ghanizadeh, A., \& Faghih, M. (20II). The impact of general medical condition on sleep in children with mental retardation. Sleep and Breathing, 15, 57-62.

Hartshorne, T. S., Heussler, H. S., Dailor, A. N., Williams, G. L., Papadopoulos, D., \& Brandt, K. K. (2009). Sleep disturbances in CHARGE syndrome: Types and relationships with behavior and caregiver well-being. Developmental Medicine \& Child Neurology, 51, I43-I5O.

Hunt, A., \& Stores G. (I994). Sleep disorder and epilepsy in children with tuberous sclerosis: A questionnaire-based study. Developmental Medicine a Child Neurology, 36, I08-II5.

Johnson, H., Wiggs, L., Stores, G., \& Huson, S. M. (2005). Psychological disturbance and sleep disorders in children with neurofibromatosis type I. Developmental Medicine Q Child Neurology, 47, 237-242.

Kronk, R., Dahl, R., \& Noll, R. (2009). Caregiver reports of sleep problems on a convenience sample of children with Fragile X syndrome. American Journal on Intellectual and Developmental Disabilities, 114, 383-392.

Maas, A. P. H. M., Didden, R., Korzilius H., Braam, W., Smits, M. G., \& Curfs, L. M. G. (2009). Sleep in individuals with Cri du Chat syndrome: A comparative study. Journal of Intellectual Disability Research, 53, 704-7I5.

Maas, A. P. H. M., Grossfeld, P. D., Didden, R., Korzilius, H., Braam, W. J., Smits, M. G., \& Curfs, L. M. G. (2008). Sleep problems in individuals with IIq terminal deletion disorder (Jacobsen syndrome). Genetic Counseling, 19, 225-235.

MacCrosain, A. M., \& Byrne, M. C. (2009). Are we ignoring the problem of sleep disorder in children with intellectual disabilities? Irish Journal of Medical Science, 178, 427-43I.

Owens, J. A., Spirito, A., \& McGuinn, M. (2000). The Children's Sleep Habits Questionnaire (CSHQ): Psychometric properties of a survey instrument for schoolaged children. Sleep, 23, I043-IO5I.

Quine, L. (200I). Sleep problems in primary school children: Comparison between mainstream and special school children. Child: Care, Health and Development, 27, 2OI-22I.

Sarimski, K. (I996). Specific eating and sleeping problems in Prader-Willi and WilliamsBeuren syndrome. Child: Care, Health and Development, 22, I43-I5O.

Schreck, K. A., Mulick, J. A., \& Rojahn, J. (2003). Development of the Behavioral Evaluation of Disorders of Sleep Scale. Journal of Child and Family Studies, 12, 349-359.

Simonds, J. F., \& Parraga, H. (1982). Prevalence of sleep disorders and sleep behaviors in children and adolescents. Journal of the American Academy of Child Psychiatry, 21, 383-388. 
Spruyt, K., \& Gozal, D. (20II). Pediatric sleep questionnaires as diagnostic or epidemiological tools: A review of currently available instruments. Sleep Medicine Reviews, 15, 19-32.

Stores, G., Wiggs, L., \& Campling, G. (1998). Sleep disorders and their relationship to psychological disturbance in children with epilepsy. Child: Care, Health and Development, 24, 5-19.

Stores, R., Stores, G., \& Buckley, S. (1996). The pattern of sleep problems in children with Down's syndrome and other intellectual disabilities. Journal of Applied Research in Intellectual Disabilities, 9, I45-I59.

Stores, R., Stores, G., Fellows, B., \& Buckley, S. (1998). A factor analysis of sleep problems and their psychological associations in children with Down's Syndrome. Journal of Applied Research in Intellectual Disabilities, 11, 345-354.

Walz, N. C., Beebe, D., \& Byars, K. (2005). Sleep in individuals with Angelman syndrome: Parent perceptions of patterns and problems. American Journal on Mental Retardation, 110, 243-252.

Wiggs, L. (2007). Sleep disorders. In A. Carr, G. O’Reilly, P. Noonan Walsh \& J. McEvoy (Eds.), The handbook of intellectual disability and clinical psychology practice (pp. 37I42I). Hove, England: Routledge.

Wiggs, L., \& Stores, G. (I996). Severe sleep disturbance and daytime challenging behaviour in children with severe learning disabilities. Journal of Intellectual Disability Research, 40, 518-528.

Wiggs, L., \& Stores, G. (1998). Behavioural treatment for sleep problems in children with severe learning disabilities and challenging daytime behaviour: Effect on sleep patterns of mother and child. Journal of Sleep Research, 7, II9-126.

Wiggs, L., \& Stores, G. (2004). Sleep patterns and sleep disorders in children with autistic spectrum disorders: Insights using parent report and actigraphy. Developmental Medicine a Child Neurology, 46, 372-380. 
Psychometric Properties of a Sleep Questionnaire 


\section{APPENDIX}

\section{Sleep Questionnaire}

\section{PART FOUR}

During the LAST THREE MONTHS has your child has shown any of the following behaviours? Please put a tick in the box which describes how often each behaviour happens.

\begin{tabular}{|c|c|c|c|c|c|c|c|}
\hline Description & Never & $\begin{array}{l}\text { Less than } \\
\text { once a } \\
\text { month }\end{array}$ & $\begin{array}{l}\text { About } \\
\text { once a } \\
\text { month }\end{array}$ & $\begin{array}{l}\text { to } 4 \\
\text { times a } \\
\text { month } \\
\end{array}$ & $\begin{array}{l}\text { or } 2 \\
\text { times a } \\
\text { week } \\
\end{array}$ & $\begin{array}{l}\text { to } 6 \\
\text { times a } \\
\text { week } \\
\end{array}$ & Daily \\
\hline \multicolumn{8}{|l|}{ I) Talks in sleep } \\
\hline \multicolumn{8}{|l|}{ 2) Walks in sleep } \\
\hline \multicolumn{8}{|l|}{ 3) Grinds teeth in sleep } \\
\hline \multicolumn{8}{|l|}{ 4) Bangs head in sleep or going off to sleep } \\
\hline \multicolumn{8}{|l|}{$\begin{array}{l}\text { 5) Has quick movements of arms or legs during } \\
\text { sleep (e.g. kicking, jumping, arm flailing) }\end{array}$} \\
\hline \multicolumn{8}{|l|}{$\begin{array}{l}\text { 6) Moves around a lot in bed during sleep } \\
\text { (restless sleep) }\end{array}$} \\
\hline \multicolumn{8}{|l|}{ 7) Bites tongue during sleep } \\
\hline \multicolumn{8}{|l|}{ 8) Snores loudly during sleep } \\
\hline \multicolumn{8}{|l|}{ 9) Gags, chokes or snorts loudly during sleep } \\
\hline \multicolumn{8}{|l|}{$\begin{array}{l}\text { Io) Seems to repeatedly stop breathing for } \\
\text { periods of time lasting up to } 30 \text { seconds during } \\
\text { sleep }\end{array}$} \\
\hline \multicolumn{8}{|l|}{ II) Wets bed during sleep } \\
\hline \multicolumn{8}{|l|}{$\begin{array}{l}\text { I2) Wakes in night complaining of nightmares } \\
\text { or frightening dreams and seems quite } \\
\text { anxious. This usually happens in the last half } \\
\text { of the night. }\end{array}$} \\
\hline \multicolumn{8}{|l|}{$\begin{array}{l}\text { I3) Wakes during the night screaming in } \\
\text { terror. Anxiety may be so bad that sweating, } \\
\text { gasping or trembling may happen. This usually } \\
\text { happens during the first half of the night. She/ } \\
\text { he is not aware of their surroundings and will } \\
\text { not remember it the next day. }\end{array}$} \\
\hline \multicolumn{8}{|l|}{$\begin{array}{l}\text { I4) Doesn't want to go to bed because she/he } \\
\text { is afraid }\end{array}$} \\
\hline \multicolumn{8}{|l|}{$\begin{array}{l}\text { I5) Expresses fear that if she/he goes to sleep } \\
\text { they might die }\end{array}$} \\
\hline \multicolumn{8}{|l|}{$\begin{array}{l}\text { I6) Insists on sleeping with somebody else at } \\
\text { sleep onset/in night }\end{array}$} \\
\hline \multicolumn{8}{|l|}{ I7) Afraid of the dark } \\
\hline \multicolumn{8}{|l|}{$\begin{array}{l}\text { I8) Needs security object (e.g. teddy bear) } \\
\text { before she/he goes to sleep }\end{array}$} \\
\hline \multicolumn{8}{|l|}{$\begin{array}{l}\text { I9) Insists on bedtime ritual (e.g. bedtime } \\
\text { story) before sleep }\end{array}$} \\
\hline \multicolumn{8}{|l|}{ 20) Needs sleeping medication } \\
\hline $\begin{array}{l}\text { 2I) During the day, muscles become so weak } \\
\text { that she/he falls to the ground or has to lie } \\
\text { down before falling (usually after laughing, } \\
\text { crying or being frightened) }\end{array}$ & & & & & & & \\
\hline
\end{tabular}


Psychometric Properties of a Sleep Questionnaire

\begin{tabular}{|c|c|c|c|c|c|c|c|}
\hline Description & Never & $\begin{array}{l}\text { Less than } \\
\text { once a } \\
\text { month }\end{array}$ & $\begin{array}{l}\text { About } \\
\text { once a } \\
\text { month }\end{array}$ & \begin{tabular}{|l|}
2 to 4 \\
times a \\
month
\end{tabular} & \begin{tabular}{|l|} 
I or 2 \\
times a \\
week \\
\end{tabular} & $\begin{array}{l}\text { to } 6 \\
\text { times a } \\
\text { week }\end{array}$ & Daily \\
\hline \multicolumn{8}{|l|}{$\begin{array}{l}\text { 22) Upon waking or going off to sleep, feels } \\
\text { paralysed even though she/he is aware of the } \\
\text { surroundings }\end{array}$} \\
\hline \multicolumn{8}{|l|}{$\begin{array}{l}\text { 23) During the day, has urges to go to sleep and } \\
\text { can't stop herself/himself }\end{array}$} \\
\hline \multicolumn{8}{|l|}{$\begin{array}{l}\text { 24) Seems drowsy during the day, but can stop } \\
\text { herself/himself from sleeping }\end{array}$} \\
\hline \multicolumn{8}{|l|}{$\begin{array}{l}\text { 25) During the day, appears more active than } \\
\text { other children }\end{array}$} \\
\hline \multicolumn{8}{|l|}{$\begin{array}{l}\text { 26) Rolls from side to side rhythmically in sleep } \\
\text { or while going off to sleep }\end{array}$} \\
\hline \multicolumn{8}{|l|}{ 27) Sleeps with head tipped right back } \\
\hline \multicolumn{8}{|l|}{$\begin{array}{l}\text { 28) Breathes through mouth rather than nose } \\
\text { when asleep }\end{array}$} \\
\hline \multicolumn{8}{|l|}{ 29) Complains of headaches on waking up } \\
\hline \multicolumn{8}{|l|}{ 30) Sweats a lot during sleep } \\
\hline \multicolumn{8}{|l|}{ 3i) Reluctant to go to bed } \\
\hline \multicolumn{8}{|l|}{$\begin{array}{l}\text { 32) Wakes in the morning before 5am and stays } \\
\text { awake }\end{array}$} \\
\hline \multicolumn{8}{|l|}{ 33) Sweats excessively whilst falling asleep } \\
\hline \multicolumn{8}{|l|}{$\begin{array}{l}\text { 34) Startles or jerks part of the body whilst } \\
\text { falling asleep }\end{array}$} \\
\hline \multicolumn{8}{|l|}{$\begin{array}{l}\text { 35) Experiences vivid-dream like scenes whilst } \\
\text { falling asleep }\end{array}$} \\
\hline \multicolumn{8}{|l|}{ 36) Heavy or loud breathing } \\
\hline \multicolumn{8}{|l|}{ 37) Have trouble breathing or struggle to breath } \\
\hline \multicolumn{8}{|l|}{ 38) Snores more than half the time while asleep } \\
\hline \multicolumn{8}{|l|}{ 39) Always snores } \\
\hline \multicolumn{8}{|l|}{$\begin{array}{l}\text { 40) You have seen your child stop breathing } \\
\text { during the night }\end{array}$} \\
\hline \multicolumn{8}{|l|}{ 4I) Legs feel restless when in bed } \\
\hline \multicolumn{8}{|l|}{$\begin{array}{l}\text { 42) Wakes from sleep in the night confused so } \\
\text { that you can't get through to them }\end{array}$} \\
\hline \multicolumn{8}{|l|}{ 43) Dry mouth on waking up in the morning } \\
\hline \multicolumn{8}{|l|}{$\begin{array}{l}\text { 44) Has a problem with sleepiness during the } \\
\text { day }\end{array}$} \\
\hline $\begin{array}{l}\text { 45) Has a fit of laughter, screaming, crying or } \\
\text { weeping at night }\end{array}$ & & & & & & & \\
\hline
\end{tabular}




\section{CHAPTER 3.1}

\section{Sleep Problems in INDividuals with Jacobsen Syndrome}

Maas, A. P. H. M., Grossfeld, P. D., Didden, R., Korzilius, H., Braam, W. J., Smits, M. G., \& Curfs, L. M. G. (2008). Genetic Counseling, 19, 225-235. 


\begin{abstract}
Characteristics of sleep and sleep problems were investigated in 43 individuals with IIq terminal deletion disorder (Jacobsen syndrome). Data were collected using a sleep questionnaire. Ten individuals (23\%) had sleep problems. Settling problems, frequent night waking and early waking occurred in 2 (4\%), 7 ( $16 \%)$ and $2(6 \%)$ individuals, respectively. Twenty-two individuals (54\%) had a history of sleep problems. Twenty-five individuals (60\%) showed restless sleep and 23 individuals (54\%) slept in an unusual position. Apart from frequent coughs, no significant relationships were found between the presence of sleep problems and other variables, such as age, level of ID, breathing problems, heart defects, constipation, daytime activity and behavioural diagnosis, restless sleep and sleeping in an unusual position.
\end{abstract}




\section{INTRODUCTION}

Jacobsen syndrome (JS) is a rare genetic disorder, caused by a terminal deletion in the long arm of chromosome II. It is characterised by psychomotor retardation, congenital heart defects, blood dyscrasias (Paris-Trousseau syndrome) and craniofacial anomalies. Seizures are uncommon in this syndrome. Cognitive level in individuals with JS usually ranges from near normal intelligence to moderate intellectual disability (ID) (see e.g., Grossfeld et al., 2004).

Sleep problems may be part of genetic syndromes associated with ID. Compared to matched controls, prevalence of specific sleep problems has been found to be higher among individuals with a genetic disorder than in those without a disorder. For example, a relatively high prevalence of sleep problems were found in Down, fragile-X, Smith-Magenis, Prader-Willi, Angelman and Rett syndrome (e.g., Cotton \& Richdale, 2006; De Leersnyder, 2006; Didden, Korzilius, Smits, \& Curfs, 2004; Harvey \& Kennedy, 2002; Nomura 2005; Richdale, 2003; Stores, Stores, \& Buckley, I996). Little is known about the characteristics of sleep or the frequency of sleep problems in JS. Our knowledge on sleep problems in individuals with JS is primarily based on anecdotal information and clinical experience, suggesting that sleep problems in individuals with JS may be prevalent. Furthermore, it is not known what other neurocognitive and/or medical problems may be associated with sleep problems in these patients. Until now, no study has been performed that characterises sleep and sleep problems in individuals with JS, and factors that may be related to sleep problems in this group. Therefore, in the present study, (a) characteristics of sleep and sleep problems were investigated in a relatively large sample $(N=43)$ of individuals with JS, (b) parental management with their childrens sleep problem was investigated, and (c) relationships between the presence of sleep problems and other variables (e.g., age, level of ID and medical problems) were explored.

\section{METHOD}

\section{Participants and Procedure}

A standardised sleep questionnaire (see section Sleep Questionnaire) was sent to parents who were members of the American IIq Research and Resource Group. Only individuals with a terminal deletion at chromosome IIq (JS) and who were living with their parents were included. Out of 95 questionnaires that were sent to parents of individuals with this syndrome, 43 were returned (response rate: $45 \%$ ). A total of 43 individuals participated in this study. Fourteen individuals were male. The sex ratio 
was .48 and this ratio is not statistically different (binomial test, test proportion .65, $p=.44$ ) from the male to female sex ratio of .53 found by Grossfeld et al. (2004). Their mean age was Io years and 4 months ( $S D=5$ years II months, range: I year 7 months-25 years Io months). Six participants were I8 years or older. Mean age at which JS was diagnosed was I year and 8 months $(S D=3$ years 6 months, range: $\circ$ years $\circ$ months-I 3 years 6 months). All participants were initially confirmed as having JS by karyotype analysis. Further mapping of the breakpoint was performed either by FISH or CGH (using microarrays). The range of the deletions was from about 7 to 16 megabases. See Table I for more information on demographic characteristiscs and information about medical problems.

\section{Materials}

Sleep Questionnaire. The Sleep Questionnaire was adapted from Wiggs and Stores (I996), Didden, Korzilius, Van Aperlo, Van Overloop and De Vries (2002) and Didden et al. (2004) and consisted of five parts. Part one addresses demographic information (e.g., presence of seizure disorder and heart defect). The second part covers current (i.e., last three months) behaviours related to settling to sleep, night waking and early waking.

Table I Number and Percentage of Participant Characteristics $(N=43)$

\begin{tabular}{|c|c|}
\hline Characteristic & $n \quad(\%)$ \\
\hline Number of males & I4 (33) \\
\hline \multicolumn{2}{|l|}{ Level of cognitive functioning } \\
\hline $\mathrm{IQ}>70$ & $5 \quad(\mathrm{I} 2)$ \\
\hline Mild/moderate & Io $(23)$ \\
\hline Severe/profound & $3(7)$ \\
\hline Unknown/unknown level & $25\left(5^{8}\right)$ \\
\hline Behavioural diagnosis ${ }^{a}$ & I2 $(28)$ \\
\hline \multicolumn{2}{|l|}{ Medical problems } \\
\hline Epilepsy & $6(15)$ \\
\hline Heart defect & $25(6 \mathrm{I})$ \\
\hline Breathing problems & Io $(26)$ \\
\hline Coughs & I7 (44) \\
\hline Constipation problems & $20(47)$ \\
\hline Overweight ${ }^{\mathrm{b}}$ & $5 \quad(\mathrm{I} 6)$ \\
\hline Blind & $\circ$ \\
\hline Hearing impairment & $20(47)$ \\
\hline Motor impairment $^{c}$ & $3(7)$ \\
\hline
\end{tabular}

${ }^{a}$ For example Attention-Deficit Hyperactivity Disorder, Autism Spectrum Disorder and/or Obsessive-Compulsive Disorder. ${ }^{\mathrm{b}}$ According to the Centers for Disease Control and Prevention Growth Charts: United States for boys and girls aged 2 to 20 years (Kuczmarski et al., 2000). 'Not able to walk independently (individuals 2 years or older). 
Questions about frequency of occurrence (e.g., 'How often does your child wake in the night?') were assessed on a 7-point Likert-type scale, from 'Never' to 'Daily'. Questions about duration (e.g., 'How long does it usually take to resettle her?') were assessed on a 5-point Likert-type scale, from 'Few minutes' to 'More than two hours'. In part three, parents were asked to fill in at what times their child usually goes to bed and wakes up in the morning, among other items. The fourth part assessed the frequency of occurrence of several behaviours related to sleep (e.g., 'Grinds teeth in sleep', 'Reluctant to go to bed') on a 7-point Likert-type scale, from 'Never' to 'Daily'. According to Wiggs and Stores (2004) behaviours that occurred only 'Sometimes' ('Once or twice a week') and those that occurred 'Often' ('Three to six times a week' or 'Daily') are distinguished. Finally, the last part contains items about parents' impression of their childrens current or past sleep problems, as well as treatment of their childrens sleep problem and family's sleep.

The items of the fourth part, some items of the third part and one of the second part of the questionnaire can be clustered into six sleep 'factors'. These factors are indicative for 'Poor quality sleep', 'Anxieties about sleep', 'Parasomnias', 'Disordered breathing', 'Early waking' and 'Narcolepsy’ (Stores, Wiggs, \& Campling, I998).

Definition of a sleep problem. Criteria for the definition of a sleep problem were established by Wiggs and Stores (I996) and Didden et al. (2002; 2004). Three types of sleep problems were distinguished. Severe settling problems occurred three or more nights a week, whereby the individual took more than I hr to fall asleep and parents were disturbed during this time. Mild settling problems occurred one or two nights a week and falling asleep took more than 30 min. Night waking was defined as severe if it occurred three or more nights a week, and if the individual woke up for more than a few minutes and disturbed parents during that time (e.g., cosleeping, crying). Finally, early waking was defined as severe if the individual woke up before 5:00 a.m. and stayed awake three or more nights a week. Night waking or early waking was considered a mild problem if it occurred once or twice a week. A sleep problem was diagnosed if an individual had at least one of the above three types of sleep problems.

\section{Statistical Analyses}

Paired sample $t$ tests were performed for the sleep factors. For nominal data a $\alpha^{2}$ test was performed. In case differences could not be tested with $\alpha^{2}$ tests, due to low cell frequencies, two-tailed Fisher's exact tests were conducted. This test only produces a significance level and no formal test statistic. For age in months an Independent samples $t$ test (Student's $t$ ) was performed and for ordinal data, such as level of ID, a Mann-Whitney test was performed. SPSS (version I2.0) was used to analyse the results. 


\section{RESULTS}

\section{Description of Sleep Problems}

Prevalence of sleep problems. Table 2 shows percentages of individuals with severe and mild sleep problems. Severe settling problems and frequent night waking were found in I $(2 \%)$ and $3(7 \%)$ participants, respectively. None of the participants had a severe type of early waking. Mild settling problems, frequent night waking and early waking were found in I ( $2 \%), 4(9 \%)$ and $2(6 \%)$ participants, respectively. Totally, Io (23\%) participants had a mild or severe sleep problem.

Out of the 34 children who woke up at night, I4 (4I\%) children called out for their parent, Io (29\%) did nothing, 9 (27\%) started to cry, 6 (I8\%) played with toys, and 5 (I5\%) went out of their bed and wandered about. In case parents responded to their childrens night waking $(n=35)$, I7 (49\%) patted or cuddled their child, I6 (46\%) provided food and/ or drinks, I6 (46\%) put their child back into bed immediately, I3 (37\%) lied with their child on the child's bed, II (3I\%) settled their child in the parent's bed, and 9 (26\%) talked, sang a lullaby or read a story to their child.

Behaviours related to sleep and types of sleep disturbance. Types and percentages of sleep behaviours that occurred sometimes ('Once or twice a week') or often ('Three to six times a week' or 'Daily') are shown in Table 3. For example, 2I participants $(50 \%, n=42)$ were reported often to be restless during sleep, and I3 $(35 \%, n=37)$ appeared often to be more active than other individuals during daytime. Most striking was the finding that 23 participants (54\%) were reported to sleep in unusual positions, such as lying all over bed and upside down (9 participants, 2I\%), on knees with bottom up (6 participants, I4\%), and

Table 2 Number and Percentage of Individuals with Severe or Mild Sleep Problems

\begin{tabular}{|c|c|}
\hline Sleep problem & $n \quad(\%)$ \\
\hline Severe sleep problems & $\begin{array}{ll}\text { I } & (2)\end{array}$ \\
\hline Settling problems & $3(7)$ \\
\hline Night waking & $\circ$ \\
\hline Early waking & $4 \quad(9)$ \\
\hline Total $^{\mathrm{a}}$ & \\
\hline Mild sleep problems & I $\quad(2)$ \\
\hline Settling problems & 4 (9) \\
\hline Night waking & $2(6)$ \\
\hline Early waking & 6 (I4) \\
\hline Total $^{\mathrm{a}}$ & \\
\hline Severe or mild sleep problem & Io $(23)$ \\
\hline
\end{tabular}

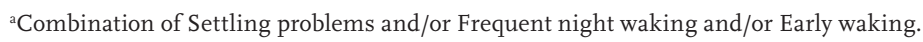


Table 3 Number and Percentage of Individuals Exhibiting Behaviours Related to Sleep (Grouped by Types of Sleep Disturbance) by Frequency of Occurrence

\begin{tabular}{|c|c|c|c|}
\hline Sleep behaviour & $\begin{array}{l}\text { Sometimes } \\
n(\%)\end{array}$ & $\begin{array}{l}\text { Often } \\
n(\%)\end{array}$ & $\begin{array}{l}\text { Total } \\
n(\%)\end{array}$ \\
\hline \multicolumn{4}{|l|}{ Poor quality sleep } \\
\hline Restless sleep & 4 (го) & $2 \mathrm{I}(50)$ & $25(60)$ \\
\hline Wakes up in a bad mood & - & - & $6(\mathrm{I} 7)$ \\
\hline Wakes up tired & - & - & $5(\mathrm{I} 3)$ \\
\hline Seems drowsy, but can stop themselves from sleeping ${ }^{\text {ab }}$ & $2(6)$ & $2(6)$ & $4(\mathrm{I} 2)$ \\
\hline Daytime naps ${ }^{\mathrm{ab}}$ & - & - & I $(3)$ \\
\hline \multicolumn{4}{|l|}{ Anxieties about sleep } \\
\hline Insists on bedtime ritual before going to sleep & $\circ$ & I8 (44) & I8 (44) \\
\hline Needs security object before going to sleep & I $(2)$ & $16(38)$ & I7 (4I) \\
\hline Insists on sleeping with somebody else at sleep onset/in night & $2(5)$ & $8(20)$ & IO $(25)$ \\
\hline Afraid of the dark & $\circ$ & $3(8)$ & $3(8)$ \\
\hline Doesn't want to go to bed because afraid & $\circ$ & $2(5)$ & $2(5)$ \\
\hline Expresses fear that if goes to sleep they might die & $\circ$ & $\circ$ & $\circ$ \\
\hline \multicolumn{4}{|l|}{ Parasomnias } \\
\hline Grinds teeth & $3(8)$ & $8(20)$ & II $(28)$ \\
\hline Talks in sleep & $2(5)$ & 5 (12) & $7(\mathrm{I} 7)$ \\
\hline Bangs head in sleep or going off to sleep & $\circ$ & $3(7)$ & $3(7)$ \\
\hline Walks in sleep & $\circ$ & I (3) & I (3) \\
\hline Wakes during the night screaming in terror ${ }^{c}$ & $\circ$ & $\circ$ & $\circ$ \\
\hline Wakes in night complaining of nightmares ${ }^{\mathrm{d}}$ & $\circ$ & ○ & $\circ$ \\
\hline \multicolumn{4}{|l|}{ Disordered breathing } \\
\hline Snores loudly & I (3) & 7 (I8) & $8(20)$ \\
\hline Gags or chokes & I $(2)$ & I $(2)$ & $2(5)$ \\
\hline Repeatedly stops breathing for $\mathrm{I} 5-30$ seconds & $\circ$ & I (3) & I (3) \\
\hline \multicolumn{4}{|l|}{ Early waking } \\
\hline Wakes in the morning before 5:00 a.m. and stays awake & $2(6)$ & $\circ$ & $2(6)$ \\
\hline \multicolumn{4}{|l|}{ Other } \\
\hline Sleeps in unusual positions & - & - & $23(54)$ \\
\hline Appears more active than other children ${ }^{\mathrm{b}}$ & $2(5)$ & I3 (35) & I5 (4I) \\
\hline Wets bed ${ }^{a}$ & $2(6)$ & I2 (35) & I4 (4I) \\
\hline Quick movements of arms or legs & $3(7)$ & I2 (29) & I5 (37) \\
\hline Reluctant to go to bed & $2(6)$ & $6(\mathrm{I} 7)$ & $8(23)$ \\
\hline Needs sleep medication & $\circ$ & $2(5)$ & $2(5)$ \\
\hline Has urges to go to sleep and can't stop themselves ${ }^{\mathrm{ab}}$ & $\circ$ & I (3) & I (3) \\
\hline Upon waking or going off to sleep, feels paralysed & $\circ$ & I (3) & I (3) \\
\hline Muscles become so weak that she/he falls to the ground ${ }^{\mathrm{b}}$ & $\circ$ & ○ & $\circ$ \\
\hline Bites tongue & $\circ$ & ○ & $\circ$ \\
\hline
\end{tabular}

Note. A dash indicates that data were not obtained for these behaviours.

${ }^{a}$ Individuals 5 years or older. ${ }^{b}$ During the day. ${ }^{c}$ First half of the night. ${ }^{d}$ Last half of the night. 
completely hidden under the blanket (3 participants, $7 \%$ ). Three participants $(7 \%)$ used medication to improve sleep ( 2 used clonidine; I used melatonin), and parents of 2 of these participants $(5 \%, n=4 \mathrm{I})$ reported that their child needed sleep medication (i.e., clonidine) on a daily basis.

As described previously, sleep behaviours were clustered into six sleep factors (see Table 3). Those factors correspond to different types of sleep disturbance. The mean scores (expressed as the percentage of maximum score) and standard deviations on the sleep factors were: Poor quality sleep 27.6 (2I.I); Anxieties about sleep 20.8 (I8.0); Parasomnias 8.5 (I2.8); Disordered breathing 9.3 (20.4), Early waking 5.6 (23.2), and Narcolepsy 2.6 (9.0).

Parents' perception of sleep problems. Parents were asked whether they thought that their child had current sleep problems (no criteria or definition of sleep problems were provided to them). This question was answered affirmatively by parents of II children $(26 \%, n=42)$. According to them 5 children had problems with settling to sleep, 5 with frequent night waking and 6 with early waking. Additionally, parents of 4 children mentioned that cosleeping was a problem.

Parents of another II children (all of whom didn't report current sleep problems) reported past sleep problems. In the past, the following sleep problems were present: 7 children had problems settling to sleep, 5 had frequent night waking problems and 5 had problems with early waking. Parents of 6 children mentioned that cosleeping had been a problem in the past. Current or past sleep problems lasted I year or longer in I7 children $(89 \%, n=19)$. Parents of I9 children $(46 \%, n=4 \mathrm{I})$ reported that their children never had sleep problems.

Treatment of sleep problems. Parents of II children $(55 \%, n=20)$ with current or past sleep problems had asked for advice on or help with treatment of those problems. Sleep medication was used most often, that is in 7 of the II individuals. Medication was effective in reducing sleep problems of 4 individuals ( 2 of them used clonidine, I used melatonin and in I individual this was not specified). One individual underwent adenoidectomy (operation) and this was effective. Parents of 3 children received psychological help and this was effective in reducing sleep problems for I individual. An example of psychological treatment was stimulus control (establishing an appropriate bedtime routine). Education/ general advice and homeopathic remedy were also mentioned for 5 and 3 individuals respectively, and both types of help were not effective in reducing sleep problems.

\section{INFERENTIAL ANALYSIS}

Upon being asked whether their child had a current sleep problem, parents mentioned sleep problems in $26 \%$ of the cases. According to the objective criteria for a sleep 
problem (see section Definition of a sleep problem), the prevalence rate of sleep problems was $23 \%$. This difference is not statistically significant ( $p=\mathrm{I}$, two-tailed Fisher's exact test). However, of the ro participants currently having sleep problems according to the objective criteria, only 2 parents mentioned that their child had sleep problems.

According to the objective criteria, $3(25 \%, n=\mathrm{I} 2)$ individuals with a behavioural diagnosis had sleep problems, compared to $7(23 \%, n=3 \mathrm{I})$ individuals without a behavioural diagnosis. This difference is not statistically significant ( $p=\mathrm{I}$, two-tailed Fisher's exact test).

No differences were found in the occurrence ('sometimes/often' compared to 'infrequent') of single sleep behaviours between individuals with and without a behavioural diagnosis.

Six $(24 \%, n=25)$ individuals with restless sleep had sleep problems. This does not statistically differ from the $4(24 \%, n=\mathrm{I})$ individuals without restless sleep $(p=\mathrm{I}$, two-tailed Fisher's exact test). Seven $(30 \%, n=23)$ individuals with an unusual sleeping position had sleep problems, compared to $3(15 \%, n=20)$ individuals without an unusual sleeping position. This difference is not statistically significant $(p=.29$, two-tailed Fisher's exact test). In addition, no significant difference was found between individuals with or without restless sleep and sleeping in an unusual position $160 \%$ versus $4 \mathrm{I} \%$ respectively, $p=.35$, two-tailed Fisher's exact test).

No differences were found in the occurrence ('sometimes/often' compared to 'infrequent') of single sleep behaviours between individuals with and without sleep problems.

Furthermore, no significant relationships were found between the presence of sleep problems and other variables, such as breathing problems, heart defects, constipation problems, overweight, medication use, having a room of their own, having a bed time routine and daytime activity. Seven $(4 \mathrm{I} \%, n=\mathrm{I} 7)$ individuals with frequent coughs had sleep problems, compared to $2(9 \%, n=22)$ individuals without frequent coughs $(p=.03$, two-tailed Fisher's exact test). This difference is statistically significant.

There was no significant relationship between the presence of sleep problems and age in months, $t(4 \mathrm{I})=\mathrm{I} .6_{3}, p=$.II. (two-tailed). When a division into age groups ('infant', 'toddler', 'preschooler', 'school aged', 'adolescent' and 'adult') was made, there also was no statistically significant difference, $z=-1.95$ ( $p=.05$, two-tailed). None of the adult (age $\geq$ I8 years) participants $(n=6)$ had sleep problems. There was no significant relationship between the presence of sleep problems and level of ID $(n=\mathrm{I} 8), z=$-I.7I $(p=.09$, twotailed). When a division was made into three groups ('IQ > 70', 'mild/moderate ID' and 'severe/profound ID'), none of the participants with an IQ >70 had sleep problems, I (Iо\%, $n=$ Iо) from the participants with a mild/moderate ID had sleep problems and 2 $(67 \%, n=3)$ from the participants with a severe/profound ID. 
A relatively high mean score on one or more of the sleep factors indicate that this type of sleep disturbance is more prevalent in this sample than other types of sleep disturbance. Results of paired $t$ tests (using Bonferroni correction for the number of comparisons) revealed that the mean score of the sleep factor Poor quality sleep was statistically different from the other sleep factors except for Anxieties about sleep (all $p s<$. .oI). The mean score for Poor quality sleep was higher than the mean scores for Parasomnias, Disordered breathing, Early waking and Narcolepsy. In addition, the mean score of Anxieties about sleep was higher than the mean scores for Parasomnias, Early waking and Narcolepsy (all ps <.ooI).

\section{DISCUSSION}

This is the first study to systematically investigate sleep and sleep problems in a large sample of individuals with JS. We used a standardised sleep questionnaire for data collection. According to well-established criteria (see Wiggs \& Stores, I996; Didden et al., 2002; 2004) Io individuals (i.e., $23 \%$ of the sample) had a mild or severe sleep problem at the time of the study. Settling problems, frequent night waking and early waking were found in 2, 7, and 2 individuals, respectively, and I participant had both night waking and early waking problems. According to the parents, 22 (54\%) individuals with JS experienced sleep problems at some point in their lives and in I7 individuals $(89 \%)$ current or past problems had lasted more than I year.

Remarkable were the high percentages on the items 'Sleeping in an unusual position' (53\%) and 'Restless sleep' (60\%). Lower percentages on restless sleep are reported in other studies using the same questionnaire: 4I\% (children with severe ID; Wiggs \& Stores, I996), 2I\% (children with ID; Didden et al., 2002), 45\% (children with Autism Spectrum Disorder; Wiggs \& Stores, 2004), 25\% (individuals with Angelman syndrome; Didden et al., 2004) of the samples, respectively. Restless sleep may indicate poor sleep quality or nonrestorative sleep. Restlessness in sleep in individuals with JS has to be clarified by objective observation, such as actigraphy or video recording during the night.

It is known that sleep problems in children with Autism Spectrum Disorder or Attention-Deficit Hyperactivity Disorder are highly prevalent (Corkum, Moldofsky, Hogg-Johnson, Humphries, \& Tannock, I999; Wiggs \& Stores, 2004). In this sample, no difference in the presence of sleep problems or sleep behaviours between individuals with or without a behavioural diagnosis was found. This might be because individuals with a behavioural diagnosis in this sample received treatment (medication) for their behaviour disorders.

The treatment of a sleep problem should be based on a careful assessment and, 
if possible, identification of an underlying diagnosis. For an overview of assessment and treatment of a sleep problem in individuals with ID see Wiggs (2007). Clinical practitioners managing a patient with JS, should determine the underlying cause for specific sleep problems and sleep behaviours in these patients. Medical problems should be identified and treated accordingly. Behavioural problems can be treated with behaviour modification procedures, and possibly medications. For example, a suitable treatment for anxiety problems is gradual withdrawal. For limit setting disorders and sleep onset association problems stimulus control and extinction procedures are suitable procedures.

Future studies should be conducted to compare characteristics of sleep and type of sleep problems in individuals with JS to those exhibited by individuals with other genetic disorders or non-specific ID. The purpose is to determine if sleep is part of the behavioural phenotype in JS. Additional individuals will be studied to determine a possible causal relationship between severity of ID and sleep problems. Furthermore, future investigation of sleep (architecture) by polysomnography may increase our understanding of the nature and cause(s) of sleep characteristics (e.g., restless sleep) in individuals with JS. 


\section{REFERENCES}

Corkum, P., Moldofsky, H., Hogg-Johnson, S., Humphries, T., \& Tannock, R. (I999). Sleep problems in children with attention-deficit/hyperactivity disorder: Impact of subtype, comorbidity, and stimulant medication. Journal of the American Academy of Child Q Adolescent Psychiatry, 38, I285-1293.

Cotton, S., \& Richdale, A. (2006). Brief report: Parental descriptions of sleep problems in children with autism, Down syndrome, and Prader-Willi syndrome. Research in Developmental Disabilities, 27, I5I-I6I.

De Leersnyder, H. (2006). Inverted rhythm of melatonin secretion in Smith-Magenis syndrome: From symptoms to treatment. Trends in Endocrinology Q Metabolism, 17, $29 \mathrm{I}-298$.

Didden, R., Korzilius, H., Aperlo, B. van, Overloop, C. van, \& Vries, M. de (2002). Sleep problems and daytime problem behaviours in children with intellectual disability. Journal of Intellectual Disability Research, 46, 537-547.

Didden, R., Korzilius, H., Smits, M. G., \& Curfs, L. M. G. (2004). Sleep problems in individuals with Angelman syndrome. American Journal on Mental Retardation, 109, 275-284.

Grossfeld, P. D., Mattina, T., Lai, Z., Favier, R., Lyons Jones, K., Cotter, F., Jones, C., \& the IIq consortium (2004). The irq terminal deletion disorder: A prospective study of IIo cases. American Journal of Medical Genetics, 129A, 5I-6I.

Harvey, M. T., \& Kennedy, C. H. (2002). Polysomnographic phenotypes in developmental disabilities. International Journal of Developmental Neuroscience, 20, 443-448.

Kuczmarski, R. J., Ogden, C. L., Grummer-Strawn, L. M., Flegal, K. M., Guo, S. S., Wei, R., ... Johnson, C. L. (2000). CDC growth charts: United States. Advance data from vital and health statistics (No. 3I4). Hyattsville, MD: National Center for Health Statistics.

Nomura, Y. (2005). Early behavior characteristics and sleep disturbance in Rett syndrome. Brain \& Development, 27, $\mathrm{S}_{35}$-S 42.

Richdale, A. L. (2003). A descriptive analysis of sleep behaviour in children with Fragile X. Journal of Intellectual \& Developmental Disability, 28, I35-I44.

Stores, G., Wiggs, L., \& Campling, G. (I998). Sleep disorders and their relationship to psychological disturbance in children with epilepsy. Child: Care, Health and Development, 24, 5-I9.

Stores, R., Stores, G., \& Buckley, S. J. (I996). The pattern of sleep problems in children with Down's syndrome and other learning disabilities. Journal of Applied Research in Intellectual Disabilities, 9, I45-I59.

Wiggs, L. (2007). Sleep disorders. In A. Carr, G. O’Reily, P. Noonan Welsh \& J. McEvoy (Eds.), The handbook of intellectual disability and clinical psychology practice (pp. 37I42I). London, England: Routledge. 
Sleep in Jacobsen Syndrome

Wiggs, L., \& Stores, G. (1996). Severe sleep disturbance and daytime challenging behaviour in children with severe learning disabilities. Journal of Intellectual Disability Research, 40, 518-528.

Wiggs, L., \& Stores, G. (2004). Sleep patterns and sleep disorders in children with autistic spectrum disorders: Insights using parent report and actigraphy. Developmental Medicine a Child Neurology, 46, 372-380. 
CHAPTER 3.2

Sleep Problems in Individuals With CRi dU Chat Syndrome: A Comparative Study

Maas, A. P. H. M., Didden, R., Korzilius, H., Braam, W., Smits, M. G., \& Curfs, L. M. G. (2009). Journal of Intellectual Disability Research, 53, 704-715. 


\section{ABSTRACT}

Sleep problems are common in individuals with intellectual disability. Little is known about sleep in children and adults with Cri du Chat syndrome (CDC). Sleep was investigated in 30 individuals with CDC using a sleep questionnaire. Sleep problems and sleep behaviours in individuals with CDC were compared with individuals with non-specific intellectual disability (NS) $(n=30)$ and Down syndrome (DS) $(n=30)$. Nine individuals with CDC (i.e., 30\%) had sleep problems, compared with seven individuals with NS (i.e., 23\%) and three individuals with DS (i.e., I0\%). Though there were few differences between diagnostic groups, night waking problems were most common in CDC. Individuals with CDC frequently showed behaviours related to disordered breathing and poor-quality sleep. Several behaviours related to sleep had a higher occurrence in CDC than in DS $(p<.05)$ but not in NS. It is concluded that individuals with CDC do not have an increased probability of sleep problems as compared with other individuals who share similar demographic characteristics. Hypotheses about causes of night waking problems in CDC are generated and suggestions for future research of sleep in individuals with CDC are given. 


\section{INTRODUCTION}

Cri du Chat syndrome (CDC) is a rare genetic disorder caused by a partial deletion in the short arm of chromosome 5. It is characterised by a cat-like cry, low birth weight, early feeding difficulties, facial and head abnormalities, congenital scoliosis, gastrointestinal and cardiovascular problems. Two subtypes of CDC are distinguished based on the location of the deletion: (a) typical CDC, and (b) atypical CDC. Individuals with atypical CDC have deletions outside the critical region 5PI5.I-5PI5.3 and do not show the characteristic cat-like cry (Cornish \& Bramble, 2002).

Individuals with typical CDC usually function in the moderate to severe range of intellectual disability (ID) (Cornish, Bramble, Munir, \& Pigram, I999). Intelligence in the normal range is only found in individuals with atypical CDC (Cornish, Cross, Green, Willatt, \& Bradshaw, I999). In individuals with typical or atypical CDC, receptive language skills are better developed than expressive skills (Cornish, Bramble et al., I999; Cornish, Cross et al., I999; Cornish \& Munir, I998).

Cornish and Pigram (I996) were the first to describe characteristic features of CDC. Results of their study in 27 children with CDC who were between 4 and I 6 years old showed that self-injurious behaviour, repetitive movements, obsessive attachments to objects, hypersensitivity to sensory stimuli and clumsiness were relatively common. In other studies hyperactivity, attention problems, aggression towards others and temper tantrums in children and adults with CDC are reported (Collins \& Cornish, 2002; Cornish, Munir, \& Bramble, I998; Dykens \& Clarke, I997). A major shortcoming of these studies is the lack of a comparison group.

Results from a small number of studies and anecdotal reports from parents suggest that abnormal sleep patterns and sleep problems may be present in individuals with CDC. However, until now, little is known about the characteristics of sleep and sleep problems in children and adults with CDC. In a sample of 20 children with CDC, Cornish and Pigram (I996) found that 30\% had an irregular sleep pattern. Van Buggenhout et al. (2000) studied 7 adults with CDC and found no evidence of sleep problems. In a study among a large sample of 75 children and adults with CDC, Cornish, Oliver, Standen, Bramble and Collins (2003) found that sleep problems were a severe cause of concern for almost $50 \%$ of the parents. Settling problems occurred in a quarter of this sample and frequent night waking occurred in nearly 50\%. Results of the above studies suggest that sleep problems may be relatively common in children with CDC.

While aforementioned studies reported on the sleep of individuals with CDC, sleep problems were not the main focus and sleep was not investigated in detail. Moreover, in none of these studies comparison groups were used to assess whether abnormal sleep patterns and sleep problems are characteristic features of CDC. The use of one or more 
comparison groups of individuals with mixed, heterogeneous, or non-specific ID is strongly recommended to investigate the behavioural phenotype of a genetic disorder (Hodapp \& Dykens, 200I).

Prevalence and nature of sleep and sleep problems in CDC have not been researched extensively. Therefore, the first aim of the present study is to examine different types of sleep problems in individuals with CDC in more detail using a standardised sleep questionnaire. The second aim is to determine whether sleep problems and behaviours related to sleep and types of sleep disturbance were specific for individuals with CDC. Results were compared with those of individuals from two comparison groups: (a) individuals with non-specific ID (NS) $(n=30)$, and (b) individuals with Down syndrome (DS) $(n=30)$. The last aim of the study is to explore the associations between individualrelated variables, such as level of cognitive functioning, and sleep variables. This study extends the literature on CDC by using a comparison group design in which differences and similarities in sleep between individuals with CDC, NS, and DS are explored.

\section{METHOD}

\section{Participants And Procedure}

Cri du Chat syndrome. A standardised sleep questionnaire (see section Materials) was sent to parents who were members of the Dutch Cri du Chat Parent Association. Out of 54 questionnaires that were sent to them, 30 were returned (response rate: $55 \cdot 5 \%$ ). Eleven individuals were male. The sex ratio was .58 and this ratio was not statistically different from the male to female sex ratio found in other studies (Dykens \& Clarke, I997 $\left[\alpha^{2}(\mathrm{I})=0.20, p=.65\right]$; Niebuhr, I978 $\left[\alpha^{2}(\mathrm{I})=0.08, p=.78\right]$; Wilkins, Brown, \& Wolf, I980 $\left.\left[\alpha^{2}(\mathrm{I})=0.20, p=.65\right]\right)$. Their mean age was I4 years and 3 months ( $S D=$ I0 years Io months, range: 2 years I month-47 years 9 months). Mean age at which CDC syndrome was diagnosed was I year and 7 months $(S D=3$ years $\circ$ months, range: 0 years o months-I2 years 6 months). This diagnosis was confirmed by genetic testing in 29 participants (97\%). Seventeen participants had a de novo deletion, two had a translocation and one had an unbalanced translocation. In 9 participants (30\%) parents did not mention the genetic subtype.

Comparison groups. There were two comparison groups: (a) NS, and (b) DS. Data on individuals from both groups were collected through nine facilities for individuals with ID (special day care centres, schools for special education and adult activity centres) in the Netherlands. The questionnaire was completed for II9 out of 350 individuals, constituting a response rate of $34 \%$. Out of this sample individuals were selected to be included in one 
of the two comparison groups. The NS group comprised of 30 individuals (I4 were male) matched to those with CDC on age $(M=13$ years 7 months, $S D=8$ years 5 months, range: 3 years 3 months-3I years 6 months) and cognitive functioning (level of functioning was based on outcomes of developmental scales such as Bayley Scales of Infant Development and Vineland Adaptive Behavior Scales); none of them had a known genetic disorder. The second group included 30 individuals ( 22 were male) with DS ( $M=$ I7 years 4 months, $S D=13$ years 2 months, range: $\mathrm{I}$ year 0 months -55 years 8 months).

Results of one-way ANOVA revealed that there were no statistically significant differences between the three diagnostic groups on age in months $(F(2,87)=0.995$, $p=37)$. Furthermore, results of a two-tailed Fisher's exact test showed that there were no significant differences between groups on level of cognitive functioning $(p=.75)$.

Demographic characteristics and information about medical problems of the three diagnostic groups are presented in Table I.

Table I Number and Percentage of Participant Characteristics by Diagnostic Group

\begin{tabular}{|c|c|c|c|c|c|}
\hline \multirow[b]{2}{*}{ Characteristic } & $\begin{array}{l}\mathrm{CDC} \\
(n=30)\end{array}$ & $\begin{array}{l}\text { NS } \\
(n=30)\end{array}$ & $\begin{array}{l}\mathrm{DS} \\
(n=30)\end{array}$ & \multirow[b]{2}{*}{$\chi^{2}(2)$} & \multirow[b]{2}{*}{$p^{\mathrm{a}}$} \\
\hline & $n \quad(\%)$ & $n \quad(\%)$ & $n \quad(\%)$ & & \\
\hline Number of males & II (37) & I4 (47) & $22(73)$ & 8.64 & $.013^{*}$ \\
\hline Level of cognitive functioning & & & & & .747 \\
\hline IQ > 70 & $2 \quad(7)$ & I $\quad(3)$ & I $\quad(3)$ & & \\
\hline Mild/moderate & $6 \quad(20)$ & $7 \quad(23)$ & IO (33) & & \\
\hline Severe/profound & Io $(33)$ & $6 \quad(20)$ & $6 \quad(20)$ & & \\
\hline Unknown $^{\mathrm{b}}$ & I2 (40) & I6 (53) & I3 (43) & & \\
\hline \multicolumn{6}{|l|}{ Medical problems } \\
\hline Epilepsy & 2 (7) & IO $(33)$ & I $\quad(3)$ & & $.003^{* * *}$ \\
\hline Ear infections & $8 \quad(28)$ & 3 (I2) & $7 \quad(24)$ & 2.08 & .354 \\
\hline Coughs and/or colds & I8 (62) & II $(4 \mathrm{I})$ & $6 \quad(2 \mathrm{I})$ & 9.69 & $.008 * *$ \\
\hline Scoliosis & IO $(33)$ & $4 \quad$ (I4) & I $\quad(4)$ & & $.008 * *$ \\
\hline Constipation problems & II $\quad(37)$ & $4 \quad(13)$ & I (3) & II.70 & $.003 * *$ \\
\hline Gastrointestinal reflux & 5 (I9) & 3 (I2) & $\circ$ & & .096 \\
\hline Overweight $^{c}$ & $\circ$ & $\circ$ & $\circ$ & - & - \\
\hline Underweight $^{c}$ & $8 \quad(30)$ & $7 \quad(32)$ & $\circ$ & & $.003^{* * *}$ \\
\hline Blind & $\circ$ & $\circ$ & $\circ$ & - & - \\
\hline Hearing impairment & $7 \quad(25)$ & 3 (II) & $9 \quad(32)$ & 3.55 & .169 \\
\hline Motor impairment ${ }^{\mathrm{d}}$ & Io $(34)$ & II $(38)$ & $\circ$ & $\mathrm{I} 3.5 \mathrm{I}$ & $.001^{* * *}$ \\
\hline
\end{tabular}

Note. $\mathrm{CDC}=\mathrm{Cri}$ du Chat syndrome; $\mathrm{NS}=$ non-specific intellectual disability; DS = Down syndrome. A dash indicates that data were not available for this characteristic.

${ }^{a}$ In case no value for $\chi^{2}$ is depicted due to low cell frequencies, the $p$ value is a result of Fisher's exact test. ${ }^{b}$ No outcomes of tests or scales were available. 'According to Dutch Growth charts for boys and girls aged o to 2I years (Fredriks, Van Buuren, Burgmeijer, Verloove-Vanhorick, \& Wit, 2004). ${ }^{\mathrm{d}}$ Not able to walk independently (individuals 2 years or older).

${ }^{*} p<.05 .{ }^{* * x} p<.01$. 


\section{Materials}

Sleep Questionnaire. The sleep questionnaire was adapted from the questionnaire developed by Simonds and Parraga (I982) and modified by Wiggs and Stores (I996), Didden, Korzilius, Van Aperlo, Van Overloop and De Vries (2002) and Didden, Korzilius, Smits and Curfs (2004) and consisted of five parts. Test-retest (after 2 weeks) reliabilities were high $(r=.83-\mathrm{I})$ and information obtained with the questionnaire corresponded very closely to information obtained with sleep diaries (Hunt \& Stores, I994).

Part one addresses demographic information (e.g., presence of seizure disorders and scoliosis). The second part covers current (i.e., last 3 months) behaviours related to settling to sleep, night waking and early waking. Questions about frequency of occurrence (e.g., 'How often does your child wake in the night?') are assessed on a 7-point Likert-type scale, from 'Never' to 'Daily'. Questions about duration (e.g., 'How long does it usually take to resettle her?') are rated on a 5-point Likert-type scale, from 'Few minutes' (I) to 'More than two hours' (5). In part three, parents are asked to fill in at what times their child usually goes to bed, wakes up in the morning, among other topics related to the timing of sleep. The fourth part assesses the frequency of occurrence of several behaviours related to sleep (e.g., 'Bangs head in sleep or going off to sleep', 'Reluctant to go to bed') on a 7-point Likert-type scale, from 'Never' (I) to 'Daily' (7). Following suggestions by Wiggs and Stores (2004) a distinction was made between behaviours that occurred only 'Sometimes' ('Once or twice a week') and those that occurred 'Often' ('Three to six times a week' or 'Daily'). Finally, the last part contains items about parents' impression of their childrens current or past sleep problems, as well as treatment of their childrens sleep problem.

Definition of a severe and mild sleep problem. Criteria for the definition of a severe and mild sleep problem were established by Wiggs and Stores (I996), Didden et al. (2002; 2004). Three types of sleep problems were distinguished. Severe settling problems occurred three or more nights a week, whereby the individual took more than I hr to fall asleep and parents were disturbed during this time. Mild settling problems occurred one or two nights a week and falling asleep took more than 30 min but less than I hr. Night waking was defined as severe if it occurred three or more nights a week, and if the individual woke up for more than a few minutes and disturbed parents during that time (e.g., cosleeping, crying). Night waking was considered a mild problem if it occurred once or twice a week. Finally, early waking was defined as severe if the individual woke up before 5:00 a.m. and stayed awake during three or more nights a week. Early waking was considered a mild problem if it occurred once or twice a week. A current sleep problem was diagnosed if an individual had at least one of the three types of sleep problems mentioned above and their level was mild or severe. 
Types of sleep disturbance. Individual items of the sleep questionnaire concerning behaviours related to sleep were grouped together to reflect different types of sleep disturbance encountered in clinical practice (see Johnson, Wiggs, Stores, \& Huson, 2005; Stores, Wiggs, \& Campling, 1998). Five types of sleep disturbance were distinguished (also see Table 2): (a) Poor quality sleep included behaviours that are indicative of nonrestorative sleep (e.g., 'Wakes up tired'), (b) Anxieties about sleep included behaviours expressing fears related to separation from their parents at night or the sleeping environment (e.g., 'Afraid of the dark'), (c) Parasomnias included behaviours describing episodic disorders that intrude on the sleep process (e.g., 'Talks in sleep' or 'Wakes during the night screaming in terror'), (d) Disordered breathing during sleep included behaviours that are indicative of disordered respiration during sleep (e.g., 'Repeatedly stops breathing for I5-30 seconds'), and, finally, (e) Early waking consisted of one behaviour 'Wakes up before 5:00 a.m. and stays awake'.

\section{Statistical Analyses}

Paired $t$ tests were performed to test differences between types of sleep disturbance within CDC. For nominal data, such as prevalence of sleep problems, $\alpha^{2}$ tests were performed to test differences between the three diagnostic groups. Where differences could not be tested with $\alpha^{2}$ tests, because of low cell frequencies, a two-tailed Fisher's exact test was conducted. This test only produces a significance level and no formal test statistic. To test differences on ordinal data, such as behaviours related to sleep and types of sleep disturbance, between the three diagnostic groups Kruskal-Wallis tests were performed. To test differences on ordinal data between two groups Mann-Whitney tests were performed. In case of multiple comparisons a Bonferroni correction was made for the number of comparisons.

\section{RESULTS}

\section{Description of Sleep in Individuals with Cri du Chat Syndrome}

Prevalence of sleep problems. Percentages of individuals with severe and mild sleep problems are shown in Table 3. None of them had a severe settling problem. However, severe night waking and severe early waking were found in $6(20 \%)$ and I (3\%) participants with CDC, respectively. One participant with severe night waking also had a problem with severe early waking. In total, 6 individuals had a severe type of sleep problem. Mild night waking and early waking were found in 3 (г\%) and I (3\%) participants, respectively. In total, 9 (30\%) participants with CDC either had a severe or a mild sleep problem. 
ChAPTER 3.2

Table 2 Number and Percentage of Individuals with CDC $(n=30)$ Exhibiting Behaviours Related to Sleep (Grouped by Types of Sleep Disturbance) by Frequency of Occurrence

\begin{tabular}{|c|c|c|c|c|c|c|}
\hline \multirow[b]{2}{*}{ Sleep behaviour } & \multirow{2}{*}{\multicolumn{2}{|c|}{$\begin{array}{l}\text { Sometimes } \\
n \quad(\%)\end{array}$}} & \multicolumn{2}{|c|}{ Often } & \multicolumn{2}{|c|}{ Total } \\
\hline & & & $n$ & $(\%)$ & $n$ & $(\%)$ \\
\hline \multicolumn{7}{|l|}{ Poor quality sleep } \\
\hline Restless sleep & 2 & (7) & 5 & (I7) & 7 & $(24)$ \\
\hline Wakes up tired & - & & - & & 6 & $(20)$ \\
\hline Daytime naps ${ }^{\mathrm{ab}}$ & - & & - & & 4 & (I7) \\
\hline Seems drowsy, but can stop themselves from sleepingab & 2 & $(8)$ & I & (4) & 3 & (13) \\
\hline Wakes up in a bad mood & - & & - & & $\circ$ & \\
\hline \multicolumn{7}{|l|}{ Anxieties about sleep } \\
\hline Needs security object before going to sleep & 3 & (Іо) & I7 & (59) & 20 & $(69)$ \\
\hline Insists on bedtime ritual before going to sleep & I & (4) & I5 & (54) & I6 & (57) \\
\hline Afraid of the dark & ○ & & 2 & (7) & 2 & (7) \\
\hline Insists on sleeping with somebody else at sleep onset/in night & $\circ$ & & $\circ$ & & $\circ$ & \\
\hline Doesn't want to go to bed because afraid & ○ & & ○ & & ○ & \\
\hline Expresses fear that if goes to sleep they might die & $\circ$ & & $\circ$ & & $\circ$ & \\
\hline \multicolumn{7}{|l|}{ Parasomnias } \\
\hline Bangs head in sleep or going off to sleep & 2 & (7) & 5 & (I7) & 7 & $(24)$ \\
\hline Grinds teeth & 2 & (7) & 2 & (7) & 4 & $(\mathrm{I} 5)$ \\
\hline Talks in sleep & I & (3) & I & (3) & 2 & (7) \\
\hline Wakes in night complaining of nightmares ${ }^{c}$ & ○ & & I & (3) & I & (3) \\
\hline Wakes during the night screaming in terror ${ }^{\mathrm{d}}$ & $\circ$ & & $\circ$ & & $\circ$ & \\
\hline Walks in sleep & ○ & & ○ & & ○ & \\
\hline \multicolumn{7}{|l|}{ Disordered breathing } \\
\hline Snores loudly & 8 & $(27)$ & 5 & (I7) & $\mathrm{I} 3$ & $(43)$ \\
\hline Gags or chokes & 4 & $(\mathrm{1} 3)$ & I & (3) & 5 & (I7) \\
\hline Repeatedly stops breathing for $15-30$ seconds & ○ & & I & (4) & I & (4) \\
\hline \multicolumn{7}{|l|}{ Early waking } \\
\hline Wakes in the morning before 5:०0 a.m. and stays awake & I & (3) & I & (3) & 2 & (7) \\
\hline \multicolumn{7}{|l|}{ Other } \\
\hline Appears more active than other children ${ }^{\mathrm{b}}$ & $\circ$ & & I4 & (50) & I4 & (50) \\
\hline Wets bed ${ }^{a}$ & I & (4) & IO & $(42)$ & II & $(46)$ \\
\hline Sleeps in unusual positions & - & & - & & 9 & (33) \\
\hline Laughs, screams, cries & I & (3) & 3 & (г) & 4 & (I4) \\
\hline Needs sleep medication & I & (3) & 3 & (Iо) & 4 & (I3) \\
\hline Has urges to go to sleep and can't stop themselves ${ }^{\text {ab }}$ & $\circ$ & & 2 & (8) & 2 & (8) \\
\hline Muscles become so weak that she/he falls to the ground ${ }^{\mathrm{b}}$ & I & (3) & I & (3) & 2 & (7) \\
\hline Upon waking or going off to sleep, feels paralysed & ० & & I & (3) & I & (3) \\
\hline Quick movements of arms or legs & $\circ$ & & I & (3) & I & (3) \\
\hline Reluctant to go to bed & I & (3) & $\circ$ & & I & (3) \\
\hline Bites tongue & $\circ$ & & $\circ$ & & $\circ$ & \\
\hline
\end{tabular}

Note. $\mathrm{CDC}=\mathrm{Cri}$ du Chat syndrome. A dash indicates that data were not obtained for this behaviours. ${ }^{a}$ Individuals 5 years or older. ${ }^{b}$ During the day. ${ }^{c}$ Last half of the night. ${ }^{d}$ First half of the night. 
Table 3 Number and Percentage of Individuals with Severe or Mild Sleep Problems by Diagnostic Group

\begin{tabular}{|c|c|c|c|c|}
\hline & $\begin{array}{l}\text { CDC } \\
(n=30)\end{array}$ & $\begin{array}{l}\text { NS } \\
(n=30)\end{array}$ & $\begin{array}{l}\mathrm{DS} \\
(n=30)\end{array}$ & \\
\hline Sleep problem & $n(\%)$ & $n(\%)$ & $n(\%)$ & $p^{\mathrm{a}}$ \\
\hline \multicolumn{5}{|l|}{ Severe sleep problems } \\
\hline Settling problems & $\circ$ & $4(\mathrm{I} 3)$ & ○ & $.03^{*}$ \\
\hline Night waking & $6(20)$ & 3 (Iо) & $2(7)$ & .37 \\
\hline Early waking & I (3) & I $(4)$ & I $(3)$ & I \\
\hline Total $^{\mathrm{b}}$ & $6(20)$ & $5(\mathrm{I} 7)$ & $2(7)$ & $.4 \mathrm{I}$ \\
\hline \multicolumn{5}{|l|}{ Mild sleep problems } \\
\hline Settling problems & $\circ$ & I (3) & $\circ$ & I \\
\hline Night waking & 3 (Іо) & $2(7)$ & I $(3)$ & .87 \\
\hline Early waking & I (3) & I $(4)$ & $\circ$ & .76 \\
\hline Total $^{\mathrm{b}}$ & $\begin{array}{l}4 \\
\text { (I3) }\end{array}$ & $4(\mathrm{I} 3)$ & I $(3)$ & .38 \\
\hline Severe or mild sleep problem ${ }^{c}$ & $9(30)$ & $7(23)$ & 3 (Iо) & .15 \\
\hline
\end{tabular}

Note. $\mathrm{CDC}=\mathrm{Cri}$ du Chat syndrome; NS = non-specific intellectual disability; DS = Down syndrome.

${ }^{a}$ Fisher's exact test except for Severe or mild sleep problem: $\chi^{2}(2)=3.74 \cdot{ }^{b}$ Combination of Settling problems and/or Frequent night waking and/or Early waking. 'Three participants (I with CDC and 2 with NS) have a combination of a severe and a mild sleep problem.

${ }^{*} p<.05$.

Behaviours related to sleep and types of sleep disturbance. Types and percentages of behaviours related to sleep that occurred sometimes ('Once or twice a week') or often ('Three to six times a week' or 'Daily') in individuals with CDC are shown in Table 2. For example, I4 participants $(50 \%, n=28)$ appeared to be more active during daytime than other individuals and 7 participants $(24 \%, n=29)$ were reported to bang their head during sleep or when going off to sleep. Thirteen participants $(43 \%)$ snored loudly. Four participants (13\%) took medication to improve sleep (3 participants used melatonin on a daily basis; I participant used chloral hydrate and midazolam one or two times a week).

Five types of sleep disturbance were distinguished. The mean scores (expressed as the percentage of maximum score) and standard deviations on each type are shown in Table 4. Mean scores on 'Anxieties about sleep' (22.3), 'Disordered breathing during sleep' (2I.I) and 'Poor quality sleep' (20.0) were relatively high compared with other types of sleep disturbance. A relatively high mean score indicated that a specific type of sleep disturbance might be more prevalent than other types of sleep disturbance. Differences in mean scores between types of sleep disturbance were explored using paired $t$ tests (with Bonferroni correction for the number of comparisons). The mean score on 'Anxieties about sleep' was significantly higher than the mean score on 
'Parasomnias' $(t(27)=4.48, p<.00 \mathrm{I})$. This means that behaviours that were related to 'Anxieties about sleep' were more common than behaviours related to 'Parasomnias'. No statistically significant differences between 'Poor quality sleep' or 'Disordered breathing during sleep' and other types of sleep disturbance were found.

Treatment of sleep problems. Parents of ig children $(66 \%, n=29)$ reported that their child ever had sleep problems (no criteria or definition of a sleep problem were provided to them). Only Io of them (53\%, $n=$ I9) had asked for advice on or help with treatment of sleep problems. Medication was used most often, that is in 6 of the ro participants. For 3 participants this treatment was effective in reducing sleep problems (effectiveness was defined as a substantial reduction or elimination of the target behaviours). Parents of 2 children received psychological help and this was effective for I child. Parents of 2 children received education/general advice and this was not effective. Parents of 2 children mentioned alternative treatments (e.g., homeopathy) and these were reported to be effective in both cases.

\section{Comparison of Siefp between Individuals with Cri du Chat Syndrome, Non- Specific Intellectual Disability and Down Syndrome}

Prevalence of sleep problems. The highest percentage of a severe or mild sleep problem was found in the CDC group (i.e., 30\%, 9 out of 30 participants), followed by the NS group (23\%, 7 out of 30 participants) and DS group (10\%, 3 out of 30 participants). Differences between diagnostic groups in percentage of individuals with either a severe or a mild sleep problem were not statistically significant ( $p=. \mathrm{I}_{5}$, Fisher's exact test). Differences in frequency between groups on different types of severe or mild sleep problems were not statistically significant (Table 3), except for severe settling problems. That is, severe settling problems occurred in 4 participants in the NS group and none of the participants from the CDC and DS groups ( $p=.03$, Fisher's exact test).

Behaviours related to sleep and types of sleep disturbance. Results of Kruskal-Wallis tests showed that differences in occurrence of participants exhibiting specific behaviours related to sleep between diagnostic groups were statistically significant for 'Head banging during sleep or when going off to sleep' $\left(\alpha^{2}(2)=6.85, p=.03\right)$, 'Needs security object' $\left(\alpha^{2}(2)=\right.$ I0.00, $\left.p=.007\right)$, 'Gagging or choking' $\left(\alpha^{2}(2)=6.97, p=.03\right)$ and 'Appears more active during daytime than other individuals' $\left(\alpha^{2}(2)=\mathrm{I} 3.44, p=.00 \mathrm{I}\right)$. Following MannWhitney tests for differences in occurrence on these behaviours between the CDC group and the NS group using Bonferroni correction did not show statistically significant differences. Following Mann-Whitney tests between the CDC group and the DS group using Bonferroni correction showed statistically significant differences for 'Head banging 
Table 4 Mean Scores (SDs) for Types of Sleep Disturbance by Diagnostic Group

\begin{tabular}{|c|c|c|c|}
\hline Type of sleep disturbance & $M^{\mathrm{a}}(S D)$ & $\chi^{2}(2)^{\mathrm{b}}$ & $p$ \\
\hline Poor quality sleep & & .99 & .61 \\
\hline $\mathrm{CDC}$ & $20.0(22.7)$ & & \\
\hline NS & I8.7 (20.6) & & \\
\hline DS & I3.7 (I6.2) & & \\
\hline Anxieties about sleep & & 2.38 & .30 \\
\hline $\mathrm{CDC}$ & $22.3(\mathrm{I} 4.4)$ & & \\
\hline NS & $2 \mathrm{I} .7 \quad(\mathrm{I} 7.2)$ & & \\
\hline DS & I6.9 (I6.7) & & \\
\hline Parasomnias & & 3.89 &. $\mathrm{I} 4$ \\
\hline $\mathrm{CDC}$ & $8.0 \quad(9.6)$ & & \\
\hline NS & $3.9 \quad(8.4)$ & & \\
\hline DS & $7.9 \quad$ (II.5) & & \\
\hline Disordered breathing & & $4 \cdot 5^{I}$ &. $\mathrm{II}$ \\
\hline $\mathrm{CDC}$ & 2I.I $(27.0)$ & & \\
\hline NS & $8.6 \quad$ (I8.2) & & \\
\hline DS & IG.I (2I.I) & & \\
\hline Early waking & & .46 & .80 \\
\hline $\mathrm{CDC}$ & $6.7 \quad(25.4)$ & & \\
\hline NS & $7.4 \quad(26.7)$ & & \\
\hline DS & $3.4 \quad(\mathrm{I} 8.6)$ & & \\
\hline
\end{tabular}

Note. $\mathrm{CDC}=\mathrm{Cri}$ du Chat syndrome; $\mathrm{NS}=$ non-specific intellectual disability; DS = Down syndrome. ${ }^{\mathrm{a}}$ Mean scores expressed as percentage of maximum score. ${ }^{\mathrm{b}} \mathrm{Kruskal}-\mathrm{Wallis}$ tests.

during sleep or when going off to sleep' $(z=-2.28, p=.022)$, 'Needs security object' $(z=-3 . \mathrm{I} 4, p=.002)$, 'Gagging or choking' $(z=-2.32, p=.02 \mathrm{I})$ and 'Appears more active during daytime than other individuals' $(z=-3.57, p<.00 \mathrm{I})$. All these four behaviours occurred significantly more often in the CDC group than in the DS group.

Results of Kruskal-Wallis tests for different types of sleep disturbance did not show significant differences in mean scores between diagnostic groups (see Table 4). However, results of a Mann-Whitney test between the CDC and the NS group using Bonferroni correction showed that the $p$ value approached significance for 'Disordered breathing during sleep' $(p=.039)$.

Parents' opinion about sleep. Parents were asked whether their child ever had sleep problems (no criteria or definition of a sleep problem were provided to them). The highest percentage of affirmative answers was found in the CDC group (i.e., 66\%, i9 out of 29 participants), followed by the NS group (48\%, I4 out of 29 participants) and the DS group ( $24 \%, 7$ out of 29 participants). Results showed a statistically significant difference between diagnostic groups in percentage of individuals that had sleep problems at some point in their lives $\left(\alpha^{2}(2)=10.09, p=.006\right)$. The difference between CDC and NS was not 
statistically significant $\left(\alpha^{2}(\mathrm{I})=\mathrm{I} .76, p=. \mathrm{I} 9\right)$, but the difference between CDC and DS was significant $\left.\left(\alpha^{2} \mathrm{I}\right)=\mathrm{I0.04}, p=.002\right)$. This means that more children with CDC ever had sleep problems than children with DS.

Treatment of sleep problems. About half of the parents of children with CDC $(53 \%$, Io out of I9 participants) and parents of children with NS (50\%, 7 out of I4 participants) had sought advice on or help with treatment of sleep problems compared with $29 \%$ of the parents of children with DS (2 out of 7 participants). This difference was not statistically significant ( $p=.64$, Fisher's exact test). Medication was used most often in 6 out of Io participants with CDC and 5 out of 7 participants with NS. Participants with DS had not used medication. Medication was effective in about half the participants with CDC and NS. Psychological help was provided to parents of 2 out of Io participants with CDC, 3 out of 7 participants with NS and I out of 2 participants with DS. Psychological help was effective in I participant in each group (CDC, NS and DS). Parents mentioned alternative treatments (e.g., homeopathy) for 2 out of Io participants with CDC and 4 out of 7 participants with NS. For participants with DS alternative treatments were not mentioned. Alternative treatments were effective in both participants with CDC and in I out of 3 participants with NS.

Individual-related variables. Statistically significant differences between the CDC group and the NS group were found on epilepsy $\left(\alpha^{2}(\mathrm{I})=6.67, p=. \mathrm{OI}\right)$ and constipation problems $\left(\alpha^{2}(\mathrm{I})=4.36, p=.04\right)$. Between the CDC and the DS group statistically significant differences between groups were found on gender $\left(\alpha^{2}(\mathrm{I})=8 . \mathrm{I}_{5}, p=.004\right)$, coughs and/or colds $\left(\alpha^{2}(\mathrm{I})=9.65, p=.002\right)$, scoliosis $\left(\alpha^{2}(\mathrm{I})=8.35, p=.004\right)$, constipation problems $\left(\alpha^{2}(\mathrm{I})=\mathrm{I} 0.04, p=.002\right)$, underweight $(p=.004$, Fisher's exact test) and motor impairment ( $p=$. .ooI, Fisher's exact test). Because of low frequencies, it was not possible to test for the influence of these variables on prevalence of sleep problems, frequency of occurrence of behaviours related to sleep and rates on types of sleep disturbance between the diagnostic groups.

\section{IndividuAl-RELATEd VARIAbles ANd SleEP ACRoss Diagnostic Groups}

Prevalence of sleep problems. Individuals with a severe or mild sleep problem $(M=8$ years 7 months, $S D=6$ years II months) were statistically significant younger than individuals without a severe or mild sleep problem $(M=\mathrm{I} 6$ years Io months, $S D=$ II years 3 months $)(F(\mathrm{I}, 88)=9.22, p=.003)$. Fisher's exact tests across diagnostic groups revealed that severe frequent night waking was more prevalent in individuals with coughs and/or colds ( $p=.007)$, those who were underweight $(p=.024)$ and those with motor impairment $(p=.022)$ than in individuals without these problems. There 
were no statistically significant associations between the presence of sleep problems and epilepsy, constipation problems, scoliosis and level of cognitive functioning.

Behaviours related to sleep. Mann-Whitney tests across diagnostic groups revealed that several behaviours related to sleep occurred more frequently in individuals with the following medical problems ( $p<.05$ ): scoliosis ('Feels paralysed'; 'Gagging or choking'; 'Loud snoring'; 'Mouth breathing during sleep'; 'Sweats a lot'), coughs and/or colds ('Gagging or choking'; 'Restless sleep'; 'Repeatedly stops breathing during sleep'; 'More active during daytime than others'), constipation problems ('Gagging or choking'; 'Bed wetting'; 'Afraid of bed'), motor impairment ('Bed wetting'; 'Head banging'; 'Body rocking'), underweight ('Needs security object'; 'Sweats a lot') and epilepsy ('Feels paralysed').

Types of sleep disturbance. Mann-Whitney tests revealed associations between type of sleep disturbance and individual-related variables. Higher rates on 'Disordered breathing during sleep' were found in individuals with scoliosis than in individuals without scoliosis $(z=-3.30, p=.00 \mathrm{I})$. Higher rates on 'Parasomnias' were found in individuals with coughs and/or colds than in individuals without coughs and/or colds $(z=-2.08, p=.038)$. Higher rates on 'Anxieties about sleep' were found in individuals who were underweight than in individuals with normal weight $(z=-2.08, p=.037)$. Epilepsy, constipation problems, motor impairments and gender were not associated with any type of sleep disturbance.

\section{DISCUSSION}

This is the first study on sleep and sleep problems in CDC in which a standardised questionnaire is used and in which outcomes were compared with those of two comparison groups. Within-group analyses show that $30 \%$ of the individuals with CDC had severe or mild sleep problems, especially problems with frequent night waking. Furthermore, $7 \%$ of the individuals with CDC also had severe or mild problems with early waking. Finally, no severe or mild settling problems were found in our sample. Our findings do not corroborate those of Cornish et al. (2003) who found settling problems in $25 \%$ of their sample. Prevalence rates of night waking problems in the the present study (i.e., 30\%) are also lower than the prevalence of about 50\% found by Cornish et al. Differences in both definition and measurement of sleep problems between our study and Cornish et al.'s study may account for the differences in prevalence rates. The validity of the study by Cornish et al. may be questioned based on the fact that a description about criteria for sleep problems and methodology is lacking and only 
general results are presented in a booklet for parents of children with CDC. Comparative analyses show that there were no significant differences in frequency and type of sleep problems between diagnostic groups except for an increased prevalence of settling problems in the NS group. It may be concluded that individuals with CDC do not have an increased probability on sleep problems as compared to other individuals who share similar demographic characteristics.

Some of the frequently observed behaviours related to sleep (e.g., 'More active during daytime than others' and 'Needs security object') within the group of individuals with CDC are similar to those previously described in individuals with CDC such as hyperactivity and obsessive attachments to objects (Cornish \& Bramble, 2002). These behaviours related to sleep fit in with the characteristic features of CDC. The relatively high score on 'Anxieties about sleep' is related to the frequent occurrence of 'Needs security object' and 'Insists on bedtime ritual'. It may be possible that these two behaviours do not genuinely reveal anxieties, if examined apart from the other items. Impaired expressive language skills in CDC make it difficult to assess whether an individual has fears related to sleep or not. In earlier studies, anxiety was not mentioned as a characteristic behaviour of CDC. Fear of separation of parents at night is unlikely because 'Insists on sleeping with somebody else' was not mentioned by parents of children with CDC.

We found no settling problems in individuals with CDC, which could be partly explained by the fact that some of the participants took melatonin. Melatonin is effective in the treatment of settling problems (see Braam, Didden, Smits, \& Curfs, 2008) in individuals with ID. A relatively large number of individuals with CDC had problems with frequent night waking (see Table 3). We also found a variety of medical problems in these individuals that may cause frequent night waking to some extend, such as coughs/colds, scoliosis and constipation problems. These medical problems often occur in individuals with CDC (Cornish \& Bramble, 2002) and might cause frequent night waking problems in some of them. Apart from medical problems, it is also possible that behaviours during night waking are reinforced by parental attention (see e.g., Didden, Curfs, Van Driel, \& De Moor, 2002; Wiggs, 2007).

To increase our knowledge about causes of sleep problems (specifically frequent night waking) in individuals with CDC more objective (physiological and biomedical) research methods are required. Measurements of melatonin in saliva at night could reveal information on the duration of melatonin secretion. The period of melatonin secretion might be shorter in individuals with CDC than in other individuals and this may cause frequent night waking. Future polysomnographic studies might generate hypotheses about the causes for frequent night waking, and more specifically provide information on disordered breathing during sleep in individuals with CDC. Structural 
laryngeal abnormality and hypotonia, features that are overrepresented in individuals with CDC (Cornish \& Bramble, 2002), may be responsible for an increased incidence of obstructive sleep apnoea.

In the present study, about half of the parents of children with CDC had received help or advice in managing the sleep problem of their child. Although parents evaluated several treatment modalities as effective, the validity of these conclusions is unknown. Until now, no (controlled) studies on the effects of treatment of sleep problems in individuals with CDC have been published.

The results of the present study should be interpreted in the context of the study's methodological shortcomings. The first shortcoming relates to the research method. Parental reports such as a sleep questionnaire are subjective and a more objective method such as actigraphy would have provided additional data on the sleep patterns of individuals with CDC, more specifically night waking. However, actigraphy is not necessarily a good measure of night waking (Sitnick, Goodlin-Jones, \& Anders, 2008). The second shortcoming concerns the distinction between several types of sleep disturbance. These types were based on individual items of the sleep questionnaire. Individual items were allocated by other researchers (Johnson et al., 2005; Stores et al., I998) to the different groups based on clinical experience instead of based on outcomes of factor analysis. It still remains to be assessed whether the distinction between types of sleep disturbance is valid. In a future study, psychometric (e.g., factor analysis, interrater agreement) research on the sleep questionnaire should be conducted. The third shortcoming concerns the relatively low response rate $(55 \%)$ and wide age range which may limit the generalisability of the outcomes. However, the response rate is comparable with other studies using the same questionnaire and procedure (Didden et al., 2002; Wiggs \& Stores, 1996) and we used comparison groups which were matched on age. The fourth shortcoming relates to the small sample size as a result of which it was difficult to explore associations between individual-related variables and sleep problems, behaviours related to sleep and types of sleep disturbance between diagnostic groups. For the same reason, it was not possible to explore differences in sleep problems between genetic subtypes of CDC. This highlights the need of international collaboration in order to obtain larger numbers of participants which will make it possible to subdivide the sample so that many important variables such as age and genetic subtype could be controlled and explored for.

Despite these shortcomings, the present study offers several directions for future research of sleep in individuals with CDC and provides important clues for assessment of sleep problems faced by individuals with CDC and their families in clinical practice. After careful assessment of the sleep problem, appropriate medical or nonmedical treatment procedures should be started to eliminate or reduce sleep problems. 


\section{REFERENCES}

Braam, W., Didden, R., Smits, M., \& Curfs, L. (2008). Melatonin treatment in individuals with intellectual disability and chronic insomnia: A randomized placebo-controlled study. Journal of Intellectual Disability Research, 52, 256-264.

Buggenhout, G. J. van, Pijkels, E., Holvoet, M., Schaap, C., Hamel, B. C., \& Fryns J. P. (2000). Cri du Chat syndrome: Changing phenotype in older patients. American Journal of Medical Genetics, 90, 203-2I5.

Collins, M. S., \& Cornish, K. (2002). A survey of the prevalence of stereotypy, self-injury and aggression in children and young adults with Cri du Chat syndrome. Journal of Intellectual Disability Research, 46, I33-I40.

Cornish, K., \& Bramble, D. (2002). Cri du Chat syndrome: Genotype-phenotype correlations and recommendations for clinical management. Developmental Medicine Q Child Neurology, 44, 494-497.

Cornish, K., Oliver, C., Standen, P., Bramble, D., \& Collins, M. (2003). Cri-du-Chat syndrome: Handbook for parents and professionals (2nd ed.). Earl Shilton, England: Cri du Chat Syndrome Support Group.

Cornish, K. M., Bramble, D., Munir, F., \& Pigram, J. (I999). Cognitive functioning in children with typical Cri du Chat (5p-) syndrome. Developmental Medicine \& Child Neurology, 41, 263-266.

Cornish, K. M., Cross, G., Green, A., Willatt, L., \& Bradshaw, J. M. (I999). A neuropsychological-genetic profile of atypical Cri du Chat syndrome: Implications for prognosis. Journal of Medical Genetics, 36, 567-570.

Cornish, K. M., \& Munir, F. (I998). Receptive and expressive language skills in children with Cri-du-Chat syndrome. Journal of Communication Disorders, 31, 73-80.

Cornish, K. M., Munir, F., \& Bramble, D. (I998). Adaptive and maladaptive behaviour in children with Cri-du-Chat syndrome. Journal of Applied Research in Intellectual Disabilities, 11, 239-246.

Cornish, K. M., \& Pigram, J. (I996). Developmental and behavioural characteristics of Cri du Chat syndrome. Archives of Disease in Childhood, 75, 448-450.

Didden, R., Curfs, L. M. G, Driel, S. van, \& Moor, J. M. H. de (2002). Sleep problems in children with developmental disabilities: Home-based functional assessment and treatment. Journal of Behavior Therapy and Experimental Psychiatry, 33, 49-58.

Didden, R., Korzilius, H., Aperlo, B. van, Overloop, C. van, \& Vries, M. de (2002). Sleep problems and daytime problem behaviours in children with intellectual disability. Journal of Intellectual Disability Research, 46, 537-547.

Didden, R., Korzilius, H., Smits, M. G., \& Curfs, L. M. G. (2004). Sleep problems in individuals with Angelman syndrome. American Journal on Mental Retardation, 109, 275-284. 
Dykens, E. M., \& Clarke, D. J. (I997). Correlates of maladaptive behaviour in individuals with 5p- (Cri du Chat) syndrome. Developmental Medicine a Child Neurology, 39, 752756 ,

Fredriks, A. M., Buuren, S. van, Burgmeijer, R. J. F., Verloove-Vanhorick, S., \& Wit, J. (2004). Groeidiagrammen [Growth curves] (3rd ed.). Houten, The Netherlands: Bohn Stafleu Van Loghum.

Hodapp, R. M., \& Dykens, E. M. (200I). Strengthening behavioral research on genetic mental retardation syndromes. American Journal on Mental Retardation, 106, 4-I5.

Hunt, A., \& Stores, G. (I994). Sleep disorder and epilepsy in children with tuberous sclerosis: A questionnaire-based study. Developmental Medicine \& Child Neurology, 36, I08-II5.

Johnson, H., Wiggs, L., Stores, G., \& Huson, S. M. (2005). Psychological disturbance and sleep disorders in children with Neurofibromatosis type I. Developmental Medicine Q Child Neurology, 47, 237-242.

Niebuhr, E. (I978). Cytologic observations in 35 individuals with a 5p- karyoptype. Human Genetics, 42, I43-I56.

Simonds, J. F., \& Parraga, H. (I982). Prevalence of sleep disorders and sleep behaviors in children and adolescents. Journal of the American Academy of Child Psychiatry, 21, 383-388.

Sitnick, S. L., Goodlin-Jones, B. L., \& Anders, T. F. (2008). The use of actigraphy to study sleep disorders in preschoolers: Some concerns about detection of nighttime awakenings. Sleep, 31, 395-40I.

Stores, G., Wiggs, L., \& Campling, G. (I998). Sleep disorders and their relationship to psychological disturbance in children with epilepsy. Child: Care, Health and Development, 24, 5-I9.

Wiggs, L. (2007). Sleep disorders. In A. Carr, G. O’Reilly, P. Noonan Walsh \& J. McEvoy (Eds.), The handbook of intellectual disability and clinical psychology practice (pp. 37I42I). Hove, England: Routledge.

Wiggs, L., \& Stores, G. (I996). Severe sleep disturbance and daytime challenging behaviour in children with severe learning disabilities. Journal of Intellectual Disability Research, 40, 518-528.

Wiggs, L., \& Stores, G. (2004). Sleep patterns and sleep disorders in children with autistic spectrum disorders: insights using parent report and actigraphy. Developmental Medicine \& Child Neurology 46, 372-380.

Wilkins, L. E., Brown, J. A., \& Wolf, B. (I980). Psychomotor development in 65 homereared children with Cri-du-Chat syndrome. Journal of Pediatrics 97, 40I-405. 
CHAPTER 3.3

Exploration of Differences in Types of Sleep Disturbance and Severity of Sleep Problems BeTWEEN INDIVIDUALS WITH Cri du Chat Syndrome, Down Syndrome and Jacobsen Syndrome: A Case Control Study Research in Developmental Disabilities, 33, I773-1779. 


\begin{abstract}
The prevalence of sleep problems in individuals with intellectual disability (ID) seems to vary between genetic syndromes associated with ID. Different types of sleep disturbance may indicate underlying causes of sleep problems and these types of sleep disturbance may vary between genetic syndromes. We examined and compared five types of sleep disturbance as well as severity of sleep problems in individuals with Cri du Chat syndrome (CDC), Down syndrome (DS), Jacobsen syndrome (JS), and individuals with non-specific ID (NS). We used Simonds and Parraga's Sleep Questionnaire (I982) to assess prevalence of types of sleep disturbance and to explore differences in types of sleep disturbance and severity of sleep problems between the four diagnostic groups. In each group, mean scores for Snoring were significantly higher than those for Sleep apnoea and Snoring was the most prevalent type of sleep disturbance in CDC, DS, and JS. The mean score on Complaints related to sleep was remarkably high in the JS group. There were no differences in severity of sleep problems between groups. These findings suggest that snoring is an important underlying cause of sleep problems in individuals with CDS, DS, and JS.
\end{abstract}




\section{INTRODUCTION}

The prevalence of sleep problems in individuals with intellectual disability (ID) seems to vary between genetic syndromes associated with ID (Didden \& Sigafoos, 200I; Stores \& Wiggs, 200I). For example, of children and adults with Angelman syndrome $37 \%$ have severe night-waking problems and $2 \%$ have severe settling problems (Didden, Korzilius, Smits, \& Curfs, 2004). Of children with Down syndrome 32\% have severe night-waking problems and $20 \%$ have severe settling problems (Stores, Stores, \& Buckley, I996). These prevalence rates differ in some ways from prevalence rates found in children with mixed or heterogeneous ID (i.e., children having different etiologies or no clear aetiology for their ID). Of children with mixed or heterogeneous ID I0-26\% have severe night-waking problems, 4-26\% have severe settling problems (Didden, Korzilius, Van Aperlo, Van Overloop, \& De Vries, 2002; Wiggs \& Stores, I996).

During the last decade a growing number of studies have targeted sleep problems in individuals with genetic syndromes. In order to assess whether certain sleep problems are characteristic features of a genetic syndrome, using one or more control groups of individuals with mixed, heterogeneous or non-specific ID (NS) is strongly recommended (Hodapp \& Dykens, 200I). Few studies assessing sleep problems in genetic syndromes have used appropriate control groups, i.e., in Cornelia de Lange syndrome (Hall, Arron, Sloneem, \& Oliver, 2008), Cri du Chat syndrome (Maas et al., 2009), Down syndrome (Cotton \& Richdale, 2006; Stores et al., I996), tuberous sclerosis (Hunt \& Stores, 1994), and Prader-Willi syndrome (Cotton \& Richdale, 2006).

Furthermore, different types of sleep disturbance may indicate different underlying causes of sleep problems (Wiggs \& Stores, 2004). These types of sleep disturbance may vary between genetic syndromes (Cotton \& Richdale, 2006). For example, obstructive sleep apnoea syndrome is commonly observed in children with Down syndrome and may indicate a specific underlying cause for settling and night-waking problems frequently observed in Down syndrome (Shott et al., 2006).

Prevalence of sleep problems among samples of individuals with ID is usually assessed by questionnaires. The Sleep Questionnaire by Simonds and Parraga (SQ-SP; I982) - adapted version for use in individuals with ID (Wiggs \& Stores, I996) - is the sleep questionnaire used most often in prevalence studies in individuals with ID (Maas et al., 20II). Several types of sleep problems (i.e., settling problems, frequent night waking and early waking), as well as their level of severity can be assessed with the SQ-SP. Severity level can be reported for each type of sleep problem separately, but can also be expressed in a total severity score, which is called the Composite Sleep Index (CSI) (Wiggs \& Stores, I998). Furthermore, the SQ-SP enables one to collect data on different types of sleep disturbance. Psychometric properties of part four of the SQ-SP (see section Materials) for use in individuals with ID 
have been recently examined in a sample of 345 individuals with mixed or heterogeneous ID (Maas et al., 20II). Internal consistency (Cronbach's $\alpha=.80$ ) and test-retest reliability (Spearman's rank correlation $=.83$ ) appeared to be good and convergent validity was adequate (Pearson correlation $=.79)$. Factor analysis revealed five sleep factors that were related to five types of sleep disturbance: (a) Snoring, (b) Daytime sleepiness, (c) Complaints related to sleep, (d) Sleep apnoea, and (e) Anxiety related to sleep. Differences in CSI and factor scores between a group of individuals with ID that were referred to a sleep clinic for individuals with ID (sleep clinic group) and a group of individuals with mixed or heterogeneous ID (control group) were explored. CSI and factor scores on Daytime sleepiness and Complaints related to sleep differentiated between the sleep clinic group and the control group, further demonstrating validity.

Data on types of sleep problems, their level of severity and types of sleep disturbance collected with the SQ-SP in three genetic syndromes (i.e., Jacobsen syndrome (JS), Cri $\mathrm{du}$ Chat syndrome (CDC) and Down syndrome (DS)) have been published in two studies (Maas et al., 2009; Maas et al., 2008). Severe sleep problems were found in 9\%, 20\%, and $7 \%$ of the syndrome groups, respectively. No data on the CSI were reported. In both studies five types of sleep disturbance were distinguished, which reflect different types of sleep disturbance encountered in clinical practice (Johnson, Wiggs, Stores, \& Huson, 2005; Stores, Wiggs, \& Campling, I998). However, the five types of sleep disturbance encountered in clinical practice appeared not to match the five sleep factors in individuals with ID (Maas et al., 2OII), resulting in a lack of information on types of sleep disturbance in CDC, DS, and JS. Thus the underlying causes for sleep problems remain unclear. Furthermore, data on sleep problems and type of sleep disturbance for CDC and DS have been compared with a NS control group, but so far this had not been done for JS. Therefore, the principal aim of the present study is to assess the prevalence of five types of sleep disturbance in individuals with CDC, DS, JS, and NS using the SQ-SP. We also compared the level of severity of sleep problems expressed in the CSI, and different types of sleep disturbance in order to explore differences in severity of sleep problems and the underlying causes of sleep problems between the four diagnostic groups.

\section{METHOD}

\section{Participants And Procedure}

The sample included individuals who had participated in two previously published studies (Maas et al., 2009; Maas et al., 2008) and consisted of too individuals with ID, of whom 75 suffered from a genetic syndrome and 25 had a non-specific ID (NS). Of the sample of individuals with a genetic syndrome, 25 had CDC, 25 had DS, and 25 had JS. 
The parents of individuals with CDC and individuals with JS were recruited via parent organizations (the American IIq Research and Resource Group and the Dutch Cri du Chat Parent Association). The parents of the individuals with DS and the individuals with NS were recruited via their childrens day care centre, special school or adult activity centre. All parents received a package by mail. Each package consisted of a covering letter, the SQ-SP, a consent form and a stamped self-addressed envelope. Data from individuals for whom more than nine responses were missing on part four of the SQ-SP or for whom more than four consecutive responses were missing on part four of the SQ-SP were excluded from analyses. The individuals with NS were matched to those with CDC, DS, and JS on age, level of cognitive functioning, presence of epilepsy and use of medication related to sleep problems. Demographic characteristics are presented in Tables I and 2.

Table I Mean Scores (SDs) for Age (Years;Months) by Diagnostic Group

\begin{tabular}{lllll}
\hline Group & $n$ & $M(S D)$ & Minimum & Maximum \\
\hline CDC & 25 & I3;5 $(7 ; 7)$ & $3 ; 8$ & $28 ; 5$ \\
DS & 25 & I6;4 $(9 ; 4)$ & $4 ; 2$ & 4 I;5 \\
JS & 25 & I2;9 $(5 ; 5)$ & $3 ; 9$ & $25 ; 10$ \\
NS & 25 & I2;9 $(7 ; 5)$ & $4 ; 0$ & $3 \mathrm{I} ; 6$ \\
\hline
\end{tabular}

Note . $\mathrm{CDC}=\mathrm{Cri}$ du Chat syndrome; DS = Down syndrome; JS = Jacobsen syndrome; NS = non-specific intellectual disability.

Table 2 Number and Percentage of Participant Characteristics by Diagnostic Group

\begin{tabular}{|c|c|c|c|c|c|c|c|c|c|c|}
\hline \multirow[b]{2}{*}{ Characteristic } & \multicolumn{2}{|c|}{$\begin{array}{l}\text { CDC } \\
(n=25)\end{array}$} & \multicolumn{2}{|c|}{$\begin{array}{l}\mathrm{DS} \\
(n=25)\end{array}$} & \multicolumn{2}{|c|}{$\begin{array}{l}\text { JS } \\
(n=25)\end{array}$} & \multicolumn{2}{|c|}{$\begin{array}{l}\text { NS } \\
(n=25)\end{array}$} & \multirow[b]{2}{*}{$\chi^{2}(3)^{a}$} & \multirow[b]{2}{*}{$p^{\mathrm{b}}$} \\
\hline & $n$ & $(\%)$ & $n$ & $(\%)$ & $n$ & $(\%)$ & $n$ & $(\%)$ & & \\
\hline Number of males & 8 & (32) & I9 & $(76)$ & 9 & $(36)$ & I3 & $(52)$ & II.97 & .008 \\
\hline Living situation & & & & & & & & & & .19 \\
\hline Family & 22 & $(92)$ & 25 & (IO०) & 25 & $(\mathrm{I} O 0)$ & 24 & $\left(9^{6}\right)$ & & \\
\hline Residential facility & 2 & (8) & $\circ$ & & $\circ$ & & I & (4) & & \\
\hline Level of cognitive functioning & & & & & & & & & & .88 \\
\hline $\mathrm{IQ}>70$ & I & (4) & I & (4) & 2 & (8) & I & (4) & & \\
\hline Mild/moderate ID & 6 & $(24)$ & Io & (40) & 9 & $(36)$ & II & (44) & & \\
\hline Severe/profound ID & 7 & $(28)$ & 5 & $(20)$ & 3 & (I2) & 5 & $(20)$ & & \\
\hline Unknown $^{c}$ & II & (44) & 9 & $(36)$ & II & (44) & 8 & $(32)$ & & \\
\hline Epilepsy & I & (4) & I & (4) & I & (4) & I & (4) & & .83 \\
\hline Medication use related to sleep & 3 & (I2) & $\circ$ & & $\mathrm{I}$ & (4) & I & (4) & & .39 \\
\hline
\end{tabular}

Note . $\mathrm{CDC}=\mathrm{Cri}$ du Chat syndrome; $\mathrm{DS}=$ Down syndrome; JS = Jacobsen syndrome; NS = non-specific intellectual disability; ID = intellectual disability.

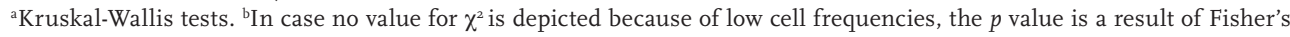
exact test. ${ }^{\mathrm{c}}$ No outcomes of tests or scales were available. 
Results of one-way ANOVA revealed that there were no significant differences between groups in age in months $(F(3,96)=\mathrm{I} .25, p=.30)$. Furthermore, results of twotailed Fisher's exact tests showed that there were no significant differences between groups in level of cognitive functioning $(p=.88)$, epilepsy $(p=.83)$ and use of medication related to sleep problems $(p=.39)$.

The male to female ratio varied across groups. Results of a $\alpha^{2}$ test revealed that there were significant differences between groups in gender $\left(\alpha^{2}(3)=\right.$ II.97, $\left.p=.008\right)$. Pairwise group comparisons using a Bonferroni correction showed that there were significantly more males in the DS group than in the CDC group $\left(\alpha^{2}(\mathrm{I})=9.74, p=.004\right)$. Due to low cell frequencies it appeared not possible to control for gender differences in further statistical analyses.

\section{Materials}

The SQ-SP was developed by Simonds and Parraga (1982) and was modified by Wiggs and Stores (1996, 2004) and consists of five parts. Part one addresses demographic information (e.g., name and dosage of current medication and presence of epilepsy). The second part covers current (i.e., last three months) behaviours related to settling to sleep, night waking and early waking. In part three, parents are asked to fill in at what times their child usually goes to bed, wakes up in the morning, among other topics related to the sleep pattern. The fourth part assesses the frequency of occurrence of 45 behaviours related to sleep (e.g., 'Moves around a lot in bed during sleep', 'Snores loudly during sleep', 'Afraid of the dark') on a 7-point Likert-type scale, from 'Never' (I) to 'Daily' (7). The fifth and last part contains items about parents' impression of their childrens current or past sleep problems, as well as treatment of their childrens sleep problem.

Five types of sleep disturbance or sleep factors (Snoring, Daytime sleepiness, Complaints related to sleep, Sleep apnoea and Anxiety related to sleep) were derived from part four of the SQ-SP (see Maas et al., 20II). The factor Complaints related to sleep refers to movements, excessive sweating and episodes of confused behaviour during sleep. This factor consists of six items with a possible range from 6 to 42 . Snoring consists of five items with a possible range from 5 to 35 . Daytime sleepiness consists of four items with a possible range from 4 to 28 . Both Sleep apnoea and Anxiety related to sleep consist of three items with a possible range from 3 to $2 \mathrm{I}$.

To assess the level of severity of sleep problems a CSI was calculated (Wiggs \& Stores, 1998). The frequency of problems with settling, night waking, early waking and cosleeping and the duration of settling and night waking were derived from the SQ-SP, resulting in the CSI ranging from o to I2. A score of $\geq 4$ is indicative of a severe sleep problem (Wiggs \& Stores, 1998) and by this the prevalence of severe sleep problems was assessed. 


\section{Statistical Analyses}

To test for differences within and between the four diagnostic groups nonparametric tests were used since data on the sleep factors and CSIs were not normally distributed and sample sizes were relatively small. To explore factor scores within a diagnostic group a percentage of maximum score was calculated for each factor and Wilcoxon tests were performed. Because multiple comparisons were involved a Bonferroni correction was applied for the number of comparisons, resulting in $\alpha=.005$. To test differences in CSI and factor scores between groups Kruskal-Wallis tests were performed and a Bonferroni correction was used for the number of comparisons $(\alpha=.005)$. Subsequent post hoc Mann-Whitney tests were performed to test for differences in CSI and factor scores between two diagnostic groups and a Bonferroni correction was applied for the number of comparisons $(\alpha=.0083)$.

\section{RESULTS}

\section{Prevalence of Types of Sleep Disturbance}

Mean factor scores are shown in Table 3. To explore factor scores within each diagnostic group mean scores expressed as percentage of maximum score were calculated which are shown in Table 4. Within each group the factor Snoring had the highest mean score while the factor Sleep apnoea had the lowest score. Wilcoxon tests within each group using Bonferroni correction revealed that the difference in mean score for Snoring and Sleep apnoea was statistically significant within each group $(p<.005)$. In the CDC, DS, and NS group, Daytime sleepiness showed the second highest score, while in the JS group Complaints related to sleep showed the second highest score. The difference in mean score between the highest and the second highest score was substantial within the CDC, DS, and JS group. P values approached significance when Snoring and Daytime sleepiness were compared within the CDC group ( $z=2.8 \mathrm{I}, p=.005)$ and the DS group $(z=2.8 \mathrm{I}, p=.005)$, but not within the JS group ( $z=\mathrm{I} .55, p=. \mathrm{I} 2)$. Also in the JS group the difference in mean score for Snoring and Daytime sleepiness approached significance $(z=2.74, p=.006)$.

\section{Comparison between Individuals with Cri du Chat Syndrome, Down Syndrome, Jacobsen Syndrome and Non-Specific Intellectual Disability}

Severity of sleep problems. Mean CSI and number of individuals with a CSI score $\geq 4$, indicating a severe sleep problem, are shown in Table 5. The highest mean CSIs were found in the JS group and the NS group and the lowest mean CSI was found in the DS group. Results of a Kruskal-Wallis test revealed that differences in mean CSI between groups were not statistically significant $\left(\alpha^{2}(3)=6.8 \mathrm{I}, p=.08\right)$. The highest percentage of individuals with 
a severe sleep problem was found in the JS group (i.e., 20\%, 5 out of 25 participants), followed by the CDC and the NS group (i.e., I $2 \%, 3$ out of 25 participants), and the DS group (i.e., $4 \%$, I out of 25 participants). Differences in percentage of individuals with a severe sleep problem between groups were not statistically significant $(p=.43$, Fisher's exact test).

Types of sleep disturbance. Differences in mean factor scores between diagnostic groups were explored using Kruskal-Wallis tests (see Table 3). Whereas differences between groups on Snoring approached significance $(p=. \circ 6)$, differences on Complaints related to sleep were statistically significant. Subsequent Mann-Whitney tests revealed that the JS group showed significantly more Complaints related to sleep than the DS group $(z=2.89, p=.004)$. $P$ values approached significance if mean scores on Complaints related to sleep were compared between the JS group and the CDC group $(z=2.60$, $p=. \circ 09)$ and between the JS group and the NS group $(z=2.49, p=.013)$.

Table 3 Mean Scores (SDs) and Median Scores for Sleep Factors by Diagnostic Group

\begin{tabular}{|c|c|c|c|c|c|}
\hline Factor & $n$ & $M(S D)$ & $M d n$ & $\chi^{2}(3)^{a}$ & $p$ \\
\hline Snoring & & & & $7.5 \mathrm{I}$ & .06 \\
\hline $\mathrm{CDC}$ & $2 \mathrm{I}$ & I4.95 (7.95) & I4 & & \\
\hline DS & I7 & I6.47 (9.58) & I4 & & \\
\hline JS & I9 & $16.05(9.00)$ & I4 & & \\
\hline NS & 20 & $10.52(7.26)$ & 7 & & \\
\hline Daytime sleepiness & & & & 3.85 & .28 \\
\hline $\mathrm{CDC}$ & 25 & $7.72 \quad(4.50)$ & 7 & & \\
\hline DS & 24 & $5.83 \quad(3 . \mathrm{I} 7)$ & 4 & & \\
\hline JS & 24 & $7.21 \quad(3.64)$ & 7 & & \\
\hline NS & 22 & $6.95 \quad(3.84)$ & 6 & & \\
\hline Complaints related to sleep & & & & II. 48 & .009 \\
\hline $\mathrm{CDC}$ & 22 & $8.77 \quad(3.89)$ & 6 & & \\
\hline DS & $2 \mathrm{I}$ & $8.00 \quad(2.39)$ & 7 & & \\
\hline JS & 23 & I4.I7 (8.I7) & $\mathrm{I} 2$ & & \\
\hline NS & I9 & $8.53 \quad(3.84)$ & 7 & & \\
\hline Sleep apnoea & & & & 0.44 & .93 \\
\hline $\mathrm{CDC}$ & 23 & $3.74 \quad(3.12)$ & 3 & & \\
\hline DS & 24 & $3.83 \quad(2.84)$ & 3 & & \\
\hline JS & 24 & $3.29 \quad(\mathrm{I} .08)$ & 3 & & \\
\hline NS & 25 & $3.36 \quad$ (1.60) & 3 & & \\
\hline Anxiety related to sleep & & & & $4.5^{2}$ & $.2 \mathrm{I}$ \\
\hline $\mathrm{CDC}$ & 25 & $3.92 \quad(1.98)$ & 3 & & \\
\hline DS & 22 & $3.9 \mathrm{I} \quad(2.09)$ & 3 & & \\
\hline JS & 24 & $4.87 \quad(3.80)$ & 3.5 & & \\
\hline NS & 23 & $5.00(4.46)$ & 3 & & \\
\hline
\end{tabular}

Note . $\mathrm{CDC}=\mathrm{Cri}$ du Chat syndrome; $\mathrm{DS}=$ Down syndrome; $\mathrm{JS}=$ Jacobsen syndrome; NS = non-specific intellectual disability. ${ }^{a}$ Kruskal-Wallis tests. 
Sleep in Cri du Chat, Down and Jacobsen Syndrome: A Case Control Study

Table 4 Mean Scores (SDs) for Sleep Factors by Diagnostic Group

\begin{tabular}{|c|c|c|c|c|c|}
\hline Group & & $n$ & $M^{\mathrm{a}}(S D)$ & Minimum & Maximum \\
\hline \multicolumn{6}{|l|}{ CDC } \\
\hline & Snoring & 2I & $42.72 \quad(22.70)$ & 14.29 & IO० \\
\hline & Daytime sleepiness & 25 & $27.57 \quad(\mathrm{I} 6.06)$ & 14.29 & 67.86 \\
\hline & Complaints related to sleep & 22 & $20.89(9.26)$ & 14.29 & 50.00 \\
\hline & Sleep apnoea & 23 & I7.8I (I4.87) & 14.29 & $85.7 \mathrm{I}$ \\
\hline & Anxiety related to sleep & 25 & $18.67 \quad(9.42)$ & 14.29 & 47.62 \\
\hline \multicolumn{6}{|l|}{ DS } \\
\hline & Snoring & I7 & $47.06(27.37)$ & 14.29 & 88.57 \\
\hline & Daytime sleepiness & 24 & 20.83 (II. 33 ) & 14.29 & $60.7 \mathrm{I}$ \\
\hline & Complaints related to sleep & $2 \mathrm{I}$ & $19.05(5.68)$ & 14.29 & 28.57 \\
\hline & Sleep apnoea & 24 & I8.25 (I3.52) & 14.29 & 66.67 \\
\hline & Anxiety related to sleep & 22 & I8.6I $(9.96)$ & 14.29 & 47.62 \\
\hline \multicolumn{6}{|l|}{ JS } \\
\hline & Snoring & I9 & $45.86(25.72)$ & 14.29 & IOO \\
\hline & Daytime sleepiness & 24 & $25.74 \quad$ (I2.98) & 14.29 & 64.29 \\
\hline & Complaints related to sleep & 23 & 33.74 (I9.46) & 14.29 & $85.7 \mathrm{I}$ \\
\hline & Sleep apnoea & 24 & $15.67 \quad(5.16)$ & 14.29 & 38.10 \\
\hline & Anxiety related to sleep & 24 & $23.2 \mathrm{I} \quad$ (I8.II) & 14.29 & IOO \\
\hline \multicolumn{6}{|l|}{ NS } \\
\hline & Snoring & 20 & $29.29(20.75)$ & 14.29 & 88.57 \\
\hline & Daytime sleepiness & 22 & 24.84 (г3.70) & 14.29 & 67.86 \\
\hline & Complaints related to sleep & I9 & $20.30(9.13)$ & 14.29 & 40.48 \\
\hline & Sleep apnoea & 25 & I6.00 (7.64) & 14.29 & 52.38 \\
\hline & Anxiety related to sleep & 23 & $23.8 \mathrm{I} \quad(2 \mathrm{I} .25)$ & $\mathrm{I} 4.29$ & 90.48 \\
\hline
\end{tabular}

Note $. \mathrm{CDC}=\mathrm{Cri}$ du Chat syndrome; DS = Down syndrome; JS = Jacobsen syndrome; NS = non-specific intellectual disability. ${ }^{\mathrm{a}}$ Mean scores expressed as percentage of maximum score.

Table 5 Mean Scores (SDs) for Composite Sleep Index (CSI) by Diagnostic Group

\begin{tabular}{llllll}
\hline Group & $n$ & $M(S D)$ & Minimum & Maximum & $\begin{array}{l}\text { CSI } \geq 4 \\
n(\%)\end{array}$ \\
\hline CDC & 25 & I.08 (I.75) & $\circ$ & 6 & 3 (I2) \\
DS & 25 & $0.48($ I.I2) & $\circ$ & 5 & I (4) \\
JS & 25 & I.68 (2.I6) & $\circ$ & 7 & 5 (20) \\
NS & 25 & I.60 (2.3I) & $\circ$ & 9 & 3 (I2) \\
\hline
\end{tabular}

Note . $\mathrm{CDC}=\mathrm{Cri}$ du Chat syndrome; DS = Down syndrome; IS = Jacobsen syndrome; NS = non-specific intellectual disability. $\mathrm{CSI} \geq 4$ indicates a severe sleep problem. 


\section{DISCUSSION}

We used Simonds and Parraga's Sleep Questionnaire (I982) to assess the prevalence of types of sleep disturbance in individuals with CDC, JS, DS, and NS, to explore differences in severity of sleep problems and the underlying cause of sleep problems between the four diagnostic groups. Severe sleep problems were prevalent in $20 \%$ of the individuals with JS, I2\% of the individuals with CDC and NS, and $4 \%$ of the individuals with DS. The differences between groups were not statistically significant and we can conclude that there was no increase in the prevalence rates of severe sleep problems in the three genetic syndromes in comparison with NS. In each group mean score for Snoring was significantly higher than that for Sleep apnoea. In the CDC, JS, and DS group snoring was the most prevalent type of sleep disturbance, whereas in the NS group no type of sleep disturbance was identified as most prevalent. Thus, Snoring discriminates between NS and the three genetic syndromes, but not between the three genetic syndromes. Parents of individuals with JS reported significantly more Complaints related to sleep than those of individuals with DS, and tended to report more Complaints related to sleep than those of individuals with CDC and individuals with NS.

Closer inspection of the nature of the Complaints related to sleep in the JS group revealed that restless legs, excessive sweating while falling asleep, and episodes of confused behaviours were not particularly common behaviours in the JS group (I7\%, 8\%, and ०\%, respectively), but restless sleep, quick movements of arm or legs, and startles or jerks part of the body while falling asleep were commonly reported $(60 \%, 29 \%$, and $25 \%$, respectively). Prevalence rates on the last two behaviours differed significantly between diagnostic groups, and the differences in prevalence rate on restless sleep approached significance, with the JS group having the highest score. These results broaden our knowledge of sleep in individuals with JS, since the prevalence rates on restless sleep, quick movements of arms and legs, and startles or jerks while falling asleep have not been compared to individuals with NS or other genetic syndromes before, and these behaviours appear to be characteristic sleep features of JS. However, the nature, timing, and duration of these complaints related to sleep have not yet been clarified by objective measures, as mentioned by Maas et al. (2008). Audiovisual recordings in the home setting can serve this purpose, because next to timing and duration as well as the nature of the complaints can be observed using that method.

The prevalence rates of severe sleep problems in the CDC, DS, JS, and NS groups were lower than those in a sample of 345 individuals with mixed or heterogeneous ID referred to a sleep clinic (see Maas et al., 20II). Although some individuals from each diagnostic group had a severe sleep problem, we can conclude that the prevalence rates in the diagnostic groups on the whole were not clinically elevated. However, the 
prevalence rates of Snoring in the CDC, DS, and JS groups were somewhat higher than the prevalence rates that have been found in a sleep clinic group. These results indicate that snoring is a sleep disturbance particularly prevalent in individuals with CDC, DS, and JS. Finally, the prevalence rate of Complaints related to sleep in the JS group was similar to that of a sleep clinic group, suggesting that on average individuals with JS show clinically elevated complaints related to sleep.

Snoring is the most prevalent sleep disturbance in individuals with CDC, DS, and JS. It is a well-known fact that snoring is highly prevalent in individuals with DS, and another study has shown that snoring is quite prevalent in individuals with CDC (Maas et al., 2009), but it had not reported in individuals with JS previously (Maas et al., 2008). Primary snoring (i.e., loud upper airway breathing sounds in sleep without episodes of apnoea) is at the least severe end of the Sleep Related Breathing Disorders continuum (SRBD) (Huynh, Morton, Rompré, Papadakis, \& Remise, 20II). Since SRBD is associated with craniofacial anomalies it is not surprising to find that snoring is a prevalent type of sleep disturbance in individuals with a genetic syndrome presenting with anomalous craniofacial features. Typically developing children with primary snoring have a higher risk for hyperactive and inattentive behaviour, daytime sleepiness, and poor school performance to children who never snored (Brockmann, Urschitz, Schlaud, \& Poets, 20I2). Snoring in individuals with CDC, DS, and JS should not be ignored and some individuals might benefit from treatment by a sleep medicine specialist and an ear, nose and throat specialist (ENT).

The present study has several limitations. The first limitation relates to the small sample size as a result of which we used a simple statistical model and did not attempt to explore associations between individual-related variables (e.g., age) on one hand and sleep factors scores and severity of sleep problems on the other. Diagnostic groups were matched on the most important variables, i.e., age, level of cognitive functioning, epilepsy and use of medication related to sleep problems to control for some of the individualrelated variables. The second limitation concerns the inclusion of both children and adolescents as well as adults in our sample, leading to a sample with a wide age range which may limit the generalisability of the results. However, the age range is comparable with the sample that is used to assess the psychometric properties of the SQ-SP (Maas et al., 20II) and therefore the SQ-SP is suitable for this sample. Future studies should use samples consisting of either children and adolescents with ID or adults with ID to control for developmental effect on the prevalence of different types of sleep problems. The last limitation has to do with the fact that the sample of individuals with DS deviates from other studies on sleep in individuals with DS in terms of age and gender. In the present study, relatively more males were included than in other studies. This is an indication that our sample is not representative for individuals with DS. Furthermore, 
our sample included both children and adults with DS and therefore it is impossible to compare the results of the present study to those of previously published studies (e.g., Stores et al., 1996) including samples of only children with DS.

In conclusion, the present study shows that sleep problems in individuals with CDC, DS, and JS are not more common than in individuals with NS. However, the underlying cause or specific sleep disorder in individuals with CDC, DS, and JS seems to be different from those in individuals with NS. Clinicians faced with sleep problems of individuals with CDC, DS, and JS should be alert to specific types of sleep disturbance, specifically snoring and eliminating snoring. They may want to make eliminating snoring their first aim when treating clients with sleep problems. 


\section{REFERENCES}

Brockmann, P. E., Urschitz, M. S., Schlaud, M., \& Poets C. F. (20I2). Primary snoring in school children: Prevalence and neurocognitive impairments. Sleep and Breathing, 16, 23-29.

Cotton, S., \& Richdale, A. (2006). Brief report: Parental descriptions of sleep problems in children with autism, Down syndrome and Prader-Willi syndrome. Research in Developmental Disabilities, 27, I5I-I6r.

Didden, R., Korzilius, H., Aperlo, B. van, Overloop, C. van, \& Vries, M. de (2002). Sleep problems and daytime problem behaviours in children with intellectual disability. Journal of Intellectual Disability Research, 46, 537-547.

Didden, R., Korzilius, H., Smits, M. G., \& Curfs, L. M. G. (2004). Sleep problems in individuals with Angelman syndrome. American Journal on Mental Retardation, 109, 275-284.

Didden, R., \& Sigafoos, J. (200I). A review of the nature and the treatment of sleep disorders in individuals with developmental disabilities. Research in Developmental Disabilities, 22, 255-272.

Hall, S. S., Arron, K., Sloneem, J., \& Oliver, C. (2008). Health and sleep problems in Cornelia de Lange syndrome: A case control study. Journal of Intellectual Disability Research, 52, 458-468.

Hodapp, R. M., \& Dykens E. M. (200I). Strengthening behavioral research on genetic mental retardation syndromes. American Journal on Mental Retardation, 106, 4-I5.

Hunt, A., \& Stores, G. (I994). Sleep disorder and epilepsy in children with tuberous sclerosis: A questionnaire-based study. Developmental Medicine \& Child Neurology, 36, IO8-II5.

Huynh, N. T., Morton, P. D., Rompré, P. H., Papadakis, A., \& Remise, C. (2OII). Associations between sleep-disordered breathing symptoms and facial and dental morphometry, assessed with screening examinations. American Journal of Orthodontics \& Dentofacial Orthopedics, 140, 762-770.

Johnson, H., Wiggs, L., Stores, G., \& Huson, S. M. (2005). Psychological disturbance and sleep disorders in children with Neurofibromatosis type I. Developmental Medicine Q Child Neurology, 47, 237-242.

Maas, A. P. H. M., Didden, R., Korzilius, H., Braam, W., Collin, P., Smits, M.G., \& Curfs, L. M. G. (20II). Psychometric properties of a sleep questionnaire for use in individuals with intellectual disabilities. Research in Developmental Disabilities, 32, 2467-2479.

Maas, A. P. H. M., Didden, R., Korzilius, H., Braam, W., Smits, M. G., \& Curfs, L. M. G. (2009). Sleep in individuals with Cri du Chat syndrome: A comparative study. Journal of Intellectual Disability Research, 53, 704-7I5. 
Maas, A. P. H. M., Grossfeld, P. D., Didden, R., Korzilius, H., Braam, W. J., Smits, M. G., \& Curfs, L. M. G. (2008). Sleep problems in individuals with iıq terminal deletion disorder (Jacobsen syndrome). Genetic Counseling, 19, 225-235.

Shott, S. R., Amin, R., Chini, B., Heubi, C., Hotze, S., \& Akers, R. (2006). Obstructive sleep apnea: Should all children with Down syndrome be tested? Archives of Otolaryngology - Head \& Neck Surgery, 132, 432-436.

Simonds, J. F., \& Parraga, H. (I982). Prevalence of sleep disorders and sleep behaviors in children and adolescents. Journal of the American Academy of Child Psychiatry, 21, 383-388.

Stores, G., \& Wiggs, L. (Eds.) (200I). Sleep disturbances in children and adolescents with disorders of development: Its significance and management. London, England: Mac Keith Press.

Stores, G., Wiggs, L., \& Campling, G. (I998). Sleep disorders and their relationship to psychological disturbance in children with epilepsy. Child: Care, Health and Development, 24, 5-I9.

Stores, R., Stores, G., \& Buckley, S. (I996). The pattern of sleep problems in children with Down's syndrome and other intellectual disabilities. Journal of Applied Research in Intellectual Disabilities, 9, I45-I59.

Wiggs, L., \& Stores, G. (I996). Severe sleep disturbance and daytime challenging behaviour in children with severe learning disabilities. Journal of Intellectual Disability Research, 40, 518-528.

Wiggs, L., \& Stores, G. (I998). Behavioural treatment for sleep problems in children with severe learning disabilities and challenging daytime behaviour: Effect on sleep patterns of mother and child. Journal of Sleep Research, 7, II9-126.

Wiggs, L., \& Stores, G. (2004). Sleep patterns and sleep disorders in children with autistic spectrum disorders: Insights using parent report and actigraphy. Developmental Medicine a Child Neurology, 46, 372-380. 
CHAPTER 3.4

Sleep Disturbances AND

\section{Behavioural Problems in Adults} With Prader-Willi Syndrome

Maas*, A. P. H. M., Sinnema*, M., Didden, R., Maaskant, M. A., Smits, M. G., Schrander-Stumpel, C. T. R. M, \& Curfs, L. M. G. (2010). Journal of Intellectual Disability Research, 54, 906-917.

* Equal contribution of both authors. 


\section{ABSTRACT}

Individuals with Prader-Willi syndrome (PWS) are at risk of sleep disturbances, such as excessive daytime sleepiness (EDS) and sleep apnoea, and behavioural problems. Sleep disturbances and their relationship with other variables had not been researched extensively in adults with PWS. Sleep disturbances and behavioural problems were investigated in adults with genetically confirmed PWS using standardised questionnaires. Results of adults with paternal deletion $(n=45)$ were compared with those of adults with maternal uniparental disomy $(n=33)$. Eleven adults with PWS (i.e., I5\%) had sleep problems, mostly night waking problems. Twenty-six adults with PWS (i.e., 33\%) suffered from severe EDS. No differences in prevalence of sleep disturbances between genetic subtypes were found. Seventeen adults with deletion (i.e., 38\%) and seventeen adults with maternal uniparental disomy (i.e., $52 \%$ ) had behavioural problems . No significant relationships were found between sleep disturbances and behavioural problems. In adults with PWS, EDS is the most common type of sleep disturbance. Males and individuals with relative high body mass index are at increased risk for EDS. More research, aimed at developing a suitable screening instrument for sleep apnoea in adults with PWS, is necessary. Clinical implications of the findings are discussed. 


\section{INTRODUCTION}

Prader-Willi syndrome (PWS) is characterised by infantile hypotonia, hyperphagia, intellectual disability (ID), short stature and hypogonadism (Cassidy \& Driscoll, 2009; Goldstone, Holland, Hauffa, Hokken-Koelega, \& Tauber, 2008; Holm et al., I993; Prader, Labhart, \& Willi, I956). PWS results from the abnormal or absent expression of the paternal copy of a maternally imprinted gene region at chromosome I5qII-qI3. This can arise from four different mechanisms: a paternal deletion (70\%), a maternal uniparental disomy (mUPD) (25\%), an imprinting centre defect $(<5 \%)$ or an unbalanced chromosomal translocation (<I\%) (Buiting et al., I995; Cassidy \& Driscoll, 2009; Goldstone et al., 2008; Horsthemke \& Buiting, 2006; Ledbetter et al., I98I; Nicholls et al., I989).

Temper tantrums, insistence on routine, skin-picking, obsessive traits, mood swings and stubbornness are characteristic behavioural problems often observed among individuals with PWS (Boer \& Clarke, I999; Clarke et al., 2002; Didden, Korzilius, \& Curfs, 2007; Holland et al., 2003). Also sleep disturbances, more specifically excessive daytime sleepiness (EDS) and sleep apnoea, are common in individuals with PWS (Butler et al., 2002).

Early prevalence studies in adults with PWS revealed that daytime sleepiness was observed in more than 95\% of samples (Clarke, Waters, Corbett, I989; Greenswag, I987). Validity of outcomes of these studies is limited because no standardised sleep questionnaires were used and data on other types of sleep disturbances (e.g., difficulty falling asleep, night waking and breathing disturbances during sleep; see Vela-Bueno et al., I984) than those indicating hypersomnia were lacking. Furthermore, in both studies diagnosis was not genetically confirmed for all participants. A decade later Richdale, Cotton, and Hibbit (I999) performed a study on sleep disturbances in children and adults with PWS using standardised sleep questionnaires to screen for EDS, sleep apnoea and narcolepsy. They found sleep disturbances including EDS, snoring and night waking to be present in adults. The number of adults in their sample was rather small (i.e., $n=7$ ).

In individuals with PWS, daytime sleepiness and poor sleep quality may be related to daytime irritability, temper tantrums and attention problems (Boer, 2004; O’Donoghue et al., 2005; Richdale et al., I999). Richdale et al. (I999) found that in children with PWS, EDS was associated with behavioural problems in all domains of the Developmental Behaviour Checklist (DBC; Einfeld \& Tonge, 2002). At present, studies on the relationship between sleep disturbance and behavioural problems in adults with PWS are lacking, except for Clarke et al.'s (I989) study. In their study, reports of parents showed that adults who frequently slept during the day or slept longer at night did not have more temper tantrums during the day than adults who did not show symptoms of 
hypersomnia. However, according to $43 \%$ of the parents impaired night time sleep in these adults was followed by irritability or temper tantrums the day after. According to these findings behavioural problems were associated with insomnia rather than with hypersomnia.

Other variables than behavioural problems may be associated with sleep disturbances in adults with PWS. In the general population obesity is related to EDS and sleep apnoea (Bixler et al., 2005; Shah \& Roux, 2009). Evidence supporting a positive relationship between EDS and body mass index (BMI) in individuals with PWS is mixed (Camfferman, McEvoy, O’Donoghue, \& Lushington, 2008). Breathing disturbances during sleep, including sleep apnoea, may be exacerbated by obesity in individuals with PWS (Nixon \& Brouillette, 2002; Yee et al., 2007). Other variables which have previously been found to be related with sleep disturbances in adults with ID (without PWS) are gender, age, living situation, epilepsy, medication use, evening caffeine consumption, nocturnal urinary incontinence and ability to communicate (Brylewski \& Wiggs, I998; Espie \& Tweedie, I99I). Until now, there have been no prevalence studies on different types of sleep disturbances in a large sample of adults with PWS who are genetically confirmed. Also, the relationship between sleep disturbances and other variables had not been researched extensively in adults with PWS.

The present study replicates Richdale et al.'s (I999) study by using the same standardised sleep and behaviour questionnaires. It elaborates on their study by including only adults with PWS of whom the genetic subtype is confirmed. The aim of the present study is threefold; it (a) investigated the prevalence and nature of sleep disturbances in a Dutch cohort $(N=79)$ of adults with PWS across genetic subtypes, (b) explored the relationship between sleep disturbances and behavioural problems, and (c) explored possible associations between sleep disturbances and gender, age, BMI, living situation, medication use and behavioural problems in adults with PWS.

\section{METHOD}

\section{Procedure}

This study was approved by the Medical Ethics Committee of the Academic Hospital Maastricht and Maastricht University. Adults with PWS were approached through the Dutch Prader-Willi Parent Association and physicians specialising in individuals with ID. The legal representatives (mostly parents) gave their informed written consent. The individuals with PWS and their main caregivers (family and/or professional caregivers) were visited by the second author for a semistructured interview. For each question an evaluation was made of the person who (either individual with PWS or main caregivers) 
would provide the most reliable information on sleeping behaviour. If the individual with PWS had moderate or severe ID and/or low verbal ability or if staff were present at night, information of main caregivers was considered more reliable than information of individuals with PWS. For most questions information was provided by main caregivers and this was more often than not in agreement with the information provided by individuals with PWS themselves. We are aware of the fact that orally administering standardised sleep questionnaires developed for the general population may threaten validity (Finlay \& Lyons, 200I). However, to our knowledge no self-report questionnaires for adults with ID assessing sleep disturbances have been developed so far. Information about behavioural problems was provided by main caregivers. Data on demographic information, including prescribed medication and physical conditions, were collected. The level of ID was reported by the main caregivers. Results of IQ tests were available in $52 \%$ of the cases. If no results of IQ tests were available level of ID was estimated on the basis of information (e.g., results from adaptive skills questionnaires) in participants' files. Medical information was retrieved from physicians. Genetic testing was undertaken in case of participants who did not have a previously confirmed genetic diagnosis. DNA methylation studies on the SNURF/SNRPN locus were used to confirm the diagnosis of PWS. Cytogenetic analyses were performed to establish whether a deletion was present. Parental samples, whenever available, were used to confirm mUPD with microsatellite analysis at various loci on chromosome $\mathrm{I5}$.

\section{Participants}

A total of 79 adults with PWS were included in this study, of whom 34 (43\%) were male. Their mean age was 34.4 years $(S D=$ II.8, range: $18-65)$. All participants were genetically confirmed as having PWS: 45 (57\%) had paternal deletion, 33 (42\%) had mUPD and one (I\%) participant had an imprinting centre defect. Sixty-three $(80 \%)$ participants lived in an institutional residential or community residential facility while $\mathrm{I} 6$ (20\%) participants lived at home with their parents or family. Level of ID was mild (47\%, $n=37)$ or moderate $(30 \%, n=24)$ in most participants. Five $(6 \%)$ participants had severe ID. The other participants were functioning at a borderline ID level (IQ 70-80) (I0\%, $n=8)$ or did not have ID (IQ $\geq 80)(6 \%, n=5)$. Mean BMI $\left(\mathrm{kg} / \mathrm{m}^{2}\right)$ was $33.2(\mathrm{SD}=8.0$, range: $2 \mathrm{I} .4-5 \mathrm{I} .9$ ). Forty-eight (6I\%) participants were obese (BMI $\geq 30$ ). Twenty-six (33\%) participants received (combinations of) psychotropic medication for behavioural and/or emotional problems. Six $(8 \%)$ participants received medication for sleep disturbances. See Table I for more information on demographic characteristics and information on medication use across genetic subtypes (paternal deletion vs. mUPD).

On average, participants with deletion subtype were somewhat younger $(M=32 . \mathrm{I}$, $S D=$ II.0, range: $18-65)$ than participants with $\mathrm{mUPD}(M=37.3, S D=12.4$, range: $\mathrm{I} 8$ - 
Table I Number and Percentage of Participant Characteristics by Genetic Subtype (paternal deletion vs. $m U P D$ )

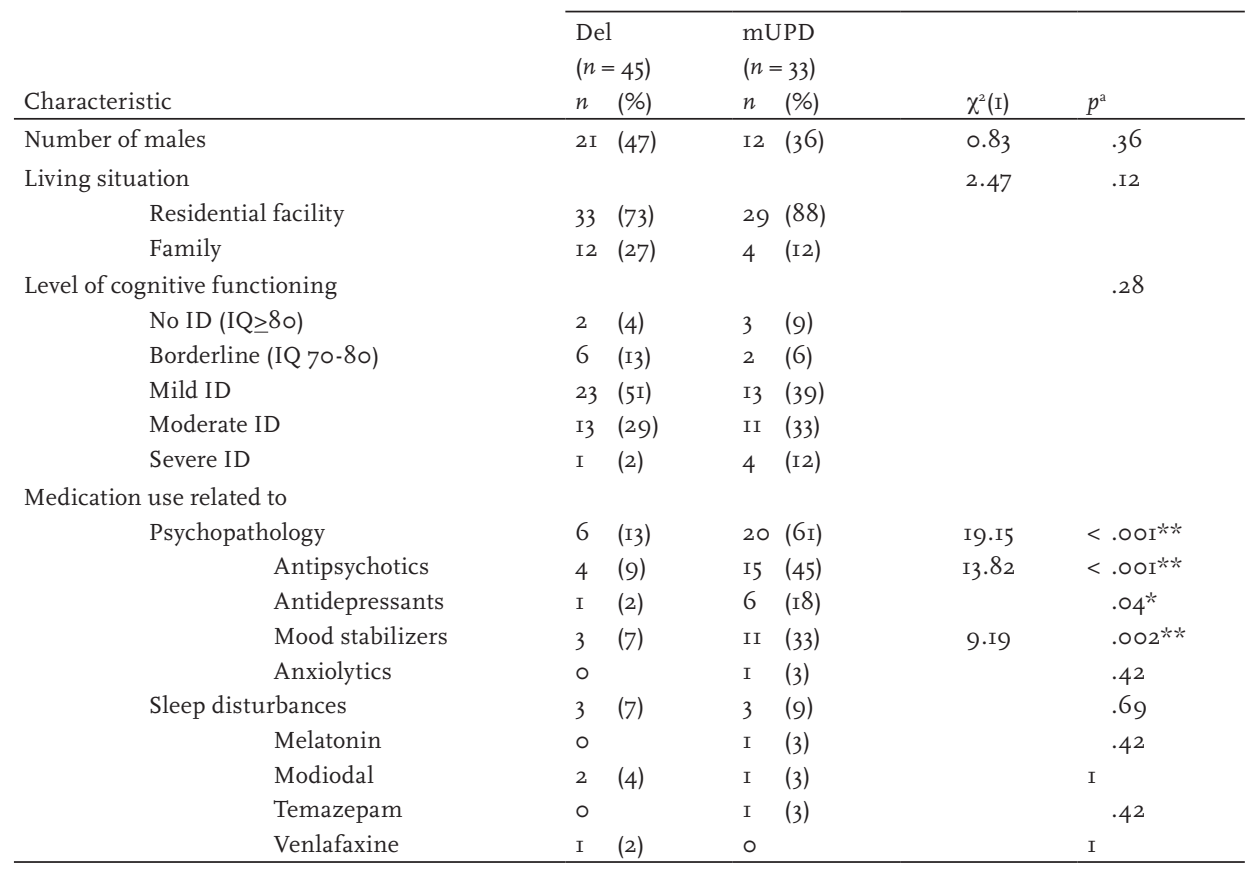

Note. Del = paternal deletion; $\mathrm{mUPD}=$ maternal uniparental disomy; $\mathrm{ID}=$ intellectual disability.

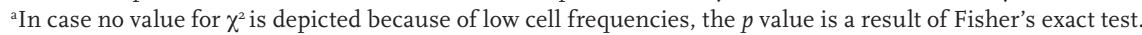

$* p<.05 . * * p<.01$.

65). Results of a $t$ test showed that this difference approached statistical significance $(t(76)=-$ I.98, $p=.05$ I $)$. Mean BMI scores were 33.7 ( $S D=8.2$, range: 2I.4-5I.9) for participants with deletion and $33.0(S D=7.7$, range: 23.I-49.9) for participants with mUPD. These differences were not statistically significant $(t(76)=0.38, p=.7 \mathrm{I})$.

\section{MATERIALS}

As part of the semistructured interview data on settling problems, night waking and early waking were collected. Questions concerning settling, night waking and early waking were asked to determine whether a current sleep problem was present according to criteria established by Wiggs and Stores (1996) and Didden, Korzilius, Van Aperlo, Van Overloop, and De Vries (2002). Frequency of occurrence of sleep problems was assessed on a 7-point Likert-type scale from 'Never' (I) to 'Daily' (7). Questions about duration were measured on a 5-point Likert-type scale from 'A few minutes' (I) to 'More 
than two hours' (5). Settling problems were defined as severe if they occurred three or more nights a week, the individual took more than I hr to fall asleep and caregivers were disturbed during this time. Settling was considered a mild problem if it occurred one or two nights a week and falling asleep took more than 30 min but less than I hr. Night waking was defined as severe if it occurred three or more nights a week, and if the individual remained awake for more than a few minutes and disturbed caregivers during that time. Night waking was considered a mild problem if it occurred once or twice a week. Finally, early waking was defined as the individual waking up before 5:00 a.m. and staying awake. This was considered a severe problem if it occurred three or more nights a week and a mild problem if it occurred once or twice a week. Participants were diagnosed with a current sleep problem if they had at least one of the three types of sleep problems mentioned above and if the level of these problems was mild or severe.

Furthermore, two standardised questionnaires were included in the interview to screen for the presence of EDS and sleep apnoea. The Epworth Sleepiness Scale (ESS; Johns, I99I) was used to measure the participants' general level of daytime sleepiness. The ESS consists of eight items, indicating a variety of circumstances, which are rated on a 4-point Likert-type scale, from 'Would never doze' (o) to 'High chance of dozing' (3) (range: 0-24). ESS scores $\geq \mathrm{I} 6$ are indicative of a high level of daytime sleepiness (i.e., EDS). The ESS has good internal consistency (Cronbach's $\alpha=.88$ ) and test-retest reliability $(r=.82)$ (Johns, I992) when administered to nondisabled individuals. ESS cutoff scores used by Richdale et al. (I999) were $7 \leq$ ESS $<\mathrm{I} 6$ and ESS $\geq 16$ in individuals with PWS. Therefore prevalence rates will be presented for $7 \leq \mathrm{ESS}<\mathrm{I} 6$ and ESS $\geq \mathrm{I} 6$.

The Sleep Apnea (SA) subscale of the Sleep Disorders Questionnaire (SDQ; Douglass et al., I994) consists of I2 items that are rated on a 5-point Likert-type scale, from 'Never' (I) to 'Always' (5) (range: I2-60). The SA-SDQ does not include questions about daytime sleepiness. Scores $\geq 36$ for males and $\geq 32$ for women are proposed as cut-off values above which sleep apnoea becomes clinically probable with satisfactory specificity (76$8 \mathrm{I} \%$ ) and sensitivity (85-88\%). Internal consistency (Cronbach's $\alpha=.86$ ) and test-retest reliability $\left(r_{s}=.84\right)$ of the SA subscale were good when administered to nondisabled individuals. A procedure for estimating a small number of missing data was as follows: a median value was calculated for each item on the basis of scores regarding that item by all participants. Missing data were replaced by this median score.

To collect data on behavioural problems main caregivers completed a questionnaire prior to the interview. The Developmental Behaviour Checklist for Adults (DBC-A; Mohr, Tonge, \& Einfeld, 2004) is designed to assess problematic behaviour and emotional state in adults with ID. The main caregiver rated I07 items on a 3-point Likert-type scale, as 'Not true' (O), 'Sometimes or somewhat true' (I) or 'Often true or very true' (2) (range: 0 -32I). To derive a total behaviour problem score (TBPS) all item scores 
were summed. TBPS $\geq 5$ I are proposed as cut-off with modest specificity $(50 \%)$ and high sensitivity $(87 \%)$ with regard to expert clinical judgement of psychiatric caseness. Furthermore, six subscale scores were obtained: Disruptive (I7 items), Self-Absorbed (28 items), Communication Disturbance (13 items), Anxiety/Antisocial (9 items), Social Relating ( 6 items) and Depressive (Io items). Internal consistency of the total scale (Cronbach's $\alpha=$.95) was excellent and internal consistency of the subscales was substantial to good (Cronbach's $\alpha$ range: .6I-.89) (Mohr et al., 2004). Intraclass correlations for test-retest (ICC $=.75$ and ICC $=.85$ ) and interrater reliability $($ ICC $=.72$ ) were good, and concurrent validity of the DBC-A with the Aberrant Behavior Checklist (ABC; Aman \& Singh, 1985) ( $r=.63)$ and the Psychiatric Assessment Scale for Adults with Developmental Disability Checklist (PAS-ADD Checklist; Moss et al., 1998) $(r=.6 \mathrm{I})$ revealed moderately positive relations (Mohr, Tonge, \& Einfeld, 2005).

\section{Statistical Analyses}

To test whether differences between genetic subtypes were statistically significant $\alpha^{2}$ tests/Fisher's exact tests and Independent samples $t$ tests/Mann-Whitney tests were performed for nominal/ordinal and metric data respectively. To test the relationship between sleep disturbances and behavioural problems Kendall's tau-b was used for ordinal data and bivariate correlation (Pearson correlation/Kendall's tau-b/Spearman's rank correlation when appropriate) for metric data. All variables that could possibly be associated with sleep disturbances in adults with PWS, i.e., gender, age, BMI, living situation, medication use related to psychopathology and TBPS, were included in a regression model to test their predictive value on the dependent sleep variables. SPSS (version $\mathrm{I} 6.0$ ) was used to analyse the data. A $p$ value of .05 or less was taken as significant for all statistical tests.

\section{RESULTS}

\section{Sieep Disturbances}

Settling problems, night waking, and early waking. Percentages of participants with a current sleep problem are shown in Table 2. Eleven participants (15\%, $n=75)$ had sleep problems, of which night waking was the most common. No participants with deletion and three (9\%) participants with mUPD had a problem with early waking. Differences between groups (deletion vs. mUPD) in percentage of participants with sleep problems were not statistically significant. Relationships between sleep problems and cut-off scores for EDS and sleep apnoea were weak and not statistically significant (Kendall's tau-b range: $|<0.0 \mathrm{I}|-|0.09|)$. 
Table 2 Number and Percentage of Participants with Sleep Problems by Genetic Subtype

\begin{tabular}{|c|c|c|c|c|}
\hline & $\begin{array}{l}\text { All } \\
(N=79) \\
n \quad(\%)\end{array}$ & $\begin{array}{l}\text { Del } \\
(n=45) \\
n \quad(\%)\end{array}$ & $\begin{array}{l}\text { mUPD } \\
(n=33) \\
n \quad(\%)\end{array}$ & $p^{\mathrm{a}}$ \\
\hline Settling problems & I $\quad(\mathrm{I})$ & 0 & I $\quad(3)$ & .42 \\
\hline Night waking ${ }^{\mathrm{b}}$ & IO (13) & 6 (I4) & $4 \quad(\mathrm{I} 3)$ & I \\
\hline Early waking & $3 \quad(4)$ & $\circ$ & 3 (9) & .07 \\
\hline Total $l^{b, c}$ & II (I5) & 6 (I4) & $5 \quad$ (I6) & I \\
\hline
\end{tabular}

Note. Del $=$ paternal deletion; $\mathrm{mUPD}=$ maternal uniparental disomy.

${ }^{a}$ Fisher's exact test. ${ }^{b} n$ all $=75 ; n$ Del $=42 ; n \mathrm{mUPD}=32$. Two participants with $\mathrm{mUPD}$ had a combination of sleep problems.

Table 3 Number and Percentage of Participants with Excessive Daytime Sleepiness (EDS) and Sleep Apnoea by Genetic Subtype

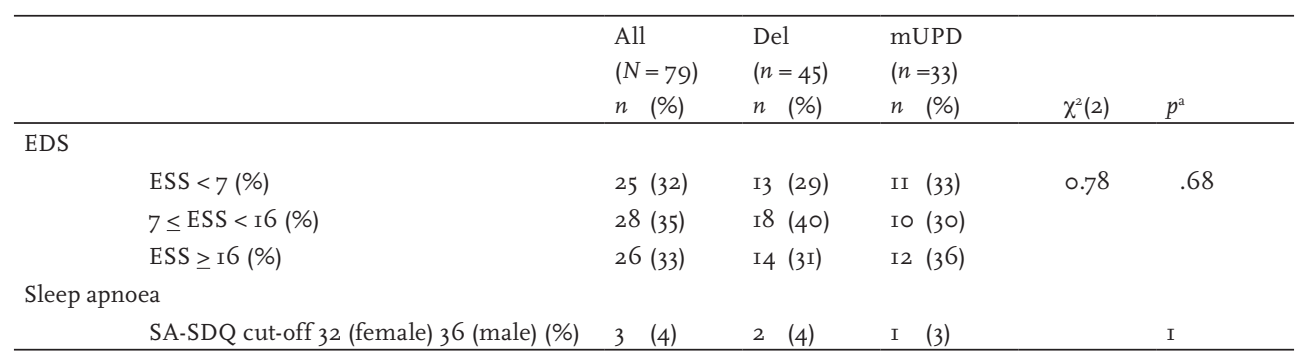

Note. Del = paternal deletion; $\mathrm{mUPD}=$ maternal uniparental disomy; ESS = Epworth Sleepiness Scale; SA-SDQ = Sleep Apnea subscale of the Sleep Disorders Questionnaire.

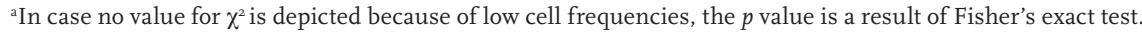

Table 4 Mean Scores (SD) on the DBC-A and DBC-A Subscales by Genetic Subtype

\begin{tabular}{|c|c|c|c|c|}
\hline & $\begin{array}{l}\text { All } \\
(N=79) \\
M(S D)\end{array}$ & $\begin{array}{l}\text { Del } \\
(n=45) \\
M(S D)\end{array}$ & $\begin{array}{l}\text { mUPD } \\
(n=33) \\
M(S D)\end{array}$ & $p^{\mathrm{a}}$ \\
\hline DBC-A TBPS & $50.2(23.7)$ & $46.3(20.7)$ & $55.4(27.0)$ & .10 \\
\hline DBC-A Disruptive & II.3 (6.5) & IO.I $(5.5)$ & I2.9 (7.4) & .06 \\
\hline DBC-A Self-Absorbed & $9.2 \quad(6.4)$ & $7.6 \quad(4.3)$ & II.I $(8.2)$ & .08 \\
\hline DBC-A Communication Disturbed & $5.9 \quad(3.6)$ & $5.9 \quad(3.5)$ & $6.0 \quad(3.9)$ & .85 \\
\hline DBC-A Anxiety/Antisocial & I.7 $\quad(2.2)$ & $\mathrm{I} .4 \quad(2.0)$ & I.9 $\quad(2.5)$ & $.4 \mathrm{I}$ \\
\hline DBC-A Social relating & $4.8 \quad(2.4)$ & $4.9 \quad(2.5)$ & $4.6 \quad(2 . \mathrm{I})$ & .50 \\
\hline DBC-A Depressive & $4.6 \quad(3.4)$ & $4.3 \quad(3.0)$ & 5.I $\quad(3.8)$ & .53 \\
\hline
\end{tabular}

Note. DBC-A = Developmental Behaviour Checklist for Adults; Del = paternal deletion; $\mathrm{mUPD}=$ maternal uniparental disomy; TBPS = Total Behaviour Problem Score.

${ }^{a} t$ test except for Self-Absorbed, Anxiety/Antisocial and Depressive: Mann-Whitney test (scores were not normally distributed on this subscale). 
Excessive daytime sleepiness. Twenty-six participants (33\%) had ESS scores of $\mathrm{I} 6$ or higher, indicating that they suffered from EDS. The differences between groups in frequency of EDS were not statistically significant (see Table 3).

Sleep apnoea. Only three participants $(4 \%)$ met criteria for sleep apnoea on the SASDQ (see Table 3). In both groups (deletion and mUPD) none of the males $(n=33)$ met the criterion for sleep apnoea. Of the women $(n=45)$, two $(8 \%, n=24)$ participants with deletion and I $(5 \%, n=2 \mathrm{I})$ participant with mUPD met the criterion for sleep apnoea. These differences, however, were not statistically significant. SA-SDQ scores were significantly, but weakly correlated with ESS scores $\left(r_{s}=.38, p=.00 \mathrm{I}\right)$.

\section{Behavioural Problems}

Thirty-five $(44 \%)$ participants, including the participant with an imprinting centre defect, had a TBPS of $5 \mathrm{I}$ or higher, which is indicative of clinically significant behavioural problems. Seventeen (38\%) participants with deletion and I7 (52\%) participants with mUPD had a TBPS of at least 5 I. This difference was not statistically significant $\left(\alpha^{2}(\mathrm{I})=\right.$ I.46, $p=.23$ ). Results from the Kolmogorov-Smirnov test showed that the scores on three of the six subscales of the DBC-A were not normally distributed. As a consequence, the MannWhitney test was used to test differences between genetic subtypes on the DBC-A subscales: Self-Absorbed, Anxiety/Antisocial and Depressive (see Table 4). Differences between groups on DBC-A subscales, Disruptive and Self-Absorbed, approached statistical significance, and on both subscales mean scores were higher for participants with mUPD than for participants with a deletion.

\section{Slefe Disturbances and Behavioural Problems}

Information on relationships between sleep measures and the DBC-A scales is given in Table 5 . There were no significant relationships between sleep disturbances and behavioural problems.

\section{SLeep Disturbances and Individual-Related Variables}

Logistic regression analyses to predict a current sleep problem and night waking could not be performed because of low prevalence rates of those problems. However, two regression analyses (method Enter) were performed to assess to what extent (a) gender, (b) age, (c) BMI, (d) living situation, (e) medication use (related to psychopathology), and (f) behavioural problems (TBPS) predict EDS and sleep apnoea. Firstly, analysis of ESS scores (indicating EDS) resulted in a statistically significant predictive model $(F(6,72)=3.52$, $\left.p<.0 \mathrm{I}, R^{2}=.23\right)$. Gender $(B=-3.4$ O,$p=.03)$ and BMI $(B=0.29, p<$. OI $)$ had a statistically significant impact on ESS scores. It showed that females had lower ESS scores than males and participants with higher BMI scores had higher ESS scores. Age had no statistically 
significant impact $(p=.70$ ). Secondly, analysis of SA-SDQ scores (indicating sleep apnoea) was performed with the above mentioned variables, but without age and BMI (because these variables are included in the SA-SDQ score). This did not result in a statistically significant predictive model $\left(F(4,74)=2.25, p=.07, R^{2}=. \mathrm{II}\right)$. Only living situation $(B=4.64, p=.007)$ had a statistically significant impact on SA-SDQ scores. It showed that participants living in residential facilities had higher SA-SDQ scores than participants living with their family. See Table 6 for results of the regression models for ESS and SA-SDQ scores.

Table 5 Relationships (Kendall's tau-b, Pearson correlation or Spearman's rank correlation) between Sleep Variables and DBC-A Scores $(N=79)$

\begin{tabular}{|c|c|c|c|c|c|c|c|c|}
\hline & $\begin{array}{l}\text { DBC-A } \\
\text { TBPS } \geq 5 \mathrm{I}\end{array}$ & $\begin{array}{l}\text { DBC-A } \\
\text { TBPS }\end{array}$ & $\begin{array}{l}\text { DBC-A } \\
\text { Disruptive }\end{array}$ & $\begin{array}{l}\text { DBC-A } \\
\text { Self- } \\
\text { Absorbed }\end{array}$ & $\begin{array}{l}\text { DBC-A } \\
\text { Commu- } \\
\text { nication } \\
\text { Disturbed }\end{array}$ & $\begin{array}{l}\text { DBC-A } \\
\text { Anxiety/ } \\
\text { Antisocial }\end{array}$ & $\begin{array}{l}\text { DBC-A } \\
\text { Social } \\
\text { relating }\end{array}$ & $\begin{array}{l}\text { DBC-A } \\
\text { Depressive }\end{array}$ \\
\hline $\begin{array}{l}\text { Current sleep } \\
\text { problem }^{\text {a }}\end{array}$ & $\tau=. I 6$ & & & & & & & \\
\hline Settling problems & $\tau=. \mathrm{I} 3$ & & & & & & & \\
\hline Night waking ${ }^{a}$ & $\tau=.2 \mathrm{I}$ & & & & & & & \\
\hline Early waking & $\tau=.09$ & & & & & & & \\
\hline ESS & & $r=.19$ & $r=. \mathrm{I} 7$ & $r_{s}=.05$ & $r=.24^{*}$ & $r_{s}=.12$ & $r=.15$ & $r_{s}=0.18$ \\
\hline SA-SDQ & & $r=-.02$ & $r=-.02$ & $r_{s}=-.12$ & $r=.04$ & $r_{s}=.3 \mathrm{I}^{* *}$ & $r=.02$ & $r_{s}=0.13$ \\
\hline
\end{tabular}

Note. DBC-A = Developmental Behaviour Checklist for Adults; TBPS = Total Behaviour Problem Score; ESS = Epworth Sleepiness Scale; SA-SDQ = Sleep Apnea subscale of the Sleep Disorders Questionnaire.

${ }^{\mathrm{a}} n=75$.

$* p<.05 . * * p<.01$.

Table 6 Summary of Regression Analyses for Variables Predicting Scores on Sleep Questionnaires $(N=79)$

\begin{tabular}{|c|c|c|c|c|c|c|}
\hline & \multicolumn{3}{|c|}{ ESS } & \multicolumn{3}{|c|}{ SA-SDQ } \\
\hline & $p$ & $B$ & $95 \% \mathrm{CI}$ & $p$ & $B$ & $95 \% \mathrm{CI}$ \\
\hline Gender (M/F) & $.03 *$ & -3.40 & $-6.47--0.33$ & .56 & -0.75 & $-3.30-1.80$ \\
\hline Age & .70 & -0.03 & - O.I7- O.II & - & - & - \\
\hline BMI & $.003^{* *}$ & 0.29 & 0.10- 0.48 & - & - & - \\
\hline Living situation ${ }^{\mathrm{a}}$ & .17 & 2.95 & $-1.34-7.25$ & $.007^{* * *}$ & $4 \cdot 64$ & I.28- 7.99 \\
\hline Medication use $(-/+)$ & .08 & -2.97 & $-6.34-0.40$ &. $\mathrm{I7}$ & -I.99 & $-4.82-0.84$ \\
\hline TBPS & .09 & 0.06 & $-0.0 \mathrm{I}-0.13$ & .44 & -0.02 & $-0.08-0.03$ \\
\hline Constant term & .97 & O.I4 & $-8.05-8.33$ & .44 & -0.02 & I7.75- 25.39 \\
\hline
\end{tabular}

Note. ESS = Epworth Sleepiness Scale; SA-SDQ = Sleep Apnea subscale of the Sleep Disorders Questionnaire; CI = confidence interval of $B ; \mathrm{M}=$ male; $\mathrm{F}=$ female; $\mathrm{BMI}=$ body mass index; TBPS = Total Behaviour Problem Score of the Developmental Behaviour Checklist for Adults. A dash indicates that variables were not included in model.

${ }^{a}$ Family vs. Residential facility. ${ }^{b}$ Medication use related to psychopathology.

$* p<.05 * * p<.01$. 


\section{DISCUSSION}

This study reported sleep and behaviour in a sample of adults with genetically confirmed PWS. No differences in prevalence of sleep disturbances and behavioural problems between genetic subtypes were found. However, adults with mUPD tended to have higher scores on the Disruptive and Self-Absorbed subscales of the DBC-A compared with adults with paternal deletion $(p<$.Io). Furthermore, no relationships between sleep variables and behavioural problems were found in adults with PWS. These findings do not corroborate those of Richdale et al. (I999) who found moderate correlations between different sleep variables and all DBC scales in children and adolescents with PWS. Differences in sample characteristics (i.e., sample size, age, and BMI) and lack of information about genetic diagnosis, living situation, medication use related to psychopathology and medication use related to sleep disturbances in Richdale et al.'s study, make comparison between studies impossible.

The results show that the overall prevalence rate of sleep problems was relatively low (i.e., I5\%). Considering the type of sleep problems, night waking problems were most often observed, i.e., in I3\% of the sample. Further, EDS was found in a minority of our sample, which is in $33 \%$ of the participants. This is in contrast with other studies using parent reports and questionnaires. For example, Clarke et al. (I989) found EDS in 63\% of adults with PWS. Differences in both definition and measurement of daytime sleepiness may account for the difference in prevalence rates. Greenswag (I987) and Clarke et al. did not use a standardised sleep questionnaire to measure daytime sleepiness. Richdale et al. (I999), also using the ESS to measure EDS, found a prevalence rate of $29 \%$ which is somewhat lower than the prevalence rate in our study. The origins of EDS in PWS remain unclear (Didden, Braam, De Weerd, Smits, \& Curfs, 2006). In the present study, EDS could be partly explained by gender and BMI. The model could only explain $23 \%$ of the variance. Other factors, not included in the model, such as breathing disturbances during sleep, hypothalamic dysfunction and lack of structured activities may contribute to EDS (Camfferman et al., 2008; Maas, Didden, Bouts, Smits, \& Curfs, 2008; Nixon \& Brouillette, 2002).

Only few participants (4\%) met the cut-off score for sleep apnoea. This is not in line with polysomnographic studies in individuals with PWS (Camfferman, Lushington, O’Donoghue, \& McEvoy, 2006) in which much higher rates of sleep apnoea were found. The explanation for this difference could be twofold. Firstly, the relatively high rate of obstructive sleep apnoea (57\%) mentioned by Camfferman et al. (2006) may not be representative. Polysomnography-based information on breathing disturbances during sleep in individuals with PWS described in literature is often limited to small groups of both children and adults. These samples are highly selected in that individuals are 
referred because of complaints of daytime sleepiness and/or loud snoring. However, high rates of obstructive sleep apnoea have been found in a sample of unselected adolescents and adults with PWS (Yee et al., 2007). Secondly, experience with the SA-SDQ scale in the present study leads to the conclusion that it may not be an appropriate instrument for screening of sleep apnoea in the population of adults with PWS. In this study, eight participants (four males) were previously diagnosed with sleep apnoea (confirmed by PSG or observed during surgery) and none of them met the cut-off score on the SA-SDQ. Mean SA-SDQ score of the participants previously diagnosed with sleep apnoea was 26 (range: I8-3I). Although Richdale et al. (I999) also have used this questionnaire with individuals with PWS, the SA-SDQ is not designed for measuring sleep apnoea in individuals with ID. Questions on sleeping position, snoring, audible apnoeas or awaking with a start were difficult to answer for both individuals with PWS themselves as well as their main caregivers. Development of cut-off scores for individuals with ID or more specifically for individuals with PWS is recommended. Specific (lower) cut-off scores on the SA-SDQ have already been developed for individuals with epilepsy (Weatherwax, Lin, Marzec, \& Malow, 2003). Cut-off scores are important when it comes to referring individuals to a (sleep) clinic for additional evaluation of breathing disorders during sleep and therefore they should minimize false negatives. Treatment options are available for this serious morbidity and treatment may improve the health and the quality of life of the individuals affected.

The results of the present study should be interpreted in the context of its methodological shortcomings. The first shortcoming relates to the use of informantbased screening questionnaires to assess sleep disturbances. Although not as objective as measurements like polysomnography and the Multiple Sleep Latency Test (MSLT), this was the only way to collect data on sleep in a relatively large sample of adults with PWS. As mentioned before, sleep studies in PWS using polysomnography are frequently biased, because they include highly selected samples of participants. In the present study, there was no selection of participants based on sleep complaints. After administration of screening questionnaires, further assessment is necessary to determine whether a sleep disorder is present. Based on high scores on the standardised questionnaires five participants of this study were studied more extensively with home respiratory polygraphy in order to determine whether they should or should not be diagnosed with sleep apnoea and one of them appeared to have sleep apnoea. A second shortcoming is that we were not able to control for differences in age and use of psychotropic medication between groups. In this study, adults with mUPD were on average older and used psychotropic medication more often than those with deletion subtype. Overall age did not have an impact on ESS and SA-SDQ scores. However, medication use related to psychopathology tended to have some impact on ESS scores (see Table 6). Unfortunately, we were not able to predict the influence of age and use of psychotropic medication on settling problems, 
night waking and early waking, due to low rates of these sleep problems. Based on earlier reports (Brylewski \& Wiggs, I999; Clarke et al., 1989) and anecdotal remarks of main caregivers during the interviews we suspect a relationship between night waking and behavioural and emotional problems during the day. Future research should focus on the relationships between sleep disturbances, such as night waking and EDS and (development of) behavioural and emotional problems in adults with mUPD.

Despite these limitations, the present study provides information about sleep disturbances and behavioural problems, that until now had not been examined with standardised questionnaires in adults with PWS across genetic subtypes.

Several clinical implications may be identified. We recommend that caregivers regularly look for sleep disturbances in adults with PWS. In our opinion, the ESS is a useful instrument that can easily be applied to determine the severity of daytime sleepiness in adults with PWS. In case of ESS scores $\geq 16$ or significant changes in ESS scores further assessment of sleep disturbances and associated variables is recommended. The SA-SDQ may not be suitable for screening breathing disturbances during sleep, and other ways to screen for these sleep disorders have to be developed. Furthermore, we advise caregivers to combine looking for sleep disturbances with looking for behavioural and emotional problems. Changes in sleep patterns, e.g., difficulty falling asleep and night waking, could be a first presenting sign of psychiatric illness and should be carefully monitored, specifically in young adults with PWS who are at risk of developing psychiatric illness (Boer, 2004; Dykens, 2004; Soni et al., 2008). We also recommend looking for sleep disturbances when daytime behaviour becomes disorganised. Regulation of the sleep pattern could prevent worsening of behavioural and emotional problems (Wirz-Justice, 2007). Once specific behavioural or psychiatric causes of the sleep disturbance have been identified, appropriate treatment can be undertaken (Costa e Silva, 2006). An individual treatment plan for sleep disturbances in adults with PWS may consist of treatment of extreme obesity, treatment of sleep apnoea, sleep hygiene measures (including activities during the day, especially in weekends) (Maas et al., 2008), treatment of (night time) behavioural problems and/or psychiatric illness. Combined assessment and treatment ultimately lead to improvement of sleep quality, behaviour and daytime functioning. This could be of considerable benefit to the individuals with PWS themselves, their families and their professional caregivers. 


\section{REFERENCES}

Aman, M. G., \& Singh, N. N. (I985). Psychometric characteristics of the Aberrant Behaviour Checklist. American Journal of Mental Deficiency, 89, 492-502.

Bixler, E. O., Vgontzas, A. N., Lin, H.-M., Calhoun, S. L., Vela-Bueno, A., \& Kales, A. (2005). Excessive daytime sleepiness in a general population sample: The role of sleep apnea, age, obesity, diabetes and depression. Journal of Clinical Endocrinology Q Metabolism, 90, 4510-4515.

Boer, H. (2004). Behavioural studies in Prader-Willi syndrome (Doctoral thesis, Maastricht University, The Netherlands). Retrieved from http://arno.unimaas.nl/show. cgi?fid $=7679$

Boer, H., \& Clarke, D. (I999). Development and behaviour in two genetic syndromes I: Prader-Willi syndrome. Journal of Applied Research in Intellectual Disabilities, 12, 294-30I.

Brylewski, J., \& Wiggs, L. (I999). Sleep problems and daytime challenging behaviour in a community-based sample of adults with intellectual disability. Journal of Intellectual Disability Research, 43, 504-512.

Brylewski, J. E., \& Wiggs, L. (I998). A questionnaire survey of sleep and night-time behaviour in a community-based sample of adults with intellectual disability. Journal of Intellectual Disability Research, 42, I54-162.

Buiting, K., Saitoh, S., Gross, S., Dittrich, B., Schwartz, S., Nicholls, R. D., \& Horsthemke, B. (I995). Inherited microdeletions in the Angelman and PraderWilli syndromes define an imprinting centre on human chromosome 15. Nature Genetics, 9, 395-400.

Butler, J. V., Whittington, J. E., Holland, A. J., Boer, H., Clarke, D., \& Webb, T. (2002). Prevalence of, and risk factors for, physical ill-health in people with Prader-Willi syndrome: A population based study. Developmental Medicine a Child Neurology, 44, 248-255.

Camfferman, D., Lushington, K., O’Donoghue, F., \& McEvoy, R. D. (2006). Obstructive sleep apnea syndrome in Prader-Willi syndrome: An unrecognized and untreated cause of cognitive and behavioral deficits? Neuropsychology Review, 16, 123-129.

Camfferman, D., McEvoy, R. D., O’Donoghue, F., \& Lushington, K. (2008). Prader Willi syndrome and excessive daytime sleepiness. Sleep Medicine Reviews, 12, 65-75.

Cassidy, S. B., \& Driscoll, D. J. (2009). Prader-Willi syndrome. European Journal of Human Genetics, 17, 3-13.

Clarke, D. J., Boer, H., Whittington, J., Holland, A., Butler, J., \& Webb, T. (2002). PraderWilli syndrome, compulsive and ritualistic behaviours: The first population-based survey. British Journal of Psychiatry, 180, 358-362. 
Clarke, D. J., Waters J., \& Corbett, J. A. (1989). Adults with Prader-Willi syndrome: Abnormalities of sleep and behaviour. Journal of the Royal Society of Medicine, 82, $2 \mathrm{I}-24$.

Costa e Silva, J. A. (2006). Sleep disorders in psychiatry. Metabolism Clinical and Experimental, 55, S40-44.

Didden, R., Braam W., Weerd, A. de, Smits, M., \& Curfs, L. (2006). Sleep and sleep problems in Angelman syndrome and Prader-Willi syndrome. In J. F. Engels (Ed.), Focus on birth defects research (pp. 81-104). Hauppauge, NY: Nova Science.

Didden, R., Korzilius, H., Aperlo, B. van, Overloop, C. van, \& Vries, M. de (2002). Sleep problems and daytime problem behaviours in children with intellectual disability. Journal of Intellectual Disability Research, 46, 537-547.

Didden, R., Korzilius, H., \& Curfs, L. (2007). Skin-picking in individuals with PraderWilli syndrome: Prevalence, functional assessment, and its comorbidity with compulsive and self-injurious behaviour. Journal of Applied Research in Intellectual Disabilities, 20, 409-419.

Douglass, A. B., Bornstein, R., Nino-Murcia, G., Keenan, S., Miles, L., Zarcone, V. P., Jr., ... Dement, W. C. (1994). The Sleep Disorders Questionnaire I: Creation and multivariate structure of SDQ. Sleep, 17, I60-167.

Dykens, E. M. (2004). Maladaptive and compulsive behavior in Prader-Willi syndrome: New insights from older adults. American Journal on Mental Retardation, 109, I42I53.

Einfeld, S. L., \& Tonge, B. J. (2002). Manual for the Developmental Behaviour Checklist: Primary carer version (DBC-P) \& Teacher version (DBC-T) (2nd ed.). Melbourne, Australia: Monash University, Centre for Developmental Psychiatry and Psychology.

Espie, C. A., \& Tweedie, F. M. (I99I). Sleep patterns and sleep problems amongst people with mental handicap. Journal of Mental Deficiency Research, 35, 25-36.

Finlay, W. M. L., \& Lyons, E. (200I). Methodological issues in interviewing and using selfreport questionnaires with people with mental retardation. Psychological Assessment, 13, 319-335.

Goldstone, A. P., Holland, A. J., Hauffa, B. P., Hokken-Koelega, A. C., \& Tauber, M. (2008). Recommendations for the diagnosis and management of Prader-Willi syndrome. Journal of Clinical Endocrinology \& Metabolism, 93, 4183-4197.

Greenswag, L. R. (1987). Adults with Prader-Willi syndrome: A survey of 232 cases. Developmental Medicine a Child Neurology, 29, I45-I52.

Holland, A. J., Whittington, J. E., Buttler, J., Webb, T., Boer, H., \& Clarke, D. (2003). Behavioural phenotypes associates with specific genetic disorders: Evidence from a population-based study of people with Prader-Willi syndrome. Psychological Medicine, 33, I4I-I53. 
Holm, V. A., Cassidy, S. B., Butler, M. G., Hanchett, J. M., Greenswag, L. R., Whitman, B. Y., \& Greenberg, F. (I993). Prader-Willi syndrome: Consensus diagnostic criteria. Pediatrics, 91, 398-402.

Horsthemke, B., \& Buiting, K. (2006). Imprinting defects on human chromosome I5. Cytogenetic and Genome Research, 113, 292-299.

Johns, M. W. (I99I). A new method for measuring daytime sleepiness: The Epworth Sleepiness Scale. Sleep, 14, 540-545.

Johns, M. W. (I992). Reliability and factor analysis of the Epworth Sleepiness Scale. Sleep, 15, 376-38I.

Ledbetter, D. H., Riccardi, V. M., Airhart, S. D., Strobel, R. J., Keenan, B. S., \& Crawford J. D. (I98I). Deletions of chromosome I5 as a cause of the Prader-Willi syndrome. New England Journal of Medicine, 304, 325-329.

Maas, A. P. H. M., Didden, R., Bouts, L., Smits, M. G., \& Curfs, L. M. G. (2008). Scatter plot analysis of excessive daytime sleepiness and severe disruptive behaviour in adults with Prader-Willi syndrome: A pilot study. Research in Developmental Disabilities, 30, 529-537.

Mohr, C., Tonge, B., \& Einfeld, S. (2004). The Developmental Behaviour Checklist for Adults (DBC-A) (Supplement to the manual for the Developmental Behaviour Checklist: DBC-P and DBC-T). Melbourne, Australia: Monash University, Centre for Developmental Psychiatry and Psychology.

Mohr, C., Tonge, B. J., \& Einfeld, S. L. (2005). The development of a new measure for the assessment of psychopathology in adults with intellectual disability. Journal of Intellectual Disability Research, 49, 469-480.

Moss, S., Prosser, H., Costello, H., Simpson, N., Patel, P., Rowe, S., ... Hatton, C. (I998). Reliability and validity of the PAS-ADD Checklist for detecting psychiatric disorders in adults with intellectual disabilities. Journal of Intellectual Disability Research, 42, I73-I83.

Nicholls, R. D., Knoll, J. H. M., Butler, M. G., Karam, S., \& Lalande, M. (1989). Genetic imprinting suggested by maternal heterodisomy in nondeletion Prader-Willi syndrome. Nature, 342, 28I-285.

Nixon, G. M., \& Brouillette, R. T. (2002). Sleep and breathing in Prader-Willi syndrome. Pediatric Pulmonology, 34, 209-2I7.

O’Donoghue, F. J., Camfferman, D., Kennedy, J. D., Martin, A. J., Couper, T., Lack, L. D., ... McEvoy, R. D. (2005). Sleep-disordered breathing in Prader-Willi syndrome and its association with neurobehavioral abnormalities. Journal of Pediatrics, 147, 823-829.

Prader, A., Labhart, A., \& Willi, H. (I956). Ein Syndrom von Adipositas, Kleinwuchs, Kryptorchismus und Oligophrenie nach myatonieartigen Zustand im Neugeborenenalter [A syndrome of adipositas, dwarfism, maldescensus testis, mental deficiency following a condition with a lack of muscle tone as a newborn]. Schweizerische Medizinische Wochenschrift, 86, I260-126I. 
Richdale, A. L., Cotton, S., \& Hibbit, K. (1999). Sleep and behaviour disturbance in Prader-Willi syndrome: A questionnaire study. Journal of Intellectual Disability Research, 43, 380-392.

Shah, N., \& Roux, F. (2009). The relationship of obesity and obstructive sleep apnea. Clinics in Chest Medicine, 30, 455-465.

Soni, S., Whittington, J., Holland, A. J., Webb, T., Maina, E. N., Boer, H., \& Clarke, D. (2008). The phenomenology and diagnosis of psychiatric illness in people with Prader-Willi syndrome. Psychological Medicine, 38, I505-I5I4.

Vela-Bueno, A., Kales, A., Soldatos, C. R., Dobladez-Blanco, B., Campos-Castello, J., Espino-Hurtado, P., Olivan-Palacios, J. (I984). Sleep in the Prader-Willi syndrome. Archives of Neurology, 41, 294-296.

Weatherwax, K. J., Lin, X., Marzec, M. L., \& Malow, B. A. (2003). Obstructive sleep apnea in epilepsy patients: The Sleep Apnea scale of the Sleep Disorders Questionnaire (SA-SDQ) is a useful screening instrument for obstructive sleep apnea in a diseasespecific population. Sleep Medicine, 4, 5I7-52I.

Wiggs, L., \& Stores, G. (I996). Severe sleep disturbance and daytime challenging behaviour in children with severe learning disabilities. Journal of Intellectual Disability Research, 40, 518-528.

Wirz-Justice, A. (2007). Chronobiology and psychiatry. Sleep Medicine Reviews, 11, 423427.

Yee, B. J., Buchanan, P. R., Mahadev, S., Banerjee, D., Liu, P. Y., Phillips, C., ... Grunstein, R. R. (2007). Assessment of sleep and breathing in adults with Prader-Willi syndrome: A case control series. Journal of Clinical Sleep Medicine, 3, 713-718. 
CHAPTER 3.5

Scatter Plot Analysis of Excessive Daytime Sleepiness and Severe Disruptive Behaviour in Adults with Prader-Willi Syndrome: A Pilot Study

Maas, A. P. H. M., Didden, R., Bouts, L., Smits, M. G., \& Curfs, L. M. G. (2009). Research in Developmental Disabilities, 30, 529-537. 


\begin{abstract}
Individuals with Prader-Willi syndrome (PWS) are at risk for excessive daytime sleepiness (EDS) and disruptive behaviour. This pilot study explores temporal characteristics of EDS and severe disruptive behaviour across time of day and day of week in 7 individuals with PWS (aged between 33 and 49 years) of whom 5 were matched to controls. Direct care staff and/or parents used a scatter plot (i.e., 2-hr partial interval recording) to collect data during 28 successive days. Overall frequency of EDS and severe disruptive behaviour was low in both groups. Individuals with PWS generally showed more EDS when there were no scheduled activities compared to when activities were scheduled, specifically in the afternoon and in the evening and during the weekend. Scatter plot methodology may be useful in identifying situations that evoke EDS and severe disruptive behaviour in people with PWS.
\end{abstract}




\section{INTRODUCTION}

Prader-Willi syndrome (PWS) is a genetically determined neurodevelopmental disorder associated with abnormal or absent expression of the paternal copy of as yet unidentified maternally imprinted gene(s) at the genetic locus I5qII-qI3 (Cassidy, Dykens, \& Williams, 2000). PWS is characterised by four main features: hypotonia during infancy, hyperphagia, hypogonadism and developmental delay. Individuals with PWS usually function in the mild to moderate range of intellectual disability (ID), and they are at increased risk for mental health and behaviour problems. Skinpicking, compulsive behaviours, overeating, anxiety, food stealing, psychosis, mood disorders, temper tantrums and sleep disorders are common among individuals with PWS (Boer \& Clarke, I999; Didden, Korzilius, \& Curfs, 2007; Holland et al., 2003).

One of the typical features in many individuals with PWS is excessive daytime sleepiness (EDS). EDS is defined as sleepiness that interferes significantly with daytime functioning. Milder levels of daytime sleepiness involve sleepiness when in a comfortable setting or being drowsy with signs of sleepiness such as yawning and stretching (Stores, 200I). Daytime sleepiness may have negative effects on performance at school or work, cognitive functioning and mood and is associated with adverse consequences such as accidents. Among individuals with PWS, EDS may be related to severe disruptive behaviour. For example, Richdale, Cotton and Hibbit (I999) found that daytime sleepiness in children with PWS was associated with severe behaviour disturbance during the day.

Information on EDS in individuals with PWS is most often obtained by indirect observation, e.g., parent reports, the Epworth Sleepiness Scale (Johns, I99I) or other questionnaires (Clarke, Waters, \& Corbett, I989; Greenswag, I987; Richdale et al., I999). Also, more objective measures have been employed, such as polysomnography and Multiple Sleep Latency Test (MSLT) (for a review, see Camfferman, McEvoy, O’Donoghue, \& Lushington, 2008). In studies using parent reports and questionnaires EDS was found in 90 to nearly Io०\% of adults with PWS (Clarke et al., I989; Greenswag, I987). Results of studies using MSLT indicate that about 40 to $50 \%$ of adults with PWS had severe sleepiness (mean MSLT score $<5 \mathrm{~min}$ ) and about 70 to Io०\% had moderate to severe sleepiness (mean MSLT score < Io min) (Clift, Dahlitz, \& Parkes, I994; Hertz, Cataletto, Feinsilver, \& Angulo, I993; Manni et al., 200I). Results of MSLT studies are limited by relatively small samples consisting of both children and adults with PWS. Furthermore, participants of MSLT studies frequently are specifically selected for having a clinical history of sleep apnoea or EDS.

None of the above studies provide information on the temporal distribution of EDS. Behavioural problems in individuals with ID may be highly correlated with 
time of day or day of week (Touchette, MacDonald, \& Langer, 1985). Touchette et al. (I985) have developed a scatter plot, an observation tool to explore time-correlated patterns of responding in natural settings. A scatter plot is a grid with fixed time intervals within and across days (Kahng et al., I998). Observers record occurrences of behaviour within these intervals across successive days. In most studies, observers (i.e., direct care staff, teachers or parents) are instructed to record actual frequencies or durations of behavioural problems following each 30-min interval. The scatter plot has been used with various types of behavioural problems, such as self-injury, aggression, property destruction and disruption (English \& Anderson, 2004; Symons, McDonald, \& Wehby, I998; Touchette et al., 1985).

Until now, there have been no published data on temporal distribution of EDS, not in individuals of the general population, nor in individuals with PWS. Although prevalence studies generally have reported high rates of EDS in individuals with PWS little is known about its temporal distribution. Monotonous situations or situations in which individuals are unoccupied, that is situations in which no activities are scheduled, may act as setting event for EDS. A setting event is a variable that alters the relationship between an antecedent, the behavioural problems, and its maintaining consequence (McGill, 1999). Clarke et al. (1989) found that travelling by car and watching television frequently preceded daytime sleep in adults with PWS. In addition Whittington and Holland (2004) report that some participants with PWS fell asleep during a cognitive assessment test. They mention that individuals with PWS easily fall asleep, particularly when he or she is bored or when in a situation he or she does not like. Despite these indications for setting events it remains unclear at what time of day and/or day of week EDS is most (or least) likely to occur. This holds also true for daytime disruptive behaviour in individuals with PWS. As stated above, disruptive behaviour (aggressive outbursts, noncompliance and skin-picking) is common in people with PWS and it is not always clear what evokes this behaviour (see e.g., Whittington \& Holland, 2004). Furthermore, it remains unclear if severe disruptive behaviour is correlated with EDS. Clarke et al. report that temper tantrums were not associated with EDS in adults and Richdale et al. (I999) found an association between severe behaviour disturbance and daytime sleepiness in children with PWS.

This is a pilot study that uses scatter plot analysis to explore the temporal distribution of EDS and severe disruptive behaviour in 7 adults with PWS compared to a control group consisting of 5 matched controls with non-specific ID. It was expected that adults with PWS would show EDS and severe disruptive behaviour on several days during the study period of 28 days. In case adults from the control group would show EDS or severe disruptive behaviour, adults with PWS would exhibit more frequent levels. 


\section{METHOD}

\section{Participants and Setting}

Scatter plots were completed for 7 individuals (4 males, 3 females) with genetically confirmed PWS aged between 33 and 49 years $(M=39.9)$. Five individuals lived in a residential facility, one lived in a community group home and one person lived with his parents. Level of ID was moderate in three individuals, mild in three individuals and borderline in one individual. Five individuals were overweight and two had normal weight. Body mass indices $\left(\mathrm{BMI} ; \mathrm{kg} / \mathrm{m}^{2}\right)$ varied between 24.8 and $42.0(M=33.8)$. Those who lived in a residential facility were matched to controls on age, gender, level of ID, BMI, number and type of daytime activities and living environment. The control group consisted of I male and 4 females aged between 22 and 53 years $(M=42.6)$. Level of ID was moderate in two individuals, mild in two individuals and level of ID in one individual was estimated to be in the mild to moderate range. Their BMIs varied between I8.4 and 31.9 $(M=26.0)$. Individuals from the control group had no known genetic disorder or epilepsy and did not use medication that may have an effect on daytime sleepiness and functioning. The control group did not differ significantly from the group with PWS living in a residential facility on variables of gender, and level of ID ( $\alpha^{2}$ analyses). Mean age of individuals with PWS (Mrank $=4.60$ ) and the control group (Mrank $=6.40$ ) did not significantly differ, $z=-0.94, p=.35$. Mean BMI of individuals with PWS (Mrank $=6.20)$ and the control group (Mrank $=3.50$ ) also did not significantly differ, $z=-$ I.47, $p=$. I4 .

\section{MATERIALS}

Due to practical constraints, we used intervals of $2 \mathrm{hr}$. Data were collected using observation logs with a 2-hr interval data sheet for the target behaviours 'Sleepiness' and 'Disruptive behaviour'. Level of sleepiness could be rated as 'o' (Not sleepy), 'I' (Somewhat sleepy), and ' 2 ' (Very sleepy, asleep). The following operational definitions were in effect: 'Not sleepy' (o): participant shows no signs of sleep or sleepiness, 'Somewhat sleepy' (I): participant blinks and has trouble keeping his/her eyes open, participant yawns, participant is a bit drowsy, stares, and 'Very sleepy' (2): participant starts nodding, his/her eyes are closing, participant sleeps. A score of ' 2 ' was chosen to reflect EDS.

Level of disruptive behaviour could be rated as 'o' (No disruptive behaviour), 'I' (Some disruptive behaviour), and ' 2 ' (Severe disruptive behaviour). Three levels of disruptive behaviour were distinguished: 'No disruptive behaviour' (o): participants behaviour does not cause problems, 'Some disruptive behaviour' (I): participants behaviour hardly causes problems, and 'Severe disruptive behaviour' (2): participants behaviour causes severe problems. Examples of disruptive behaviour in individuals with PWS are: verbal and/or physical aggression, irritation and self-injury (e.g., skin-picking). 
For each interval, levels of sleepiness and disruptive behaviour were rated for two different situations: (a) activities, and (b) no activities. This was done to explore differences in terms of percentages of intervals with EDS between scheduled activities and no activities.

\section{Procedure}

Data were collected by direct care staff and/or parents during 28 successive days. Daily observations lasted from 9:०० a.m. to 9:०० p.m., yielding a total of 6 intervals per day. After each interval the staff member or parent, who was present during the whole interval, rated the level of sleepiness and disruptive behaviour for this interval. Partial interval recording was used to collect data on sleepiness and disruptive behaviour.

Parents and relatives of all participants were informed about the study as were direct care staff from the group home and the day activity centre. Prior to data collection, observation logs were discussed with all direct care staff and participating parents. Agreement was reached on the definition and scoring of (levels of) sleepiness and disruptive behaviour. These definitions were included in the observation log. Participants were not informed on the specific aim of the study. Throughout the study, no changes were made in the daily activities of the participants.

\section{RELIABILITY}

Estimates of interobserver reliability for sleepiness and disruptive behaviour were based on scores of two staff members or two parents. During reliability intervals, observers independently scored separate observation logs. They were never informed about the level of reliability. Interobserver reliability of recording was assessed on an interval-by-interval basis. An interval was scored as an (exact) agreement if both observers recorded sleepiness or disruptive behaviour at the same level ('o', ' $I$ ' or ' 2 '). Reliability was calculated by dividing the number of agreements by the number of agreements plus disagreements, multiplied by 100 . Reliability data were collected in $19 \%$ of all intervals across participants. Mean percentage of agreement across participants was $89 \%$ (range: 78-Ioo) and $\alpha=.64$. This indicates good interobserver agreement.

\section{Data Analysis}

For each participant data from sheets were plotted into two separate scatter plot grids, one for daytime sleepiness and one for disruptive behaviour. Vertically, the grid segments time of day in 2-hr blocks were subdivided in 'Activities' and 'No activities'. Horizontal segments of the grid represent successive days. A blank cell represents a 'o' score, a half filled cell a ' $\mathrm{I}$ ' score and filled cells a ' 2 ' score.

Group plots were made to compare the results from individuals with PWS with individuals from the control group. Values for each interval rated with score ' 2 ' were 
summed across time of day and across day of week. The values were plotted on conventional line graphs. Separate plots were made for EDS and severe disruptive behaviour, time of day and day of week and activities scheduled and no activities scheduled. Group plots were made using the General Linear Model (GLM) Repeated Measures procedure in SPSS (version I2.0).

\section{RESULTS}

\section{Excessive Daytime Sleepiness}

All participants with PWS showed EDS ( $M=5.9$ days with EDS, range: 2 -I3 days with EDS). Overall mean percentage of intervals with EDS was 4.0 ( $S D=3.3$, range: I.०-9.I). Three participants from the control group showed EDS $(M=5.7$ days with EDS, range: I-II days with EDS) and two did not show EDS during the course of this study. Overall mean percentage of intervals with EDS was $3.2(S D=3.9$, range: 0-9.5). During intervals in which activities were scheduled the mean percentage of intervals with EDS for individuals with PWS was 2.7 ( $S D=3.2$, range: 0-9.2), compared to 5.5 ( $S D=3.9$, range: 1.8 -12.2) when no activities were scheduled. For controls, means were $3.2 \%(S D=3.8$, range: $0-9.3)$ and $3.2(S D=4.0$, range: $0-9.7)$, respectively.

Visual inspection of Figure I shows that mean occurrence of EDS after 3:00 p.m. is somewhat higher than prior to 3:00 p.m. in individuals with PWS (as compared to controls), when no activities are scheduled. It appears that individuals with PWS show more EDS than controls when no activities are scheduled between 3:00 p.m. and 9:०० p.m.

Data in Figure 2 suggest that the mean percentage of intervals with EDS was relatively high on Saturdays and when no activities were scheduled, particularly for PWS.

\section{Severe Disruptive Behaviour}

Four participants with PWS showed severe disruptive behaviour ( $M=5.5$ days with severe disruptive behaviour, range: 3-9 days with severe disruptive behaviour) and three participants with PWS did not show severe disruptive behaviour during the course of this study. Overall mean percentage of intervals with severe disruptive behaviour was $2.6(S D=2.9$, range: $0-6.5)$. Two participants from the control group showed severe disruptive behaviour (on I and 6 days respectively) and three individuals did not show severe disruptive behaviour during the course of this study. Overall mean percentage of intervals with severe disruptive behaviour was I.2 (SD = 2.3, range: 0-5.3). During intervals in which activities were scheduled the mean percentage of intervals with severe disruptive behaviour for individuals with PWS was 2.8 ( $S D=3.0$, range: 0-6.7), compared to $2.4(S D=2.9$, range: $0-6.3)$ when no activities were scheduled. For controls, 
No activities scheduled

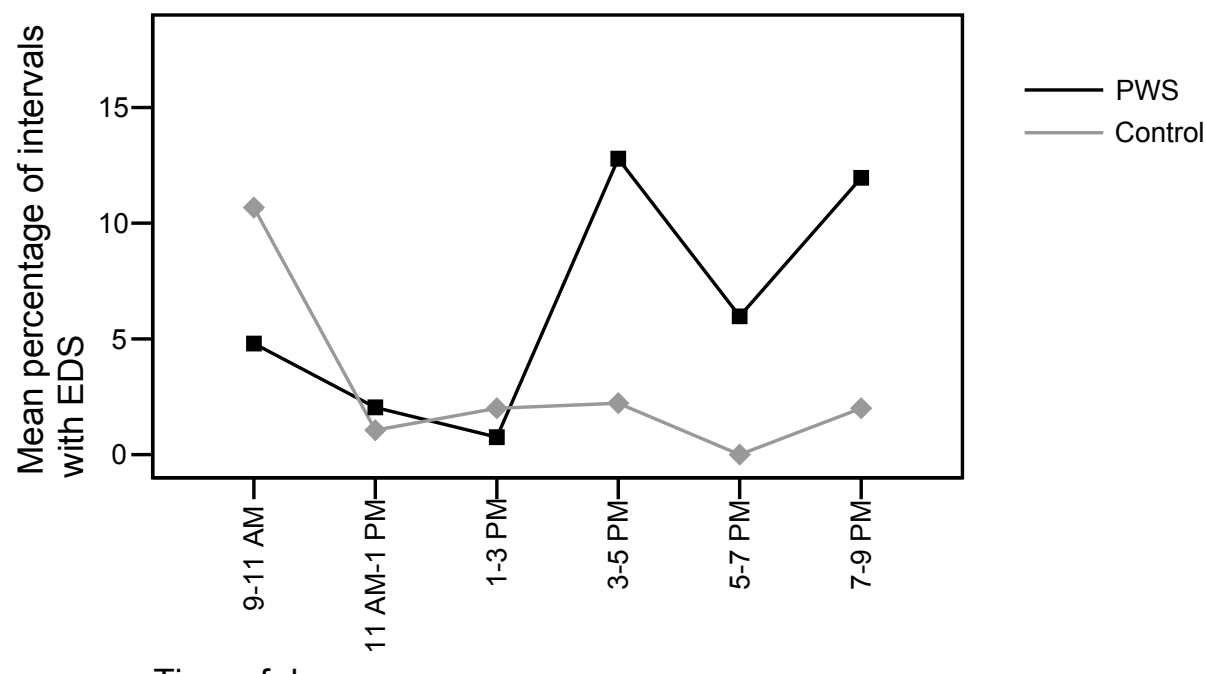

Time of day

Activities scheduled

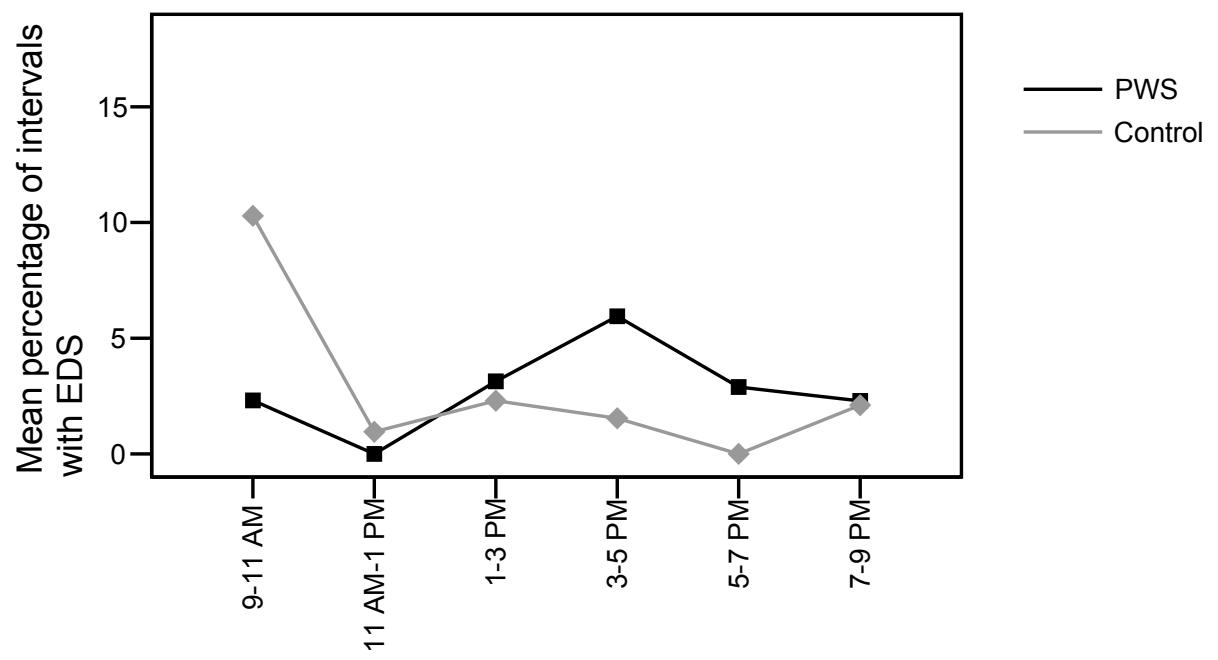

Time of day

Figure 1. Mean percentage of intervals with excessive daytime sleepiness across time of day for individuals with Prader-Willi syndrome and controls. 
No activities scheduled

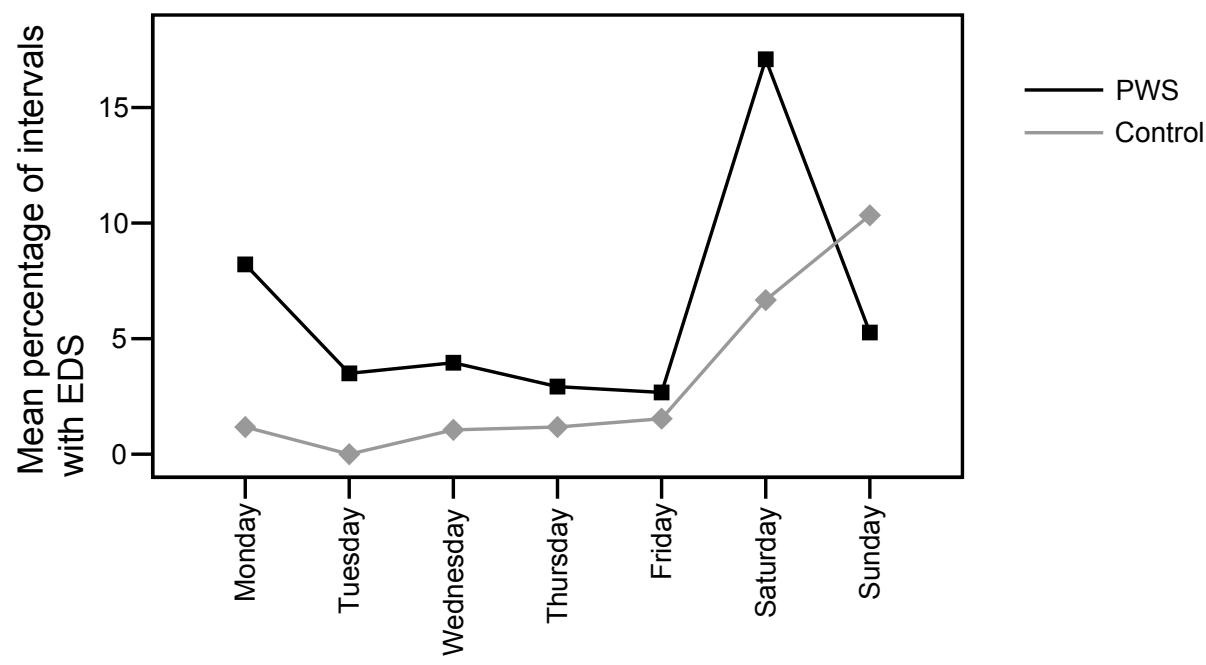

Day of week

Activities scheduled

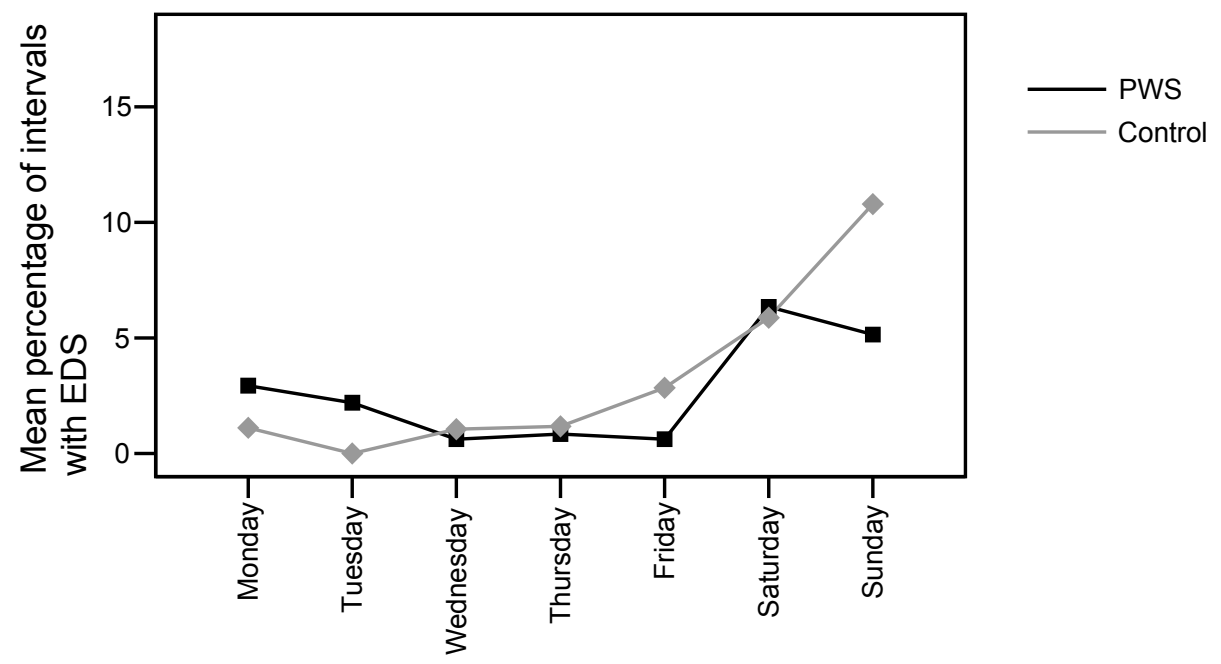

Day of week

Figure 2. Mean percentage of intervals with excessive daytime sleepiness across day of week for individuals with Prader-Willi syndrome and controls. 
No activities scheduled

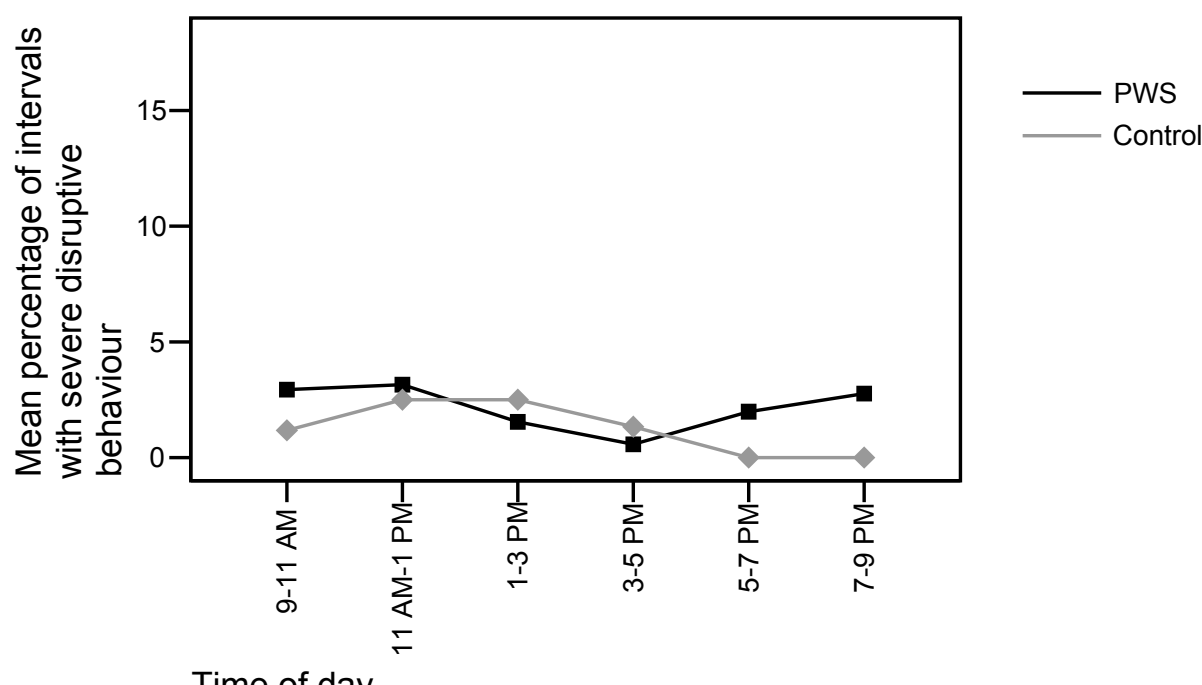

Activities scheduled

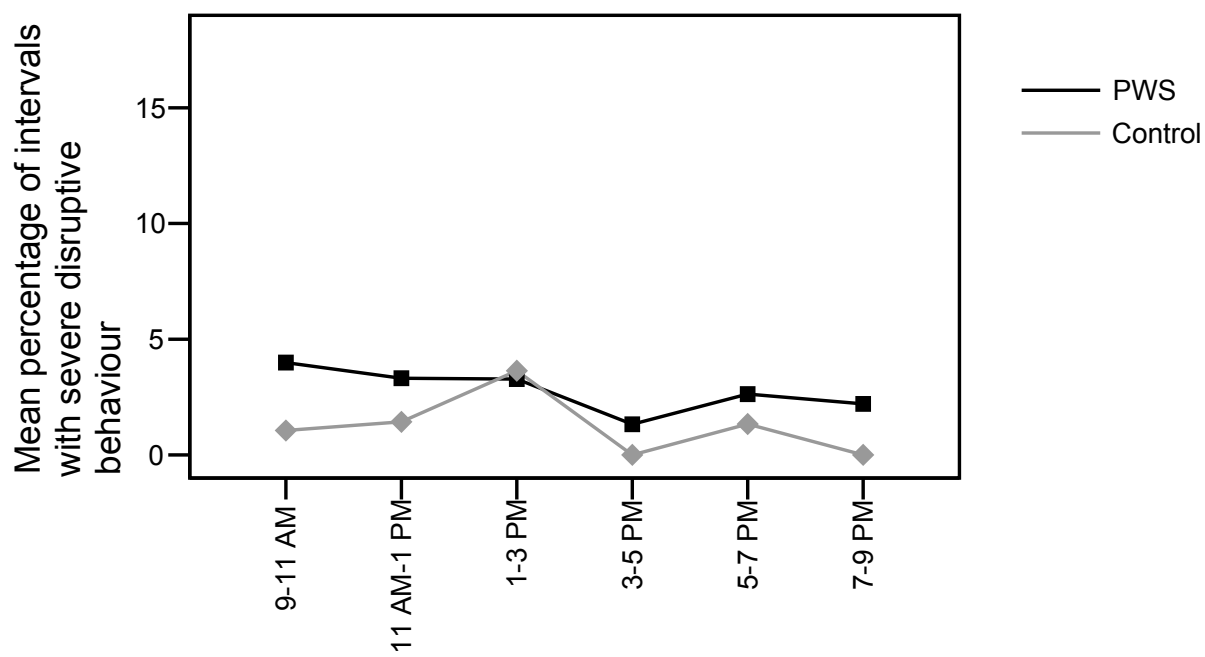

Time of day

Figure 3. Mean percentage of intervals with severe disruptive behaviour across time of day for individuals with Prader-Willi syndrome and controls. 
No activities scheduled

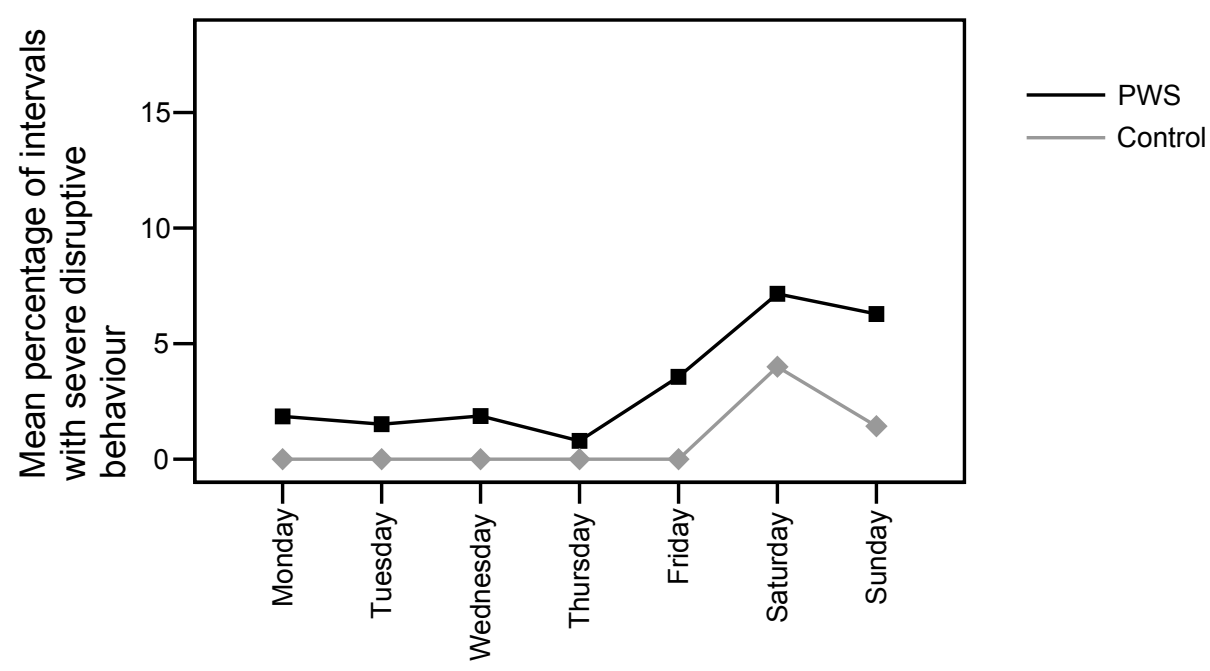

Day of week

Activities scheduled

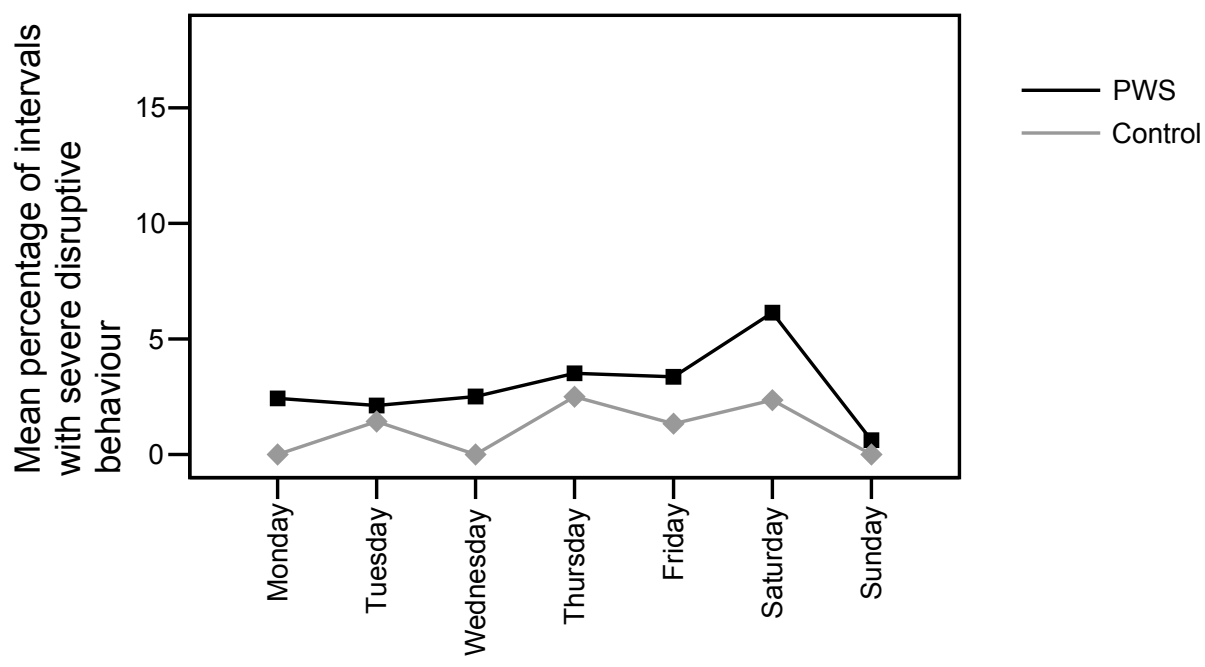

Day of week

Figure 4. Mean percentage of intervals with severe disruptive behaviour across day of week for individuals with Prader-Willi syndrome and controls. 
means were I.2\% ( $S D=2.7$, range: 0-6.0) and I.I\% ( $S D=$ I.9, range: 0-4.4), respectively.

Visual inspection of Figure 3 suggests that levels of severe disruptive behaviour across time of day were low and stable for both PWS and controls. Data in Figure 4 suggest that severe disruptive behaviour was relatively high during the weekend compared to during the other days of the week when no activities were scheduled (both groups). Differences between weekend days and other days of the week were less pronounced when activities were scheduled (both groups) than when no activities were scheduled.

In both groups and in both situations (activities vs. no activities) overall levels of EDS and severe disruptive behaviour were low. Due to these low frequencies and the small number of participants it was not possible to test for differences between individuals with PWS and controls.

\section{DISCUSSION}

This is the first study to explore the temporal distribution of EDS and severe disruptive behaviour in individuals with PWS. We used a scatter plot to explore patterns of EDS and severe disruptive behaviour. Individuals with PWS generally showed more EDS when there were no scheduled activities compared to when activities were scheduled, specifically in the afternoon and in the evening and on Saturdays. Lack of structured activities may act as an setting event for EDS. Our findings are in agreement with anecdotal reports mentioning that situations in which adults with PWS were not actively stimulated preceded daytime sleep (Whittington \& Holland, 2004). Overall frequency of EDS and severe disruptive behaviour in adults with PWS was low. This is not in agreement with other reports showing high rates of EDS and severe disruptive behaviour in adults with PWS (Clarke et al., I989; Didden et al., 2007; Greenswag, I987; Holland et al., 2003; Richdale et al., I999). An explanation for this might be differences in both definition and measurement of EDS and severe disruptive behaviour. In the present study, sleepiness and disruptive behaviour were distinguished from excessive sleepiness and severe disruptive behaviour. Six intervals a day were scored for both activities and no activities. If all intervals of one day were taken into account, on average of 5 to 6 days a month an episode of EDS was recorded in individuals with PWS. Compared to results of objective MSLT studies levels of EDS in our study were low (Clift et al., I994; Hertz et al., I993; Manni et al., 200I). The present study was performed in the natural setting and no manipulations were made. This is in contrast with MSLT studies in which the participants are asked to lie down and try to fall asleep. Furthermore, in the present study no selection criteria regarding clinical history of EDS or sleep apnoea were employed while MSLT studies often use highly selected participants. 
Until now, the origins of EDS in PWS remain unclear (Didden, Braam, De Weerd, Smits, \& Curfs, 2006). Camfferman et al. (2008) concluded in their review of EDS in PWS that Obstructive Sleep Apnoea Syndrome (OSAS) is not likely to fully explain EDS and concluded that other factors, including hypothalamic dysfunction are likely to contribute to EDS in individuals with PWS. The relationship between obesitas and EDS in PWS remains unclear. Camfferman et al. stated that in individual cases obesitas might contribute to EDS in individuals with PWS. The relationship between OSAS and EDS is partly supported by positive results on EDS of treatment with continuous positive airway pressure (CPAP; specific treatment for OSAS) in individual cases with PWS. For individuals with PWS and a history of EDS a sleep study (polysomnography) is recommended. Based on results of this sleep study an individual treatment plan of EDS is made. This may consist of treatment of extreme obesitas, treatment of sleep apnoea and/or sleep hygiene measures (regular bedtimes and get up times, etc.). Until recently, there were no reports of trials of treatment with modafinil (a drug prescribed in treatment of narcolepsy and EDS) in individuals with PWS (Eiholzer \& Lee, 2006).

A limitation of the present study was the use of a relatively large interval. Kahng et al. (I998) mention that using small samples of intervals leads to the problem of not finding outliers. In addition our 2 -hr interval length is relatively long compared to the $30 \mathrm{~min}$ - or I-hr-intervals that have been used in other studies (English \& Anderson, 2004; Kahng et al., I998; Symons et al., I998; Touchette et al., I985). Because of practical constraints and because data were collected over a relatively long period, a longer time interval was chosen. In the clinical settings were the present study was conducted it was not possible to use shorter intervals due to limited resources (e.g., availability of staff or research assistants). Another limitation was the small number of participants in both groups. Therefore, it was not possible to statistically test differences between participants with PWS and controls and for situations (activities vs. no activities).

In future studies, smaller time intervals and more participants would enable researchers to test for differences in temporal distributions of EDS and disruptive behaviour both within individuals with PWS and compared to controls. Furthermore, we recommend that investigators record duration of EDS and severe disruptive behaviour. Clarke et al. (I989) reported that daytime sleep episodes in adults with PWS ranged from 5 to $180 \mathrm{~min}$. To enable more careful observations nature and duration of different activities must be recorded in observation logs. The nature of the activity in itself may have a positive or negative effect on the occurrence of EDS and/or severe disruptive behaviour (see e.g., Whittington \& Holland, 2004). A possible result of more careful observations may be the identification of relationships between the diagnosis PWS and situations that have an increased risk for EDS and severe disruptive behaviour (setting events). Therapeutically, the occurrence of such behaviours may be changed by altering 
the situation that evokes and maintains sleepiness and disruption (i.e., antecedent control) (see e.g., Didden, 2007; Didden et al., 2007). This behavioural treatment can be supported by medical treatment of EDS in individuals with PWS in case behavioural treatment alone remains ineffective.

Despite methodological shortcomings, the present study extends the literature on EDS in individuals with PWS. While studies have found these individuals to be at risk for EDS no studies have been published on its temporal characteristics. Using the scatter plot, one may identify situations in which levels of daytime sleepiness are elevated. The findings of this study suggest that EDS in individuals with PWS is more likely to occur in situations in which no activities are scheduled, specifically in the afternoon and evenings. Future such studies may provide a more detailed picture of EDS in PWS and explore ways how to best manage EDS as to improve quality of life for these individuals. 


\section{REFERENCES}

Boer, H., \& Clarke, D. (I999). Development and behaviour in genetic syndromes: PraderWilli syndrome. Journal of Applied Research in Intellectual Disabilities, 12, 294-30I.

Camfferman, D., McEvoy, R. D., O’Donoghue, F., \& Lushington, K. (2008). Prader Willi Syndrome and excessive daytime sleepiness. Sleep Medicine Reviews, 12, 65-75.

Cassidy, S. B., Dykens, E., \& Williams, C. A. (2000). Prader-Willi and Angelman syndromes: Sister imprinted disorders. American Journal of Medical Genetics, 97, I36-I46.

Clarke, D. J., Waters, J., \& Corbett, J. A. (I989). Adults with Prader-Willi syndrome: Abonormalities of sleep and behaviour. Journal of the Royal Society of Medicine, 82, 2I-24.

Clift, S., Dahlitz, M., \& Parkes, J. D. (I994). Sleep apnoea in the Prader-Willi syndrome. Journal of Sleep Research, 3, I2I-I26.

Didden, R. (2007). Functional analysis methodology in developmental disabilities. In P. Sturmey (Ed.), Functional analysis in clinical treatment (pp. 65-86). New York, NY: Academic Press.

Didden, R., Braam, W., Weerd, A. de, Smits, M., \& Curfs, L. (2006). Sleep and sleep problems in Angelman syndrome and Prader-Willi syndrome. In J. F. Engels (Ed.), Focus on birth defects research (pp. 81-104). Hauppauge, NY: Nova Science.

Didden, R., Korzilius, H., \& Curfs, L. M. G. (2007). Skin-picking in individuals with Prader-Willi syndrome: Prevalence, functional assessment and its comorbidity with compulsive and self-injurious behaviours. Journal of Applied Research in Intellectual Disabilities, 20, 409-4I9.

Eiholzer, U., \& Lee, P. D. K, (2006). Medical considerations in PWS. In M. G. Butler, P. D. K. Lee \& B. Y. Whitman (Eds.), Management of Prader-Willi syndrome (pp. 97- I52). New York, NY: Springer.

English, C. L., \& Anderson, C. M. (2004). Effects of familiar versus unfamiliar therapists on responding in the analog functional analysis. Research in Developmental Disabilities, 25, 39-55.

Greenswag, L. R. (I987). Adults with Prader-Willi syndrome: A survey of 232 cases. Developmental Medicine a Child Neurology, 29, I45-I52.

Hertz, G., Cataletto, M., Feinsilver, S. H., \& Angulo, M. (I993). Sleep and breathing patterns in patients with Prader Willi syndrome (PWS): Effects of age and gender. Sleep, 16, 366-37i.

Holland, A. J., Whittington, J. E., Butler, J., Webb, T., Boer, H., \& Clarke, D. (2003). Behavioural phenotypes associated with specific genetic disorders: Evidence from a polulation-based study of people with Prader-Willi syndrome. Psychological Medicine, 33, I4I-I53. 
Johns, M. W. (I99I). A new method for measuring daytime sleepiness: The Epworth Sleepiness Scale. Sleep, 14, 540-545.

Kahng, S. W., Iwata, B. A., Fischer, S. M., Page, T. J., Treadwell, K. R. H., Williams, D. E., \& Smith, R. G. (1998). Temporal distributions of problem behavior based on scatter plot analysis. Journal of Applied Behavior Analysis, 31, 593-604.

Manni, R., Politini, L., Nobili, L., Ferrillo, F., Livieri, C., Veneselli, E., ... Tartara, A. (200I). Hypersomnia in the Prader-Willi syndrome: Clinical-electropysiological features and underlying factors. Clinical Neurophysiology, 112, 800-805.

McGill, P. (1999). Establishing operations: Implications for the assessment, treatment, and prevention of problem behavior. Journal of Applied Behavior Analysis, 32, 393-4I8.

Richdale, A. L., Cotton, S., \& Hibbit, K. (1999). Sleep and behaviour disturbance in Prader-Willi syndrome: A questionnaire study. Journal of Intellectual Disability Research, 43, 380-392.

Stores, G. (200I). Excessive sleepiness. In G. Stores \& L. Wiggs (Eds.), Sleep disturbance in children and adolescents with disorders of development: Its significance and management (pp. 30-37). London, England: Mac Keith Press.

Symons, F. J., McDonald, L. M., \& Wehby, J. H. (1998). Functional assessment and teacher collected data. Education \& Treatment of Children, 21, I35-I59.

Touchette, P. E., MacDonald, R. F., \& Langer, S. N. (1985). A scatter plot for identifying stimulus control of problem behavior. Journal of Applied Behavior Analysis, 18, 343-35I.

Whittington, J., \& Holland, T. (2004). Prader-Willi Syndrome: Development and manifestations. Cambridge, England: Cambridge University Press. 
CHAPTER 4

General Discussion 
Chapter 4 


\section{INTRODUCTION}

The aim of this thesis is to contribute to sleep phenotyping of genetic syndromes. In Part I of this thesis, we have shown that part four of the Sleep Questionnaire (SQ-SP; Simonds \& Parraga, I982) adapted by Wiggs and Stores (I996) is a reliable and valid tool in the assessment of sleep and different types of sleep disturbance in individuals with intellectual disability (ID). In Part 2 of this thesis, we have described the results on the prevalence and associations of sleep problems in individuals with three genetic syndromes. The SQ-SP was used to assess the prevalence of sleep problems and variables that might be associated with sleep problems in Jacobsen syndrome (JS) and Cri du Chat syndrome (CDC). Standardised questionnaires and direct observations were used to assess sleep problems and behavioural problems in adults with Prader-Willi syndrome (PWS).

In this general discussion, the use of SQ-SP in the assessment of prevalence of sleep problems in individuals with ID will be placed in a broader perspective. The results of the studies in three genetic syndromes will also be addressed. Next, the methodological considerations and clinical implications will be discussed. Finally, we will describe considerations for future sleep research in genetic syndromes.

\section{ASSESSMENT OF PREVALENCE OF SLEEP PROBLEMS IN INDIVIDUALS WITH INTELLECTUAL DISABILITY USING A SLEEP QUESTIONNAIRE}

In order to assess the prevalence of sleep problems in individuals with ID, various sleep questionnaires and different definitions of a sleep problem have been used across studies (Didden \& Sigafoos, 200I; Van de Wouw, Evenhuis, \& Echteld, 20I2). It should be noted that the psychometric properties of these sleep questionnaires in individuals with ID have not been assessed and remain unknown. In addition, about half of the studies did not use standardised sleep questionnaires and as a result, they solely provided information on sleep problems (e.g., settling problems, night waking), and not on the different types of sleep disturbance that are subdivided in six broad categories of sleep disorders (e.g., Sleep Related Breathing Disorders, Circadian Rhythm Sleep Disorders, Sleep Related Movement Disorders) in the International Classification of Sleep Disorders 2nd edition (ICSD-2) of the American Academy of Sleep Medicine (AASM; 2005).

The SQ-SP (Simonds \& Parraga, I982) is a standardised sleep questionnaire that was adapted for use in individuals with ID by Wiggs and Stores (I996) and has been used frequently in sleep studies in individuals with ID and in individuals with a genetic 
syndrome. However, the psychometric properties of the SQ-SP have not been examined well in samples of individuals with ID. Furthermore, there was no statistical underpinning of the different types of sleep disturbance in part four of the SQ-SP. Therefore, we investigated the psychometric properties including the factor structure of part four of the SQ-SP in the study described in Chapter 2. The SQ-SP appeared to be a reliable and valid tool in the assessment of sleep and different types of sleep disturbance in individuals with ID. Exploratory factor analysis revealed five factors, namely Snoring, Daytime sleepiness, Complaints related to sleep, Sleep apnoea, and Anxiety related to sleep. The five factors do not match the six broad categories of sleep disorders of the ICSD-2 (AASM, 2005) exactly. The SQ-SP provides a general screening for types of sleep disturbance and it is not possible to make a diagnosis of a sleep disorder based on the SQ-SP solely.

\section{Presenting Data on Prevalence of Sleep Problems}

Besides the SQ-SP, two other standardised sleep questionnaires have been used frequently in the last 5 years in sleep studies in individuals with ID: the Children's Sleep Habits Questionnaire (CSHQ; Owens, Spirito, \& McGuinn, 2000) and the Sleep Disturbance Scale for Children (SDSC; Bruni et al., I996) (see e.g., Hartshorne et al., 2009; MacCrosain \& Byrne, 2009). In studies using standardised sleep questionnaires in individuals with ID, data on the prevalence of sleep problems have been presented in several ways. In studies using the SQ-SP, the prevalence of sleep problems has been determined on the basis of either the definition of a sleep problem by Wiggs and Stores (1996) or individual items describing behaviours related to sleep. In studies using the CSHQ and the SDSC, the prevalence of sleep problems has been determined on the basis of either a cut-off score on the total score of the sleep questionnaire or individual items describing behaviours related to sleep. This raises the question of which measure (definition of a sleep problem, individual items, or total score on a standardised sleep questionnaire) should be used to present data on the prevalence of sleep problems in individuals with ID.

Information that enables researchers to define a sleep problem (Wiggs \& Stores, I996) can be derived from the SQ-SP. However, it seems to be impossible to derive solid information from the CSHQ or SDSC, because the frequency of occurrence and duration (e.g., sleep latency) of behaviours related to sleep that are used in the CSHQ and the SDSC do not fit into the criteria of the definition of a sleep problem established by Wiggs and Stores (1996). In addition, it is important to note that this definition of a sleep problem is restricted to complaints of insomnia and does not provide information regarding complaints of excessive sleepiness and parasomnias. In order to present data on complaints of excessive sleepiness and parasomnias, the prevalence of a number of individual behaviours related to sleep describing parasomnias (such as 'grinds teeth', 'bangs head in sleep', or 'wets bed') and excessive sleepiness ('daytime sleepiness') should be described in addition to the 
prevalence of sleep problems based on the definition of a sleep problem (Wiggs \& Stores, I996). Individual items from the CSHQ, the SDSC, and part four of the SQ-SP can provide information that enables researchers to describe complaints of parasomnias and excessive sleepiness.

The total score on the CSHQ and the SDSC is calculated by summing up the individual items of the questionnaire. It is possible to calculate a total score on the SQ-SP by summing the individual items of part four of SQ-SP. However, the total score on the CSHQ, SDSC, and SQ-SP reflects the frequency of occurrence of several behaviours related to sleep, but not the presenting sleep problems. A high total score on one of the three standardised sleep questionnaires reflects the occurrence of multiple behaviours related to sleep that are indicative of one or more underlying sleep disorders, but does not reflect the sleep problems. In other words, an individual may exhibit severe sleep problems despite a nonclinical total score on a standardised sleep questionnaire or the other way around. So, presenting data on prevalence of sleep problems derived from total scores does not provide us with appropriate information on the prevalence of presenting sleep problems.

Therefore, in the studies described in Part 2 of this thesis, we provided prevalence data on sleep problems collected with the SQ-SP using the definition of a sleep problem by Wiggs and Stores (1996) and in addition we provided data on individual items describing behaviours related to sleep.

\section{Presenting Data on Types of Sleep Disturbance}

Besides the prevalence of sleep problems, additional data on types of sleep disturbance or sleep disorder should be provided in prevalence studies. For treatment purposes it is necessary to identify the underlying cause of the sleep problem, i.e., the sleep disorder (Stores \& Stores, 2013a; Wiggs, 2007). Therefore, data on subscales of the standardised sleep questionnaires should be presented and it is important to report on which subscales scores are elevated compared with a control group or within the group under research. Since subscale scores provide information on different types of sleep disturbance while a total score does not, presenting total scores on a standardised sleep questionnaire seems less important. Therefore, in the studies described in Part 2 of this thesis, we provided data on types of sleep disturbance as collected with the SQ-SP.

\section{PREVALENCE AND ASSOCIATIONS OF SLEEP PROBLEMS IN INDIVIDUALS WITH THREE GENETIC SYNDROMES}

The first aim of the studies described in Part 2 of this thesis was to assess the prevalence and associations of sleep problems in individuals with JS, individuals with 
CDC and adults with PWS. The second aim was to investigate whether syndromespecific sleep problems or types of sleep disturbance were present in these three genetic syndromes. In order to investigate whether characteristics of sleep were syndromespecific, we used a control group with individuals with NS since we aimed to prevent aetiology of ID with specific sleep disorders (for instance Smith-Magenis syndrome [SMS] and Angelman syndrome [AS]) from confounding the data. In two studies (see Chapter 3.2 and Chapter 3.3) we used an additional control group with Down syndrome (DS) because the sleep phenotype of DS has already been described in detail in the scientific literature (e.g., Stores, Stores, \& Buckley, I996). As recommended by Horsler and Oliver (2006), we matched the control groups on age and level of cognitive functioning. In adults with PWS, we also explored within syndrome variability in sleep disturbances by comparing the two most prevalent genetic subtypes of PWS (i.e., paternal deletion and maternal uniparental disomy).

\section{JACOBSEN SYNDROME}

According to the definition of a sleep problem (Wiggs \& Stores, I996), Io of the 43 individuals with JS $(23 \%)$ had sleep problems, which consisted of settling problems $(n=2,4 \%)$, night waking $(n=7,16 \%)$, and early waking $(n=2,6 \%)$. Five of 30 individuals with JS (20\%) had severe sleep problems according to the CSI (Wiggs \& Stores, I998). In comparison with CDC, DS, and NS, prevalence of severe sleep problems is elevated in JS, but the difference is not statistically significant. This is an indication that sleep problems are not specific to individuals with JS. However, twentyfive individuals $(60 \%)$ were reported to have restless sleep. This behaviour is part of the factor Complaints related to sleep on the SQ-SP. Closer inspection of this factor and comparison with individuals with CDC, DS, and NS, revealed that restless sleep, quick movements of arms or legs, and startles or jerks with part of the body while asleep are characteristic sleep features in JS. As in CDC and DS, snoring was the most prevalent type of sleep disturbance in JS. Furthermore, frequent coughs were found to be associated with sleep problems in individuals with JS. It remains unknown whether sleep-related movements observed in individuals with JS interfere with sleep or not. Further studies using objective measures, such as audiovisual recordings should be conducted to investigate the nature, timing, and duration of the reported sleep-related movements in individuals with JS.

\section{Cri du Chat Syndrome}

According to the definition of a sleep problem (Wiggs \& Stores, I996) 9 of the 30 individuals with CDC $(30 \%)$ had sleep problems. These consisted of night waking $(n=9,30 \%)$, and early waking $(n=2,6 \%)$. No settling problems were found in this 
sample, which is in contrast with the findings of Cornish, Oliver, Standen, Bramble, and Collins (2003) who reported settling problems in $25 \%$ of their sample. Three of 30 individuals with CDC (12\%) had severe sleep problems according to the CSI (Wiggs \& Stores, I998). The same rate was found in NS and a lower rate was found in DS, but this difference was not statistically significant. This is an indication that sleep problems are not specific to individuals with CDC. However, thirteen individuals with CDC (43\%) were reported to snore loudly during sleep. This behaviour is part of the factor Snoring on the SQ-SP. As in JS and DS, snoring was the most prevalent type of sleep disturbance in CDC. Because of low frequencies of medical problems and the small sample sizes no analyses were performed to test for differences in sleep-related variables between CDC, DS, and NS. Analyses across diagnostic groups revealed that individuals with sleep problems were younger than individuals without sleep problems. Furthermore, frequent coughs and/or colds, underweight, and motor impairment were associated with frequent night waking. Further studies using objective measures (such as home respiratory polygraphy) should be conducted to investigate whether snoring is benign or malignant in individuals with CDC and JS. Another aim should be to examine whether snoring has a harmful effect on daytime functioning of individuals with CDC and JS.

\section{Prader-Willi Syndrome}

According to the definition of a sleep problem, II of 79 adults with PWS (15\%) had sleep problems, which consisted of settling problems ( $n=\mathrm{I}, \mathrm{I} \%)$, night waking ( $n=\mathrm{IO}$, 13\%), and early waking $(n=3,4 \%)$. In addition, 26 of the adults (33\%) suffered from excessive daytime sleepiness (EDS). The main presenting sleep problem in adults with PWS is EDS. In our direct observation study (Chapter 3.5), all of the 7 adults with PWS showed EDS, but overall frequency of EDS was low, occurring on an average of 5.9 of 28 successive days and this overall frequency was the same as in 3 of 5 controls matched on gender, age, level of cognitive functioning, body mass index (BMI), type of daytime activities, and living environment. The prevalence rates of EDS in adults with PWS in our studies were much lower in comparison with early questionnaire studies (Clarke, Waters, \& Corbett, I989; Greenswag, I987). However, the use of different instruments to measure daytime sleepiness makes comparison between these studies and our studies difficult. Following Richdale, Cotton, and Hibbit (1999), we used the Epworth Sleepiness Scale (ESS; Johns, I99I), a standardised questionnaire to measure daytime sleepiness, with a cut-off score of 16 indicating EDS. The prevalence rate of EDS in our sample (i.e., 33\%) is almost equal to the prevalence rate of EDS in the sample of Richdale et al. (I999). The ESS was also used in adults with two other genetic syndromes (Van Eeghen et al., 2orI; Goldman, Malow, Newman, Roof, \& Dykens, 
2009). Reported prevalence rates for daytime sleepiness according to the ESS using a cut-off score of Io was $43 \%$ for adults with tuberous sclerosis (Van Eeghen et al., 20II) and $35 \%$ for adolescents and young adults with Williams syndrome (Goldman et al., 2009). The use of different cut-off scores make comparisons between these studies and our study impossible, and it remains unknown whether the prevalence rate of EDS in adults with PWS is elevated in comparison with adults with tuberous sclerosis and Williams syndrome. In comparison with the other two studies the cut-off score of $\mathrm{I} 6$ in our study is rather strict. Further analysis of data in our sample of adults with PWS using the same cut-off score is necessary.

In our direct observation study 4 of the 7 adults with PWS showed severe disruptive behaviour and overall frequency of severe disruptive behaviour was low, occurring on 5.5 of 28 successive days. This overall frequency was elevated in comparison with 2 of 5 matched controls, who showed severe disruptive behaviour on I and 6 days, respectively. According to the cut-off score on the Developmental Behaviour Checklist for Adults (Mohr, Tonge, \& Einfeld, 2004), 35 of the 79 (44\%) adults with PWS showed clinically significant behavioural problems. In our study, behavioural problems were not associated with sleep disturbances. Gender and BMI were associated with EDS; males and adults with higher BMI scores experienced more EDS. Genetic subtype was not associated with sleep problems and EDS.

Results of the observation study reveal that adults with PWS generally showed more EDS when there were no scheduled activities compared with when activities were scheduled, specifically in the afternoon and in the evening and on Saturdays. Both adults with PWS and adults from the control group showed relatively more severe disruptive behaviour during the weekend compared with weekdays, specifically when no activities were scheduled. Because of low frequencies of EDS and severe disruptive behaviour and the small sample size, no analyses were performed to test for differences between adults with PWS and adults from the control group. Further investigation in a larger sample and using smaller time intervals is necessary.

\section{Conclusion}

The results of our prevalence studies add to the knowledge of the sleep phenotype in individuals with JS, CDC, and PWS, as the sleep problems in these genetic syndromes are described for the first time and/or described in greater detail than before. The main conclusion of our studies using the SQ-SP is that sleep problems (insomnia) are present in 15 to $30 \%$ of the three genetic syndromes. Although sleep problems are prevalent in individuals with JS and CDC, these prevalence rates seem not higher than in individuals with NS. EDS and, to a lesser extent, night waking are prevalent in adults with PWS and no differences between the genetic subtypes of PWS were 
found. However, the prevalence rates of EDS in adults with PWS are much lower than those reported in early studies using questionnaires that were not standardised and it is possible that the prevalence rate of EDS has been overestimated in the previous studies. This shows the importance of using standardised questionnaires to assess the prevalence of sleep problems in genetic syndromes. We should mention that the psychometric properties of the ESS, just like most standardised sleep questionnaires, have not been examined well in adults with ID. We have identified several other factors (such as age and frequent coughs) which are associated with sleep problems across the genetic syndromes. In none of our studies associations were found between sleep problems and level of cognitive functioning, epilepsy, or behavioural problems. In further studies associations between sleep problems and behavioural problems in CDC and JS should be explored using a standardised questionnaire to assess behavioural problems.

Although prevalence rates were not elevated in comparison with individuals with NS, sleep problems may have adverse consequences for affected individuals with JS, CDC, or PWS and may be a heavy burden for their parents. The duration of sleep problems (often lasting more than I year) probably adds to the clinical significance. About half of the parents of the children with JS, CDC, and NS asked for advice on or help with treatment of the sleep problems. These percentages are much higher than those reported by Didden, Korzilius, Smits, and Curfs (2004) in AS (one third) and by Didden, Korzilius, Van Aperlo, Van Overloop, and De Vries (2002) in mixed or heterogeneous ID (about one fifth). An explanation for this difference might be that parents' views on their childrens sleep problem are changing, and that more and more parents think something needs to be done and/or can be done about their childrens sleep problem, despite the genetic syndrome or ID. Parents' views might be influenced by syndrome-specific information provided by their genetic counselors and/or (international) parent support groups (e.g., through websites).

In the last 5 years, the methodological quality of questionnaire studies investigating the prevalence and associations of sleep problems in individuals with genetic syndromes has improved. The use of standardised sleep questionnaires is the first and main improvement. Besides our prevalence studies, described in Part 2 of this thesis, 7 studies using standardised sleep questionnaires were published between 2008 and August 2013 (Annaz, Hill, Ashworth, Holley, \& Karmiloff-Smith, 2oII; Ashworth, Hill, Karmiloff-Smith, \& Dimitriou, 20I3; Breslin, Edgin, Bootzin, Goodwin, \& Nadel, 20II; Carter, McCaughey, Annaz, \& Hill, 2008; Hall, Arron, Sloneem, \& Oliver, 2008; Hartshorne et al., 2009; Kronk, Dahl, \& Noll, 2009). These studies described the prevalence of sleep problems in children with CHARGE syndrome, Cornelia de Lange syndrome, Down syndrome, Fragile X syndrome, and Williams syndrome. In the 
above-mentioned studies, the CSHQ was used most often ( 5 out of 7 studies). A second improvement is made regarding the comparison of sleep problems in children with a genetic syndrome and children without the genetic syndrome. This was performed in 6 of the 7 above-mentioned studies. In 5 studies, however, sleep problems in children with genetic syndromes were compared with sleep problems in typically developing children, and only I study (Hall et al., 2008) compared sleep problems in children with a genetic syndrome with sleep problems in children with mixed or heterogeneous ID. A third improvement is that study samples are more homogeneous with respect to age (including only children), and 2 studies performed a subgroup analysis on sleep problems between different age groups (Carter et al., 2008; Kronk et al., 2009). The results of the above-mentioned 7 studies have to be interpreted carefully because at least two methodological shortcomings remain. Firstly, the psychometric properties of the CSHQ and other standardised sleep questionnaires that were used have not been examined well in children with ID. Secondly, with the exception of one study (Hall et al., 2008), the control group consisted of typically developing children and therefore it remains unknown whether a specific feature of sleep characterises a group with a specific genetic syndrome or, conversely, individuals with ID.

\section{METHODOLOGICAL CONSIDERATIONS}

The results of the studies in this thesis should be interpreted in the context of its methodological strengths and limitations. The strengths and limitations of this thesis will be discussed for Part I. Sleep questionnaire and Part 2. Prevalence and associations of sleep problems in three genetic syndromes, respectively.

\section{Sleep Questionnaire}

The study described in Chapter 2 is the first study to examine the psychometric properties of a standardised sleep questionnaire (i.e., SQ-SP) in individuals with ID. This study has several strengths. Firstly, the sample size was relatively large $(N=345)$. Secondly, the sample consisted of individuals with mixed or heterogeneous ID which corresponds to the population of individuals with ID. Thirdly, we performed both exploratory and confirmatory factor analyses to define the factor structure of the SQ-SP and to evaluate these factors against the six broad categories of sleep disorders mentioned in the ICSD-2 (AASM, 2005). Fourthly, we included a sleep clinic group and a control group in the study which is a first step towards the development of norms (Spruyt \& Gozal, 20II).

The study described in Chapter 2 also has several limitations. Firstly, we have 
examined the psychometric properties of only one part of the SQ-SP (i.e., part four), and information on, for example, test-retest reliability of the other parts remains unknown. Secondly, convergent validity was examined using another standardised sleep questionnaire, and we did not use a sleep diary for validation. In addition, we did not use more objective instruments such as actigraphy or polysomnography to assess validity of the SQ-SP. Thirdly, we did not compare the data collected with the SQ-SP to the clinical diagnosis of a sleep disorder in the sleep clinic group. Therefore, it remains unclear how the different factors of the SQ-SP relate to different sleep disorders as described in the ICSD-2 (AASM, 2005). Finally, reliability and validity of the SQ-SP was not specifically assessed for individuals with ID living in a community group home or residential facility with professional caregivers. The reliability and validity of information provided by professional caregivers on the SQ-SP might differ from that of information provided by parents.

\section{Prevalence and Associations of Sleep Problems in Individuals with Three Genetic Syndromes}

A major strength of the studies described in Chapter 3 is that a standardised sleep questionnaire (i.e., SQ-SP) and a previously determined definition of a sleep problem (Wiggs \& Stores, I996) were used in individuals with three genetic syndromes. For two of these syndromes (i.e., JS and CDC) this had not been done previously. Another major strength is that control groups that were matched on age and level of cognitive functioning were included in three out of five studies (i.e., Chapter 3.2, Chapter 3.3, and Chapter 3.5). A final strength is that all but one participants in our studies were confirmed as having the syndrome by genetic testing.

The studies described in Chapter 3 have several limitations. First of all, we have investigated the prevalence of sleep problems by using a standardised sleep questionnaire (i.e., SQ-SP), which is a subjective measurement of sleep whereas more objective measurements such as actigraphy are available. Secondly, several limitations are connected to the composition of our study samples. We included both children and adults in three out of five of our samples (i.e., Chapter 3.I to Chapter 3.3) and we were not able to control for age-related changes, since the sizes of the study samples were too small to subdivide the sample in age groups (see e.g., Horsler \& Oliver, 2006). Due to small sample sizes it was also not possible to control for genetic subtype within JS and CDC. Furthermore, we also included individuals who were receiving treatment for their sleep problems (e.g., melatonin) and this might have affected the prevalence rates. Finally, a sample bias might be present in the studies on JS and CDC, since both samples were contacted through a support group for these specific genetic syndromes (Horsler \& Oliver, 2006). These limitations with regard to the composition of our 
study samples decrease the generalisability of the results. Thirdly, it was difficult to explore associations between sleep variables and individual-related variables mainly due to small sample sizes. Unfortunately, this is an issue one frequently encounters in systematic reviews of the literature in individuals with developmental disabilities (see e.g., Hollway \& Aman, 20II). Moreover, the low frequency of occurrence on sleep variables made it impossible to statistically test for differences between groups (see Chapter 3.3 3.4, and 3.5). In addition, this study lacks adequate statistical power to be able to determine (subtle) differences between groups.

\section{CLINICAL IMPLICATIONS}

First of all, we have shown that part four of the SQ-SP is a reliable and valid tool in the assessment of sleep problems in individuals with ID. In addition, R. J. Stores and Stores (2013b) showed that the SQ-SP completed by parents provides useful information in screening for obstructive sleep apnoea in children with DS. Therefore, we recommend that professionals use the SQ-SP in clinical practice when faced with sleep problems of individuals with ID who are living with their family. Recently, Johnson and colleagues argued for the use of the SQ-SP rather than the CSHQ in clinical practice (Johnson, Turner, Foldes, Malow, \& Wiggs, 20I2). One of their arguments is that part four of the SQ-SP includes more items about different parasomnias and specific sleep related breathing disorders than the CSHQ. Another argument in favour of the SQ-SP is that the SQ-SP is also useful for treatment planning, since items of part two and part five of the questionnaire are more qualitative, and, for example, question details about the bedtime routine, history of treatment of the child's sleep, and the effect the child's sleep problems have on parents and siblings (Johnson et al., 20I2). We recommend that professionals also use a sleep diary kept by parents in their assessment of sleep problems. A sleep diary provides additional information about the sleep pattern and the interaction between the child and the parents. To obtain sufficient information to screen for a circadian rhythm sleep disorder a sleep diary should be kept for 2 to 4 weeks (Blankenburg et al., 2013). Together, the SQ-SP and a sleep diary are the basic tools that enable professionals to efficiently interview parents in order to identify the underlying sleep disorder that causes a sleep problem or suggest appropriate definitive further assessment which is required.

Secondly, we have described the sleep problems in individuals with three genetic syndromes. These detailed descriptions provide important clues for screening, assessment, and treatment of sleep problems in these genetic syndromes. Since prevalence rates of sleep problems in these genetic syndromes were not elevated when compared to individuals with NS, we recommend that parents of children with a genetic 
syndrome and a sleep problem ask advice on or help with treatment of sleep problems from professionals who are specialised in working with individuals with ID. However, we recommend that professionals when faced with an individual with a genetic syndrome and sleep problems, routinely search the scientific literature and websites from parent support groups for syndrome-specific sleep problems and sleep disorders.

Thirdly, in one of our studies (Chapter 3.I) we have found a disparity between what parents consider to be a sleep problem and the objective criteria of a sleep problem. This probably influences which parents ask for advice on or help with treatment of sleep problems and might have implications for assessment and treatment planning giving the limited capacity of service providers. It shows the need to inform parents of children with a genetic syndrome about what is considered to be normal in terms of sleep, what aspects of sleep problems might improve as a result from treatment (and what not), and what aspects of sleep, even if not problematic for parents, might have adverse consequences for their child.

\section{FUTURE SLEEP RESEARCH IN GENETIC SYNDROMES}

Although the methodological quality of studies has improved, the picture of the prevalence and associations of sleep problems in individuals with genetic syndromes is still incomplete. For example, according to a leading textbook on genetic syndromes (Cassidy \& Allanson, 20I0) sleep problems are a common complaint in Mowat-Wilson syndrome, Phelan McDermid syndrome, and Wolf-Hirschhorn syndrome, whereas to our knowledge, the prevalence of sleep problems has not been investigated systematically (i.e., using a standardised sleep questionnaire and a control group) in these three genetic syndromes. Our considerations for future research in individuals with genetic syndromes focus on five points: (a) study sample, (b) assessment of prevalence of sleep problem, (c) assessment of associations of sleep problems, (d) exploration of sleep disorders, and (e) treatment of sleep problems.

\section{STUdy SAMple}

It is important that individuals to be included in a study on sleep in a specific genetic syndrome have a genetically confirmed diagnosis and the genetic subtype should be provided. It is imperative to include either children or adults to control for developmental stage. In order to investigate whether sleep problems are syndrome-specific, we recommend to include a control group with individuals with NS, since we do not want aetiology of ID with specific sleep disorders to confound the data. Individuals from the control group should be matched on age and level cognitive functioning. 
To explore associations between sleep characteristics and individual-related characteristics (such as age, genetic subtype, and behavioural problems), larger study samples are indispensable. Ideally, the study sample should be large enough to perform a subgroup analysis for age, both in samples of children and in samples of adults. International collaboration is needed to obtain larger study samples in order to study sleep in a specific genetic syndrome, however it is important to control for cultural differences in sleep (see e.g., Mindell, Sadeh, Wiegand, How, \& Goh, 20I0). For some rare genetic syndromes (e.g., Jacobsen syndrome) it will remain impossible to perform subgroup analysis for age groups because of small samples, but results for children and adults should at least be presented separately because sleep variables may be associated with the chronological age. To achieve a sample that is representative for the population of individuals with a specific genetic syndrome, participants should not only be recruited via support groups for a specific genetic syndrome, but also via physicians specialising in individuals with ID, paediatricians or clinical geneticists.

\section{Assessment of Prevalence of Sleep Problems}

In order to collect data on prevalence of sleep problems, studies using a cross-sectional study design with a control group are the norm. We believe that collecting data on prevalence of sleep problems using a standardised sleep questionnaire may be preferable to actigraphy and we recommend using the SQ-SP to collect data on prevalence of sleep problems in individuals with ID living with their family. Recently, a standardised sleep questionnaire, called SNAKE, has been developed to assess sleep in children with ID and comorbid physical disabilities (Blankenburg et al., 2013) and this appears to be a reliable and valid tool in the assessment of sleep problems. The SNAKE provides information on different types of sleep disturbance and it seems possible to derive information to define a sleep problem (Wiggs \& Stores, 1996) from the items of the SNAKE. Whether the SNAKE is preferable to the SQ-SP in individuals with genetic syndromes and comorbid physical disabilities (such as AS and CDC), has yet to be investigated.

\section{Assessment of Associations of Sleep Problems}

Besides cross-sectional study designs, studies using a prospective cohort design are advisable to gain more insight in the development of sleep problems and its associations within individuals over the lifetime. This will enable professionals to focus on prevention of factors that have adverse effects on sleep and to provide more accurate information about sleep problems to parents of children with a genetic syndrome. Larger study samples and the use of a prospective cohort design would make advanced statistical analyses possible. We believe it is not essential to investigate associations of sleep problems in specific genetic syndromes, since associated factors within a genetic 
syndrome might also be associated with sleep problems across genetic syndromes. In a systemic review of the literature on associations of sleep problems in individuals with ID, results for specific genetic syndromes should be presented separately, and not with results for individuals with NS, as the genetic syndrome might be a confounding factor.

It is important to not only measure the sleep problem with a standardised sleep questionnaire, but also to measure the associated factors with standardised measurement methods that are reliable and valid for individuals with ID. This is specifically important for the measurement of psychiatric conditions, challenging behaviours, daytime functioning, cognitive functioning, and adaptive skills.

\section{Exploration of SLeep Disorders}

In order to explore the underlying causes of sleep problems (i.e., sleep disorders) in genetic syndromes, additional studies with a case-control study design are necessary following cross-sectional studies that are used to assess the prevalence of sleep problem. These additional studies can be conducted in smaller samples than in prevalence studies.

It is imperative to use more objective measures in these additional studies. Audiovisual recordings, respiratory polygraphy, and/or ambulatory polysomnography in the natural environment provide information on timing and duration of behaviours related to sleep that might be associated with sleep related movement disorders, sleep related breathing disorders, and parasomnias, that cannot be provided by parental report. Besides a sleep diary actigraphy should be used to explore circadian rhythm sleep disorders. Measurement of melatonin levels might provide additional information besides data from a sleep diary and actigraphy. Aberrant melatonin levels have been reported for example in individuals with SMS and AS and are considered to cause circadian rhythm sleep disorders in these genetic syndromes (e.g., De Leersnyder, 2006; Potocki et al., 2000; Takaesu, Komada, \& Inoue, 20I2).

\section{Treatment of Sleep Problems}

The careful description of sleep problems and factors that might be associated does not provide information on which treatments are effective in reducing or eliminating sleep problems in individuals with a specific genetic syndrome. For example in AS, at least two types of treatment have been studied, i.e., melatonin treatment (Braam, Didden, Smits, \& Curfs, 2008; Zhdanova, Wurtman, \& Wagstaff, I999) and behavioural treatment (Allen, Kuhn, DeHaai, \& Wallace, 20I3). Both types of treatment have been found to be more or less effective to treat sleep problems in individuals with AS. This illustrates that an important factor for successful treatment of sleep problems is the identification of the underlying cause (Stores \& Stores, 2013a; Wiggs, 2007), and this underlying cause may vary within genetic syndromes. 


\section{FINAL REMARK}

Sleep problems have adverse consequences for individuals with a genetic syndrome and their parents. There is a need for professionals with adequate knowledge about the prevalence, nature, and factors associated with sleep problems in individuals with genetic syndromes. This thesis demonstrates that the careful description of sleep problems in genetic syndromes provides specific information that is significant for parents and professionals and enables them to provide the best possible care for individuals with a genetic syndrome and sleep problems. 


\section{REFERENCES}

Allen, K. D., Kuhn, B. R., DeHaai, K. A., \& Wallace, D. P. (2013). Evaluation of a behavioural treatment package to reduce sleep problems in children with Angelman syndrome. Research in Developmental Disabilities, 34, 676-686.

American Academy of Sleep Medicine (2005). International classification of sleep disorders, 2nd edition: Diagnostic and coding manual. Westchester, IL: Author.

Annaz, D., Hill, C. M., Ashworth, A., Holley, S., Karmiloff-Smith, A. (20II). Characterisation of sleep problems in children with Williams syndrome. Research in Developmental Disabilities, 32, 164-169.

Ashworth, A., Hill, C. M., Karmiloff-Smith, A., \& Dimitriou, D. (2013). Cross syndrome comparison of sleep problems in children with Down syndrome and Williams syndrome. Research in Developmental Disabilities, 34, I572-1580

Blankenburg, M., Tietze, A.-L., Hechler, T., Hirschfeld, G., Michel, E., Koh, M., \& Zernikow, B. (20I3). SNAKE: The development and validation of a questionnaire on sleep disturbances in children with severe psychomotor impairment. Sleep Medicine, 14, 339-35I.

Braam, W., Didden, R., Smits, M. G., \& Curfs, L. M. G. (2008). Melatonin for chronic insomnia in Angelman syndrome: A randomized placebo-controlled trial. Journal of Child Neurology, 23, 649-654.

Breslin, J. H., Edgin, J. O., Bootzin, R. R., Goodwin, J. L., \& Nadel, L. (20II). Parental report of sleep problems in Down syndrome. Journal of Intellectual Disability Research, 55, Io86IO9I.

Bruni, O., Ottaviano, S., Guidetti, V., Romoli, M., Innocenzi, M., Cortesi F., \& Giannotti, F. (I996). The Sleep Disturbance Scale for Children (SDSC): Construction and validation of an instrument to evaluate sleep disturbances in childhood and adolescence. Journal of Sleep Research, 5, 25I-26I.

Carter, M., McCaughey, E., Annaz, D., \& Hill, C. M. (2008). Sleep problems in a Down syndrome population. Archives of Disease in Childhood, 94, 308-310.

Cassidy, S. B., \& Allanson, J. E. (2010). Management of genetic syndromes (3rd ed.). Hoboken, NJ: John Wiley \& Sons.

Clarke, D. J., Waters, J., \& Corbett, J. A. (I989). Adults with Prader-Willi syndrome: Abnormalities of sleep and behaviour. Journal of the Royal Society of Sleep Medicine, 82, 2I-24.

Cornish, K., Oliver, C., Standen, P., Bramble, D., \& Collins, M. (2003). Cri-du-Chat syndrome: Handbook for parents and professionals (2nd ed.). Earl Shilton, England: Cri du Chat Support Group.

De Leersnyder, H. (2006). Inverted rhythm of melatonin secretion in Smith-Magenis syndrome: From symptoms to treatment. Trends in Endocrinology \& Metabolism, 17, $29 \mathrm{I}-298$. 
Didden, R., Korzilius, H., Aperlo, B. van, Overloop, C. van, \& Vries, M. de (2002). Sleep problems and daytime problem behaviours in children with intellectual disability. Journal of Intellectual Disability Research, 46, 537-547.

Didden, R., Korzilius, H., Smits, M. G., \& Curfs, L. M. G. (2004). Sleep problems in individuals with Angelman syndrome. American Journal on Mental Retardation, 109, 275-284.

Didden, R., \& Sigafoos, J. (200I). A review of the nature and treatment of sleep disorders in individuals with developmental disabilities. Research in Developmental Disabilities, 22, 255-272.

Eeghen, A. M. van, Numis, A. I., Staley, B. A., Therrien, S. E., Thibert, R. L., \& Thiele, E. A. (2OII). Characterizing sleep disorders of adults with tuberous sclerosis complex: A questionnaire-based study and review. Epilepsy \& Behavior, 20, 68-74.

Goldman, S. E., Malow, B. A., Newman, K. D., Roof, E., \& Dykens, E. M. (2009). Sleep patterns and daytime sleepiness in adolescents and young adults with Williams syndrome. Journal of Intellectual Disability Research, 53, I82-188.

Greenswag, L. R. (I987). Adults with Prader-Willi syndrome: A survey of 232 cases. Developmental Medicine a Child Neurology, 29, I45-I52.

Hall, S. S., Arron, K., Sloneem, J., \& Oliver, C. (2008). Health and sleep problems in Cornelia de Lange syndrome: A case control study. Journal of Intellectual Disability Research, 52, 458-468.

Hartshorne, T. S., Heussler, H. S., Dailor, A. N., Williams, G. L., Papadopoulos, D., \& Brandt, K. K. (2009). Sleep disturbances in CHARGE syndrome: Types and relationships with behaviour and caregiver well-being. Developmental Medicine $Q$ Child Neurology, 51, I43-I50.

Hollway, J. A., \& Aman, M. G. (20II). Sleep correlates of pervasive developmental disorders: A review of the literature. Research in Developmental Disabilities, 32, I399-I42I.

Horsler, K., \& Oliver, C. (2006). The behavioural phenotype of Angelman syndrome. Journal of Intellectual Disability Research, 50, 33-53.

Johns, M. W. (I99I). A new method for measuring daytime sleepiness: The Epworth Sleepiness Scale. Sleep, 14, 540-545.

Johnson, C. R., Turner, K. S., Foldes, E. L., Malow, B. A., \& Wiggs, L. (2012). Comparison of sleep questionnaires in the assessment of sleep disturbances in children with autism spectrum disorders. Sleep Medicine, 13, 795-80I.

Kronk, R., Dahl, R., \& Noll, R. (2009). Caregiver reports of sleep problems on a convenience sample of children with Fragile X syndrome. American Journal on Intellectual and Developmental Disabilities, 114, 383-392.

MacCrosain, A. M., \& Byrne, M. C. (2009). Are we ignoring the problem of sleep disorder in children with intellectual disabilities? Irish Journal of Medical Science, 178, 427-431. 
Mindell, J. A., Sadeh, A., Wiegand, B., How, T. H., \& Goh, D. Y. T. (2010). Cross-cultural differences in infant and toddler sleep. Sleep Medicine, 11, 274-280.

Mohr, C., Tonge, B., \& Einfeld, S. (2004). The Developmental Behaviour Checklist for Adults (DBC-A) (Supplement to the manual for the Developmental Behaviour Checklist: DBC-P and DBC-T). Melbourne, Australia: Monash University, Centre for Developmental Psychiatry and Psychology.

Owens, J. A., Spirito, A., \& McGuinn, M. (2000). The Children's Sleep Habits Questionnaire (CSHQ): Psychometric properties of a survey instrument for schoolaged children. Sleep, 23, I043-I051.

Potocki, L., Glaze, D., Tan, D.-X., Park, S.-S., Kashork, C. D., Shaffer, L. G., ... Lupski, J. R. (2000). Circadian rhythm abnormalities of melatonin in Smith-Magenis syndrome. Journal of Medical Genetics, 37, 428-433.

Richdale, A. L., Cotton, S., \& Hibbit, K. (I999). Sleep and behaviour disturbance in Prader-Willi syndrome: A questionnaire study. Journal of Intellectual Disability Research, 43, 380-392.

Simonds, J. F., \& Parraga, H. (I982). Prevalence of sleep disorders and sleep behaviors in children and adolescents. Journal of the American Academy of Child Psychiatry, 21, 383-388.

Spruyt, K., \& Gozal, D. (20II). Development of pediatric sleep questionnaires as diagnostic or epidemiological tools: A brief review of dos and don'ts. Sleep Medicine Reviews, 15, 7-I7.

Stores, G., \& Stores, R. (20I3a). Sleep disorders and their clinical significance in children with Down syndrome. Developmental Medicine a Child Neurology, 55, I26-130.

Stores, R., Stores, G., \& Buckley, S. (I996). The pattern of sleep problems in children with Down's syndrome and other intellectual disabilities. Journal of Applied Research in Intellectual Disabilities, 9, I45-I59.

Stores, R. J., \& Stores, G. (2013b). The significance of aspects of screening for obstructive sleep apnoea in children with Down syndrome. Journal of Intellectual Disability Research. Advance online publication. doi: Io.IIII/jir.I2033

Takaesu, Y., Komada, Y., \& Inoue, Y. (20I2). Melatonin profile and its relation to circadian rhythm sleep disorders in Angelman syndrome patients. Sleep Medicine, 13, II64II70.

Wiggs, L. (2007). Sleep disorders. In A. Carr, G. O’Reilly, P. Noonan Walsh \& J. McEvoy (Eds.), The handbook of intellectual disability and clinical psychology practice (pp. 37I42I). Hove, England: Routledge.

Wiggs, L., \& Stores, G. (I996). Severe sleep disturbance and daytime challenging behaviour in children with severe learning disabilities. Journal of Intellectual Disability Research, 40, 518-528. 
Wiggs, L., \& Stores, G. (1998). Behavioural treatment for sleep problems in children with severe learning disabilities and challenging daytime behaviour: Effect on sleep patterns of mother and child. Journal of Sleep Research, 7, II9-I26.

Wouw, E. van de, Evenhuis, H. M., \& Echteld, M. A. (20I2). Prevalence, associated factors and treatment of sleep problems in adults with intellectual disability: A systematic review. Research in Developmental Disabilities, 33, I310-I332.

Zhdanova, I. V., Wurtman, R. J., \& Wagstaff, J. (I999). Effects of a low dose of melatonin on sleep in children with Angelman syndrome. Journal of Pediatric Endocrinology and Metabolism, 12, 57-67. 
SUMMARY 


\section{SUMMARY}

Results of several studies show that sleep problems are prevalent in individuals with intellectual disability (ID). Sleep problems may be a phenotypic feature of genetic disorders associated with ID (i.e., genetic syndromes). The prevalence of sleep problems has been assessed in a number of genetic syndromes. However, in the majority of these studies, the study design did not include a standardised sleep questionnaire and an appropriate control group to examine whether any identified sleep problems in individuals with a genetic syndrome were syndrome-specific. Furthermore, types of sleep disturbance, and other variables that might be associated with sleep have not been investigated systematically in individuals with genetic syndromes.

The Sleep Questionnaire by Simonds and Parraga (SQ-SP) is a standardised questionnaire that was adapted for use in individuals with ID. The prevalence of sleep problems (i.e., settling problems, night waking, and/or early waking), behaviours related to sleep, the sleep pattern, the severity of sleep problems, different types of sleep disturbance, and parents' impression of current and past sleep problems, and experiences of their treatment be assessed using this questionnaire. The SQ-SP has been used frequently in sleep studies in individuals with ID and in individuals with a genetic syndrome. However, the psychometric properties of the SQ-SP had not been examined well in samples of individuals with ID.

The aim of this study was to contribute to sleep phenotyping of genetic syndromes. In the first part of this thesis, the psychometric properties of part four of the SQ-SP (regarding behaviours related to sleep) for use in individuals with ID were investigated. In de second part of this thesis the prevalence of sleep problems, types of sleep disturbance, and other variables that might be associated with sleep problems were assessed in three genetic syndromes. The results of the studies are described below.

The psychometric properties of part four of the adapted version of the SQ-SP are described in Chapter 2. The SQ-SP was completed for 345 individuals with ID. Analyses revealed that internal consistency and test-retest reliability were good, while convergent validity was adequate and concurrent validity was satisfactory. Exploratory factor analysis suggested a 5-factor structure (i.e., Snoring, Daytime sleepiness, Complaints related to sleep, Sleep apnoea, and Anxiety related to sleep) and confirmatory factor analysis corroborated this structure. The five factors do not match the six broad categories of sleep disorders of the International Classification of Sleep Disorders 2nd edition (American Academy of Sleep Medicine [AASM], 2005) exactly. The SQ-SP provides a general screening for types of sleep disturbance and it is not possible to make a diagnosis of a sleep disorder based on the SQ-SP solely. Furthermore, the Composite Sleep Index (CSI; i.e., a construct that reflects the severity of sleep problems) and the factor scores on 
Daytime sleepiness and Complaints related to sleep were able to differentiate the control group from an outpatient sleep clinic group.

Results of the first study on sleep problems in individuals with Jacobsen syndrome (JS) are presented in Chapter 3.I. Parents of 43 individuals with JS completed the adapted version of the SQ-SP. Sleep problems were present in Io individuals (23\%). Settling problems, night waking, and early waking occurred in $2(4 \%), 7$ (I6\%), and $2(6 \%)$ of the individuals, respectively. Most notable behaviours related to sleep were restless sleep $(60 \%)$ and sleeping in an unusual position $(54 \%)$. Apart from frequent coughs, no significant associations were found between sleep problems and other variables such as demographic factors (e.g., age), medical conditions (e.g., heart defects), sleep hygiene (e.g., having a bed time routine), and daytime activity (e.g., child's type of education) .

In Chapter 3.2, for the first time, sleep in individuals with Cri du Chat syndrome (CDC) was assessed using a standardised sleep questionnaire (i.e., SQ-SP) and compared with two control groups, i.e., individuals with nonsyndromic ID (NS) and individuals with Down syndrome (DS). In each group, 30 individuals participated. Sleep problems were present in 9 individuals with CDC (30\%), compared with 7 individuals with NS (23\%) and 3 individuals with DS (10\%). Night waking was the most prevalent type of sleep problem in individuals with CDC and prevalence of night waking was not statistically different from the two control groups. No settling problems were reported for individuals with CDC and DS, while 4 individuals with NS (I3\%) showed settling problems. Head banging, need for security object before going to sleep, gagging or choking, and more active during the day were behaviours related to sleep that occurred more often in the CDC group than in the DS group, but not in the NS group. The variables age, frequent coughs and/or colds, underweight, and motor impairment appeared to be associated with sleep problems across diagnostic groups.

The samples of individuals with CDC, JS, DS, and NS were reanalysed to determine whether the severity of sleep problems and the types of sleep disturbance were specific for CDC and/or JS (Chapter 3.3). The types of sleep disturbance were expressed in the five factors described in Chapter 2. Severe sleep problems were present in I individual with DS (4\%), 3 individuals with CDC (12\%), 5 individuals with JS (20\%), and 3 individuals with NS (I2\%). Differences in percentage of indivuals with severe sleep problems between diagnostic groups were not statistically significant. This is an indication that sleep problems might not be specific to individuals with CDC and JS. The factor Snoring was the most prevalent type of sleep disturbance in CDC, JS, and DS groups, whereas no type of sleep disturbance was identified as most prevalent in the NS group. Furthermore, the mean score on the factor Complaints related to sleep was remarkably high in the JS group compared with the other three diagnostic groups.

In Chapter 3.4, the results of the first study on sleep disturbances and behavioural 
problems in a large sample of adults with genetically confirmed Prader-Willi syndrome (PWS) using standardised questionnaires are presented. From the 79 adults with PWS who participated in the study, II adults (I5\%) had sleep problems, mostly frequent night waking. Excessive daytime sleepiness (EDS) was a severe problem for 26 adults with PWS (33\%) and gender and body mass index were found to be associated with EDS. Results of 45 adults with paternal deletion were compared to those of 33 adults with maternal uniparental disomy (mUPD), and differences in prevalence of sleep disturbances appeared not to be statistically significant. Behavioural problems were clinically significant in I7 adults with paternal deletion (38\%) and I7 adults with mUPD (52\%). Adults with mUPD tended to have higher scores on the Disruptive and SelfAbsorbed subscales of the Developmental Behaviour Checklist for Adults compared with adults with paternal deletion. No significant relationships were found between sleep disturbances and behavioural problems.

In a pilot study, temporal characteristics of EDS and severe disruptive behaviour were explored for the first time using scatter plot analysis (Chapter 3.5). Over a period of 28 successive days, 7 adults with PWS and 5 adults with NS were observed by their professional caregivers and/or parents between 9:00 a.m. and 9:0० p.m. The overall prevalence of EDS and severe disruptive behaviour was low in both groups. Adults with PWS generally showed more EDS when there were no scheduled activities compared to when activities were scheduled, specifically in the afternoon and in the evening and on Saturdays. It was not possible to statistically test differences between adults with PWS and adults from the control group because of the low prevalence rates and the small number of participants in both groups.

In Chapter 4, the results of the studies described in this thesis are addressed and we also discussed the methodological considerations and the clinical implications. In conclusion, we described our considerations for future research in individuals with genetic syndromes with a focus on five points: (a) study sample, (b) assessment of prevalence of sleep problems, (c) assessment of associations of sleep problems, (d) exploration of sleep disorders, and (e) treatment of sleep problems. 
SAMENVATTING 


\section{SAMENVATTING}

Resultaten van verschillende wetenschappelijke onderzoeken tonen aan dat slaapproblemen vaak voorkomen bij personen met een verstandelijke beperking (VB). Slaapproblemen kunnen een fenotypisch kenmerk zijn van genetische stoornissen geassocieerd met VB (d.w.z. genetische syndromen). De prevalentie van slaapproblemen is vastgesteld voor een aantal genetische syndromen. In de meerderheid van deze studies werd het onderzoek echter uitgevoerd zonder gestandaardiseerde slaapvragenlijst en zonder passende controlegroep om te onderzoeken of slaapproblemen, die bij personen met een genetisch syndroom zijn vastgesteld, syndroomspecifiek zijn. Verder zijn verschillende typen slaapverstoring en andere variabelen die kunnen samenhangen met slaap tot nu toe niet op een systematische wijze onderzocht bij personen met een genetisch syndroom.

De Vragenlijst Slaapgedrag van Simonds en Parraga (SQ-SP) is een gestandaardiseerde vragenlijst die werd bewerkt voor gebruik bij personen met VB. De prevalentie van slaapproblemen (d.w.z. problemen met inslapen, 's nachts wakker worden en/of vroeg wakker worden), de aan slaap gerelateerde gedragingen, het slaappatroon, de ernst van slaapproblemen, de verschillende typen slaapverstoring, de indruk van ouders over huidige en vroegere slaapproblemen en ervaringen met de behandeling daarvan kunnen met deze vragenlijst worden vastgesteld. De SQ-SP is veelvuldig gebruikt in wetenschappelijk onderzoek naar slapen bij personen met VB en personen met een genetisch syndroom. De psychometrische eigenschappen van de SQ-SP zijn echter nog niet goed onderzocht in steekproeven van personen met VB.

Het doel van deze studie was om bij te dragen aan fenotypering van de slaap bij genetische syndromen. In het eerste deel van dit proefschrift, werden de psychometrische eigenschappen onderzocht van deel vier van de SQ-SP (met betrekking tot de aan slaap gerelateerde gedragingen) voor gebruik bij personen met VB. In het tweede deel van dit proefschrift werden de prevalentie van slaapproblemen, de typen slaapverstoring en andere variabelen die mogelijk samenhangen met slaapproblemen vastgesteld bij drie genetische syndromen. De resultaten worden hieronder per onderzoek beschreven.

De psychometrische eigenschappen van deel vier van de bewerkte versie van de SQ-SP zijn beschreven in Hoofdstuk 2. De SQ-SP werd ingevuld over 345 personen met VB. De analyses toonden aan dat de interne consistentie en de test-hertest betrouwbaarheid goed waren, terwijl de convergente validiteit voldoende was en de concurrente validiteit toereikend was. Exploratieve factoranalyse wees op een structuur met vijf factoren (d.w.z. Snurken, Slaperigheid overdag, Klachten gerelateerd aan slaap, Slaapapneu en Angst gerelateerd aan slaap) en confirmatieve factoranalyse bevestigde deze structuur. De vijf factoren komen niet precies overeen met de zes brede categorieën met slaapstoornissen van de International Classification of Sleep Disorders 2nd edition (American Academy of Sleep Medicine [AASM], 2005). De SQ-SP is een algemeen 
instrument om te screenen op typen slaapverstoring. Het is niet mogelijk om een diagnose van een specifieke slaapstoornis te stellen op basis van de SQ-SP alleen. Verder bleek dat er onderscheid kon worden gemaakt tussen de controlegroep en de groep van de slaappolikliniek op basis van de Samengestelde Slaap Index (CSI; d.w.z. een construct dat de ernst van de slaapproblemen weergeeft) en de scores op de factoren Slaperigheid overdag en Klachten gerelateerd aan slaap.

Resultaten van het eerste wetenschappelijke onderzoek naar slaapproblemen bij personen met het Jacobsen syndroom (JS) zijn weergegeven in Hoofdstuk 3.I. Ouders van 43 personen met JS hebben de bewerkte versie van de SQ-SP ingevuld. Tien personen (23\%) hadden slaapproblemen. Problemen met inslapen, 's nachts wakker worden en vroeg wakker worden kwamen voor bij respectievelijk 2 (4\%), 7 (16\%) en 2 (6\%) personen. De gedragingen gerelateerd aan slapen die het meest opvielen waren rusteloze slaap (60\%) en slapen in een ongewone houding (54\%). Behalve vaak hoesten werden geen significante verbanden gevonden tussen slaapproblemen en andere variabelen zoals demografische factoren (bv. leeftijd), medische aandoeningen (bv. hartproblemen), slaaphygiëne (bv. een bedtijdroutine hebben) en activiteiten overdag (bv. type onderwijs dat het kind volgt).

In Hoofdstuk 3.2 werden de slaapproblemen van personen met het Cri du Chat syndroom (CDC) voor het eerst met een gestandaardiseerde slaapvragenlijst (d.w.z. SQ-SP) in kaart gebracht en vergeleken met twee controlegroepen, d.w.z. met personen met VB zonder genetisch syndroom (NS) en personen met Down syndroom (DS). In elke groep deden 30 personen mee aan het onderzoek. Negen personen met CDC (30\%) hadden slaapproblemen, in vergelijking met zeven personen met NS (23\%) en drie personen met DS (І०\%). 's Nachts wakker worden kwam het vaakst voor bij personen met CDC en de prevalentie van 's nachts wakker worden was statistisch gezien niet afwijkend van de twee controlegroepen. Bij personen met CDC en DS werden geen problemen met inslapen gemeld, terwijl 4 personen met NS ( $13 \%)$ problemen met inslapen toonden. Hoofdbonken, behoefte aan een voorwerp voor het slapen gaan, kokhalzen of verslikken en overdag actiever zijn dan andere kinderen waren gedragingen gerelateerd aan slapen die vaker voorkwamen in de groep met CDC dan in de groep met DS, maar niet in de groep met NS. Na het samenvoegen van de gegevens van de drie groepen bleken de variabelen leeftijd, vaak hoesten en/of verkouden zijn, ondergewicht en motorische beperking samen te hangen met slaapproblemen.

De steekproeven van personen met CDC, JS, DS en NS werden opnieuw geanalyseerd om te bepalen of de ernst van de slaapproblemen en de typen slaapverstoring specifiek waren voor CDC en/of JS (Hoofdstuk 3.3). De typen slaapverstoring werden uitgedrukt in de vijf factoren die beschreven staan in Hoofdstuk 2. Drie personen met CDC (ז2\%), vijf personen met JS (20\%), een persoon met DS (4\%), en drie personen met NS (ז2\%) hadden ernstige slaapproblemen. De verschillen in het percentage van personen met ernstige slaapproblemen tussen de diagnosegroepen waren niet statistisch significant. Dit is een aanwijzing dat 
slaapproblemen waarschijnlijk niet specifiek zijn voor personen met CDC en JS. De factor Snurken was het type slaapverstoring dat het vaakst voorkwam in de groepen met CDC, JS en DS, terwijl geen enkel type slaapverstoring als vaakst voorkomend kon worden geïdentificeerd in de groep met NS. Verder was in de groep met JS de gemiddelde score op de factor Klachten gerelateerd aan slaap opvallend hoog in vergelijking met de andere groepen.

De resultaten van het eerste wetenschappelijke onderzoek dat slaapproblemen en gedragsproblemen met gestandaardiseerde vragenlijsten in kaart bracht bij volwassenen met PWS van wie de diagnose bevestigd was met genetisch onderzoek, zijn weergegeven in Hoofdstuk 3.4. Van de 79 volwassenen met PWS die deelnamen aan het onderzoek, hadden er II (I5\%) slaapproblemen, voornamelijk in de vorm van 's nachts wakker worden. Excessieve slaperigheid overdag (EDS) was een ernstig probleem voor 26 volwassenen met PWS (33\%) en de variabelen geslacht en body mass index hingen samen met EDS. Resultaten van 45 volwassenen met een paternale deletie werden vergeleken met die van 33 volwassenen met een maternale uniparentele disomie (mUPD). Verschillen in de prevalentie van slaapproblemen bleken niet statistisch significant te zijn. Gedragsproblemen waren klinisch significant bij I7 volwassenen met een paternale deletie (38\%) en I7 volwassenen met mUPD (52\%). Volwassenen met mUPD hadden in vergelijking met volwassenen met een paternale deletie de neiging om hogere scores te behalen op de subschalen Storend (Disruptive) en In zichzelf gekeerd (Self-Absorbed) van de Vragenlijst over Ontwikkeling en Gedrag voor Volwassenen (Developmental Behaviour Checklist for Adults). Er werden geen significante verbanden gevonden tussen slaapproblemen en gedragsproblemen.

In een pilotonderzoek werden de temporele kenmerken van EDS en ernstig storend gedrag voor het eerst aan de hand van patroonanalyse (scatter plot) verkend (Hoofdstuk 3.5). Gedurende een periode van 28 opeenvolgende dagen werden 7 volwassenen met PWS en 5 volwassenen met NS tussen 9:00 en 21:00 uur geobserveerd door hun begeleiders en/of ouders. De prevalentie van EDS en ernstig storend gedrag was in beide groepen laag. Volwassenen met PWS toonden over het algemeen meer EDS wanneer er geen activiteiten waren gepland dan wanneer er wel activiteiten waren gepland, vooral 's middags en 's avonds en op zaterdag. Vanwege de lage prevalentiecijfers en het kleine aantal deelnemers in beide groepen was het niet mogelijk om de verschillen tussen volwassenen met PWS en volwassenen uit de controlegroep statistisch te toetsen.

In Hoofdstuk 4 werden de resultaten van de onderzoeken die in dit proefschrift zijn beschreven aan de orde gesteld. Tevens werden de methodologische beperkingen en klinische implicaties behandeld. Ten slotte werden in vijf aandachtspunten aanbevelingen beschreven voor toekomstig onderzoek bij personen met een genetisch syndroom: (a) de steekproef voor onderzoek, (b) vaststellen van de prevalentie van slaapproblemen, (c) vaststellen van variabelen die samenhangen met slaapproblemen, (d) verkennen van slaapstoornissen en (e) behandeling van slaapproblemen. 


\section{DANKWOORD}

Er is een hele groep mensen voor nodig om een promovendus het einddoel te laten halen. Tijdens het onderzoek en bij het schrijven van dit proefschrift heb ik advies, hulp, inspiratie en afleiding gekregen vanuit verschillende hoeken. Graag wil ik hier een aantal mensen speciaal bedanken.

Als eerste wil ik prof. dr. Jan de Moor bedanken, die samen met prof. dr. Robert Didden, aan het begin van mijn wetenschappelijke carrière stond. Jan, na mijn doctoraalscriptie hebben we samen hard gewerkt aan 'het eetboek'. Voor onze collega's op de vijfde verdieping leek het soms alsof we een hevig gevecht streden, in werkelijkheid scherpten we elkaars inzichten en probeerden we deze in zo helder mogelijk Nederlands op te schrijven. Ik kijk hier met plezier op terug.

Prof. dr. Robert Didden bedank ik voor het toepassen van een most-to-least prompting procedure bij het verbeteren van mijn wetenschappelijke schrijfvaardigheden in het Nederlands en Engels. Robert, jij bent de kruiwagen geweest voor een aantal betrekkingen na mijn afstuderen en jij bracht me in contact met prof. dr. Leopold Curfs.

Prof. dr. Leopold Curfs bedank ik voor het mogelijk maken van dit bijzondere promotietraject. Leopold, jij bracht me in contact met binnen- en buitenlandse experts op het gebied van genetische syndromen bij mensen met een verstandelijke beperking en mensen van de ouderverenigingen. Daarnaast waardeer ik het dat je me mijn eigen huis hebt laten bouwen.

Het onderzoek vond plaats binnen het Expertisecentrum slaapstoornissen bij mensen met een verstandelijke beperking, een initiatief van het Gouverneur Kremers Centrum. Binnen dit multidisciplinaire expertisecentrum werk ik samen met prof. dr. Leopold Curfs (hoogleraar zorg voor mensen met een verstandelijke beperking), prof. dr. Robert Didden (hoogleraar verstandelijke beperking, leren \& gedrag en gz-psycholoog), dr. Marcel Smits (neuroloog en slaapspecialist), dr. Wiebe Braam (arts voor verstandelijk gehandicapten) en drs. Philippe Collin (kinder- en jeugdpsychiater) zowel op gebied van wetenschappelijk onderzoek als in de klinische praktijk. Het is mooi om terug te kijken op wat we in de afgelopen jaren samen hebben bereikt.

Zonder participanten is onderzoek niet mogelijk. Daarom wil ik de ouders, de familieleden en de begeleiders die de vragen- of observatielijsten hebben ingevuld hartelijk bedanken. Ook hartelijke dank aan de betrokken en enthousiaste mensen van de ouderverenigingen die mij in contact hebben gebracht met de participanten: Annet van Betuw, Linzee Carroll en Mieke van Leeuwen.

Fellow-researchers dr. Paul Grossfeld and dr. Margje Sinnema, I enjoyed working with you very much. Thank you for sharing your knowledge on 'your' syndrome. Margje, ook bedankt voor de gezelligheid en je luisterend oor tijdens mijn bezoekjes aan 
Maastricht. Verder bedank ik de methodologen dr. Lex Bouts, dr. Hubert Korzilius en dr. Marian Maaskant voor hun advies en hulp bij de statistische analyses. Ook dank aan drs. Joost Poort, voor jouw waardevolle suggesties bij het Engels in verschillende delen van dit proefschrift.

In addition, I want to extend my gratitude to the members of the assessment committee: prof. dr. G.J. Kok, prof. dr. T.A.M.J. van Amelsvoort, dr. K. Spruyt, dr. L. Wiggs, and prof. dr. M. Zeegers. Thank you very much for your willingness to read my thesis.

Dr. Wiebe Braam, wat is het fijn om samen met jou een team te vormen! Onze roeping is het verbeteren van de slaap van kinderen met een verstandelijke beperking en hun ouders. Tijdens onze gezamenlijke consulten luister ik met plezier naar je prachtige metaforen om ingewikkelde zaken te verduidelijken aan ouders. Tussen de consulten door verwonderen we ons over allerlei zaken en zien we overal aanknopingspunten voor verder onderzoek; we hebben nog zoveel te doen!

Ook de andere collega's bij Advisium van 's Heeren Loo in Wekerom dank ik voor de interesse in mij als collega en in de voortgang van mijn onderzoek. Een speciale vermelding van dank voor de continue aanvoer van detectives en thrillers ter ontspanning.

Alle (oud)collega's van Pedagogische Wetenschappen en Onderwijskunde met wie ik samenwerk aan de Radboud Universiteit wil ik bedanken, of je nu (nog)niet-gepromoveerd/ gepromoveerd/professor, (ortho)pedagoog/psycholoog/filosoof/iets anders, bekwaam op klinisch/theoretisch/methodisch gebied, 'woonachtig' op de vierde/vijfde/zesde/zevende verdieping bent of was. Prof. dr. Anna Bosman, prof. dr. Ludo Verhoeven, dr. Eliane Segers en dr. Mathijs Vervloed wil ik speciaal bedanken voor hun vertrouwen.

Lieve paranimfen, Anne en Joël, samen met Lisette hebben jullie me al die jaren van dichtbij gesteund bij de ups en downs van het proces dat promoveren heet. Mijn dank aan jullie alledrie is groot!

Ook Herman en Jan-Herman wil ik bedanken. Met regelmaat helpen jullie mij uit mijn hoofd te komen. Enkele goede ingevingen voor dit proefschrift kreeg ik juist bij jullie op de mat of tafel, waarschijnlijk zonder dat jullie hier weet van hadden.

Lieve vrienden en familie, de meeste van jullie kennen het academische wereldje niet en toch hebben juist jullie ook bijgedragen aan de voltooiing van dit proefschrift. Gezellige bezoekjes (met of zonder kinderen), etentjes, feestjes en concertbezoekjes met jullie boden me broodnodige afleiding en welkome inspiratie. Nu het proefschrift af is, hebben we hopelijk ruimer de tijd om samen van de mooie dingen in het leven te genieten.

Gert, de belangrijkste steun en de liefste van allemaal: you're simply elegant! 


\section{CURRICULUM VITAE}

Anneke Maas is op 24 januari 1979 geboren in Deurne en groeide op als middelste in een tweeoudergezin met drie kinderen in Griendtsveen en Deurne. Na het behalen van het gymnasiumdiploma aan het St. Willibrord Gymnasium te Deurne (I99II997) verhuisde ze in de zomer van 1997 naar Nijmegen. Ze studeerde Pedagogische Wetenschappen en Onderwijskunde aan de Radboud Universiteit te Nijmegen (I997200I) en tijdens het laatste studiejaar verhuisde ze naar Ubbergen waar ze haar partner Gert Jan Bosgra leerde kennen. Ze presenteerde het onderzoek voor haar doctoraalscriptie, een onderzoek naar de gedragstherapeutische behandeling van voedselweigering bij jonge kinderen met een lichamelijke beperking, op de eerste Interacademiale Orthopedagogiek Gehandicaptenzorg te Utrecht in maart 200I.

Van oktober 200I tot 2004 werkte Anneke als projectuitvoerder bij het NWO Inzicht programma Behandeling van slaapproblemen bij kinderen met een visuele beperking onder leiding van dr. Mathijs Vervloed bij de afdeling Orthopedagogiek: Leren en Ontwikkeling aan de Radboud Universiteit Nijmegen. Daarnaast schreef ze samen met prof. dr. Jan de Moor en prof. dr. Robert Didden het boek De behandeling van eetproblemen bij jonge kinderen met een lichamelijke of meervoudige handicap. Vanaf 2002 werkte ze als junior docent bij Pedagogische Wetenschappen en Onderwijskunde. In 2004 werd ze via prof. dr. Leopold Curfs als consulent orthopedagoog betrokken bij diagnostiek en behandeling van slaapproblemen bij kinderen met het Angelman syndroom, cliënten van dr. Wiebe Braam, arts voor verstandelijk gehandicapten, bij 's Heeren Loo te Wekerom.

In de zomer van 2005 begon Anneke aan haar promotieonderzoek onder leiding van prof. dr. Leopold Curfs en prof. dr. Robert Didden bij het Gouverneur Kremers Centrum en de onderzoeksschool GROW School for Oncology and Developmental Biology aan de Universiteit Maastricht. Tevens trad ze toe tot het Expertisecentrum slaapstoornissen bij mensen met een verstandelijke beperking. Vanuit het expertisecentrum werkte ze vanaf september 2005 als consulent orthopedagoog met dr. Wiebe Braam op de slaappolikliniek voor mensen met een verstandelijke beperking. Vanaf 2007 is ze als gedragswetenschapper in dienst bij 's Heeren Loo Advisium te Wekerom en zet ze haar werkzaamheden op de slaappolikliniek voort. In het voorjaar van 2008 verhuisde ze met haar partner naar Nijmegen, na enkele maanden (in de weekenden) klussen met familie en vrienden. Vanaf 2009 is ze gastdocent in de cursus Specialistische behandeltrajecten bij bijzondere kinderen van de opleiding orthopedagoog-generalist aan RINO Zuid te Eindhoven. 
In september 2009 kreeg ze een vaste aanstelling bij Pedagogische Wetenschappen en Onderwijskunde aan de Radboud Universiteit Nijmegen als coördinerend docent van de cursus Behandelingsmethodiek en als docent van cursussen waarin klinische vaardigheden centraal staan. Sinds 2012 is ze ook coördinerend docent van de cursus Ontwikkelings- en Leerproblemen.

Anneke presenteerde haar onderzoek naar slaapproblemen op Nederlandse en Europese wetenschappelijke conferenties en op Nederlandse en Europese conferenties van ouderverenigingen. 


\section{PUBLICATIONS}

\section{Peer Reviewed Journal Articles}

Maas, A. P. H. M., Didden, R., Korzilius, H., \& Curfs, L. M. G. (20I2). Exploration of differences in types of sleep disturbance and severity of sleep problems between individuals with Cri du Chat syndrome, Down's syndrome, and Jacobsen syndrome: A case control study. Research in Developmental Disabilities, 33, I773-I779.

Maas, A. P. H. M., Didden, R., Korzilius, H., Braam, W., Collin, P., Smits, M. G., \& Curfs, L. M. G. (20II). Psychometric properties of a sleep questionnaire for use in individuals with intellectual disabilities. Research in Developmental Disabilities, 32, 2467-2479.

Braam, W., Didden, R., Maas, A. P. H. M., Korzilius, H., Smits, M. G., \& Curfs, L. M. G. (2OIO). Melatonin decreases daytime challenging behaviour in persons with intellectual disability and chronic insomnia. Journal of Intellectual Disability Research, $54,52-59$.

Maas, A. P. H. M., Sinnema, M., Didden, R., Maaskant, M. A., Schrander-Stumpel, C. T. R. M., \& Curfs, L. M. G. (20IO). Sleep disturbances and behavioural problems in adults with Prader-Willi syndrome. Journal of Intellectual Disability Research, 54, 906-917.

Maas, A. P. H. M., Didden, R., Korzilius, H., Braam, W., Smits, M. G., \& Curfs, L. M. G. (2009). Sleep in individuals with Cri du Chat syndrome: a comparative study. Journal of Intellectual Disability Research, 53, 704-715.

Maas, A. P. H. M., Didden, R., Bouts, L., Smits, M. G., \& Curfs, L. M. G. (2009). Scatter plot analysis of excessive daytime sleepiness and severe disruptive behavior in adults with Prader-Willi syndrome: A pilot study. Research in Developmental Disabilities, 30 , 529-537.

Maas, A. P. H. M., Grossfeld, P. D., Didden, R., Korzilius, H., Braam, W. J., Smits, M. G., \& Curfs, L. M. G. (2008). Sleep problems in individuals with IIq terminal deletion disorder (Jacobsen syndrome). Genetic Counseling, 19, 225-235.

Maas, A. P. H. M., Didden, R., Moor, J. M. H. de, Renier, W. O., \& Curfs, L. M. G. (2005). Sleep onset problems in two children with mild intellectual disability and epilepsy: Assessment and treatment in the home setting. International Journal of Behavioral Consultation and Therapy, 1, 292-299.

Vervloed, M. P. J., Hoevenaars, E., \& Maas, A. (2003). Behavioral treatment of sleep problems in a child with a visual impairment. Journal of Visual Impairment Q Blindness, 97, 28-37. 


\section{Published Abstracts (selection)}

Maas, A., Braam, W. J., Collin, P. J. L., Didden, R., Smits, M. G., \& Curfs, L.M.G. (2008). Sleep clinic for individuals with intellectual disability. Poster presented at IASSID I3th World Congress. Cape Town, 25-30 August. Journal of Intellectual Disability Research, 52, 66I.

Maas, A., Didden, R., Korzilius, H., Braam, W. J., Smits, M. G., \& Curfs, L.M.G. (2008). Sleep characteristics in individuals with Cri du Chat syndrome. Poster presented at IASSID I3th World Congress. Cape Town, 25-30 August. Journal of Intellectual Disability Research, 52, 66I.

Maas, A., Grossfeld, P. D., Didden, R., Korzilius, H., Braam, W. J., Smits, M. G., \& Curfs, L. M. G. (2008). Sleep problems in individuals with IIq terminal deletion disorder (Jacobsen syndrome). Poster presented at IASSID I3th World Congress. Cape Town, 25-30 August. Journal of Intellectual Disability Research, 52, 661.

Maas, A., Didden, R., Smits, M., Braam, W., \& Curfs, L. M. G. (2006). Scatter plot analysis of excessive daytime sleepiness and disruptive behaviours in eight individuals with Prader-Willi syndrome. 2nd European IASSID conference, 3 August, Maastricht. Journal of Applied Research in Intellectual Disabilities, 19, 254.

\section{Other Publications (selection)}

Didden, R., Braam, W., Maas, A., Smits, M., Sturmey, P., Sigafoos, J., \& Curfs, L. (in press). Sleep problems. In: P. Sturmey \& R. Didden (Eds.), Evidence-based practice and intellectual disabilities. London: Wiley.

Maas, A., Braam, W., Collin, P., Smits, M., Didden, R., \& Curfs, L. (2007). Referrals to the sleep clinic for individuals with intellectual disability. In: G. S. F. Ruigt (Ed.), Sleep-Wake Research in the Netherlands, 18, 93-96.

\section{Publications in Dutch}

Didden, R., Maas, A., Braam, W., Smits, M., Collin, P., \& Curfs, L. (2008). Slaap en slaapstoornissen bij kinderen en jeugdigen met autisme spectrum stoornissen. In: R. Didden \& B. Huskens (Red.), Begeleiding van kinderen en jongeren met autisme (pp. 127-144). Houten: Bohn Stafleu van Loghum.

Maas, A., Didden, R., \& Tolboom, J. (2006). De behandeling van eetproblemen bij kinderen met een lichamelijke en/of additionele handicap in de basisschoolleeftijd. In: R. Didden, B. van Waesberghe, H. Oud \& A. Reinders (Red.), Opvoeden en leren in de kinderrevalidatie (pp. 56-67). Assen: Van Gorcum.

Moor, J. M. H. de, Maas, A. P. H. M., Didden, R., Gerven, M. H. J. C., \& Tolboom, J. J. M. (2004). De behandeling van eetproblemen bij jonge kinderen met een lichamelijke of meervoudige handicap. Utrecht: BOSK. 